\title{
MEDICIÓN \\ Y APLICACIONES \\ DEL IOT
}

\section{DOCUMENTOS SOBRE}

ECONOMÍA DIGITAL DE LA OCDE

Octubre 2018 No. 271

Traducido con el apoyo de

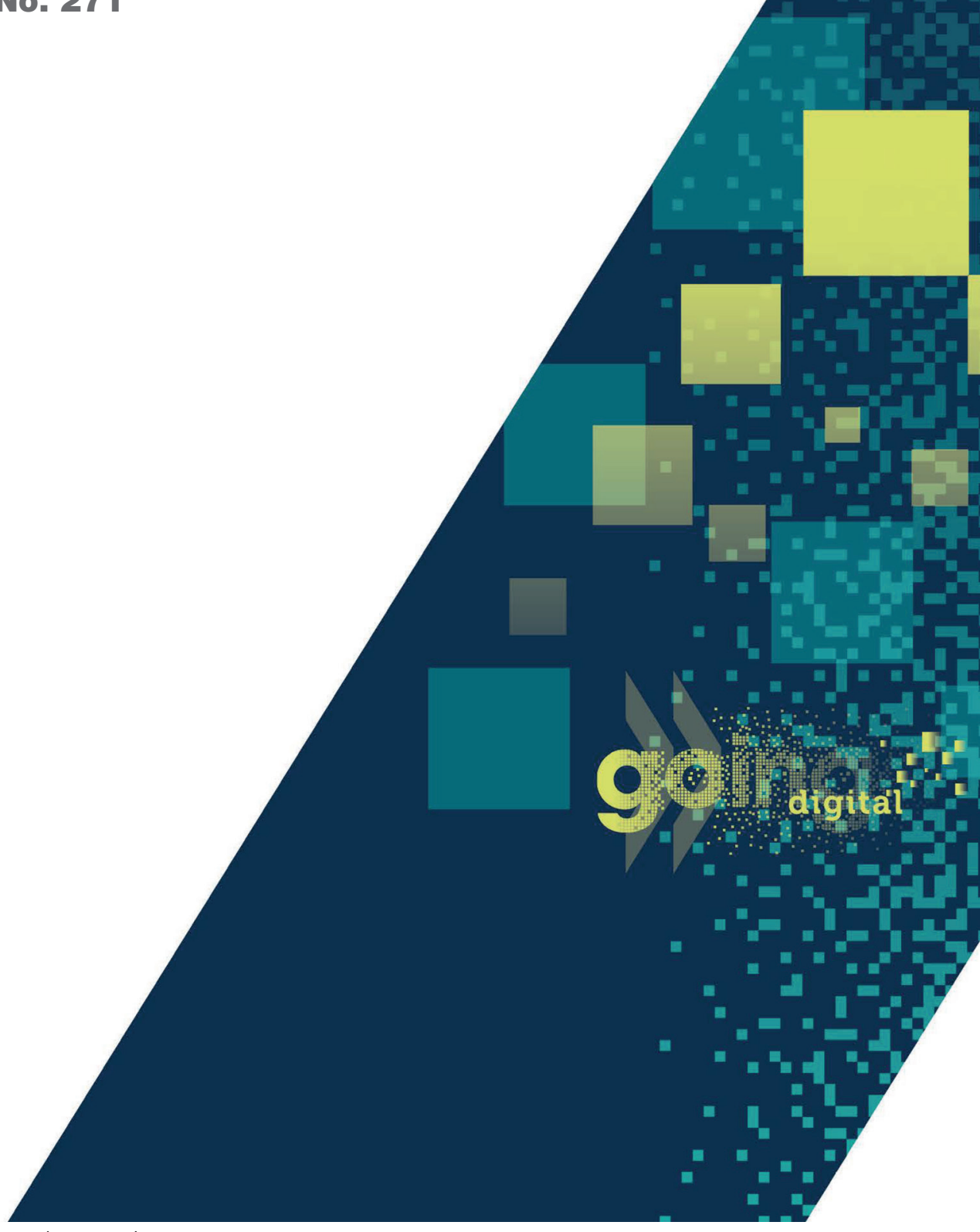




\section{Prólogo}

El presente informe fue elaborado por el Grupo de Trabajo sobre la Política de Infraestructura de Comunicación y Servicios (WPCISP, por sus siglas en inglés) y el Grupo de Trabajo sobre la Medición de la Economía Digital (MADE, por sus siglas en inglés). El informe revisa diversas definiciones del Internet de las Cosas (IoT, por sus siglas en inglés) en el contexto de una definición operativa con subcategorías correspondientes para el trabajo del Comité de Políticas sobre Economía Digital (CDEP, por sus siglas en inglés), y explora modos viables de medir el IoT, así como sus implicaciones para la infraestructura y las redes. Concluye con la propuesta de un marco de trabajo (es decir, taxonomía) para el IoT con fines de medición.

El Comité de Políticas sobre Economía Digital aprobó y desclasificó este documento mediante un procedimiento por escrito el 27 de septiembre de 2018 y fue preparado para su publicación por el Secretariado de la OCDE.

Este informe fue redactado por Alexia González Fanfalone con aportaciones de Pierre Montagnier y Sam Paltridge, del Secretariado de la OCDE.

Esta publicación es una aportación al proyecto "Going Digital" de la OCDE, cuyo objetivo es ofrecer a los responsables de las políticas las herramientas que necesitan para que sus economías y sociedades prosperen en un mundo cada vez más digital y dependiente de los datos.

Para más información visite www.oecd.org/going-digital.

\#GoingDigital

Esta traducción se publica por acuerdo con la OCDE. No es una traducción oficial de la OCDE. La calidad de la traducción y su coherencia con el texto del idioma original de la obra son responsabilidad exclusiva del autor(es) de la traducción. En el caso de cualquier discrepancia entre el trabajo original y la traducción, solo el texto del trabajo original se considerará válido.

Publicado originalmente por la OCDE en inglés bajo el título: OECD (2018), "IoT measurement and applications", OECD Digital Economy Papers, No. 271, OECD Publishing, París, https://doi.org/10.1787/35209dbf-en.

(C) 2019 Asociación Mexicana de Internet, A.C. para esta edición en español.

Este documento, así como cualquier dato y cualquier mapa incluido, se elabora sin perjuicio del estatus o de la soberanía de cualquier territorio, la delimitación de las fronteras internacionales y líneas divisorias y el nombre de cualquier territorio, ciudad o región.

Los datos estadísticos de Israel fueron proporcionados bajo la responsabilidad de las autoridades israelíes pertinentes. El uso de esos datos por parte de la OCDE es sin perjuicio del estatus de los Altos de Golán, Este de Jerusalén y los asentamientos israelíes de Cisjordania conforme a los términos del derecho internacional. 


\section{Presentación a la edición en español}

En todo el mundo, las organizaciones y las personas están experimentando un cambio fundamental en su relación con la tecnología. Esta transformación, a menudo llamada la "Cuarta Revolución Industrial", se ha caracterizado como una fusión de los mundos físico y digital, con implicaciones de gran alcance para la humanidad.

Estos cambios crean nuevas oportunidades y desafíos. Las políticas públicas, los marcos regulatorios o los modelos de gobernanza tradicionales, están bajo presión para ajustarse a nuevas circunstancias.

Y como ocurre con muchas cosas, el inicio es usualmente lo más difícil. Cuando hablamos de Internet de las Cosas ("Internet of Things" o IoT) a qué nos referimos exactamente. ¿Cuál es el género próximo para definirlo? ¿Es acaso una arquitectura técnica, o se refiere de forma más amplia a la forma en que un dispositivo conectado a Internet interactúa con el mundo físico?

La pregunta no es trivial, ya que es determinante contar con una definición que pueda ser, de manera razonable, asumida como un concepto generalmente aceptado; y que, a partir de ella, tengamos elementos para comprender y categorizar diferentes clasificaciones de IoT, que provean parámetros claros para establecer sus respectivos marcos de referencia.

Esta importante tarea es precisamente la que aborda — con profundidad y claridad - el presente estudio, "Medición y Aplicaciones del IoT", publicado originalmente en su versión en inglés bajo el título "IoT Measurements and Applications", en el contexto de la iniciativa Going Digital de la Organización para la Cooperación y el Desarrollo Económicos (OCDE).

Hacia el futuro, es previsible que los diversos aspectos de IoT no harán más que aumentar en importancia y complejidad, a medida que el mundo se vuelva más conectado y dependa crecientemente de las eficiencias y oportunidades que brinda el IoT.

La Asociación de Internet MX y Microsoft México aportamos esta edición en español, misma que no solo facilita a los lectores hispanos mayor comprensión del tema, sino que también contribuye a crear un glosario común que, con mayor frecuencia, formará parte de los marcos normativos y de política pública en materia de IoT en diversas jurisdicciones.

Agradecemos a la OCDE su confianza y consideramos que los lectores encontrarán en este documento información muy valiosa, que contribuirá al desarrollo de un ecosistema confiable, incluyente y responsable en materia de IoT.

Guadalajara, Jalisco, a 3 de diciembre de 2019.

Asociación de Internet MX

Enrique Culebro Karam

Presidente
Microsoft México, S. de R.L. de C.V.

Enrique Perezyera

Director General 


\section{Índice}

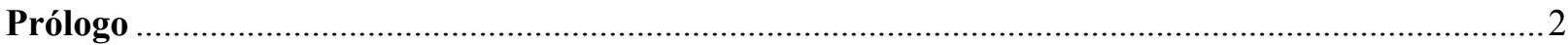

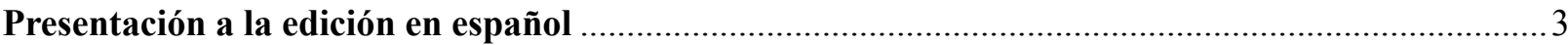

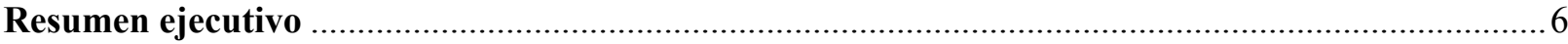

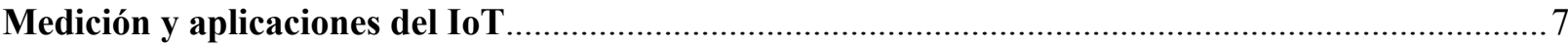

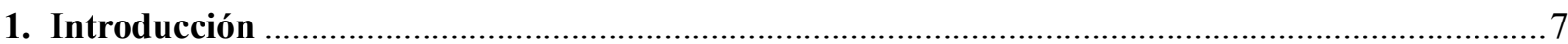

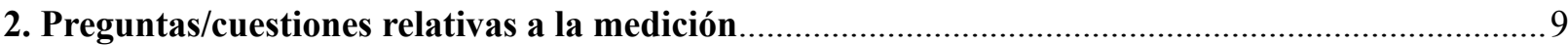

2.1. Preguntas específicas relativas a los indicadores de M2M que se emplean

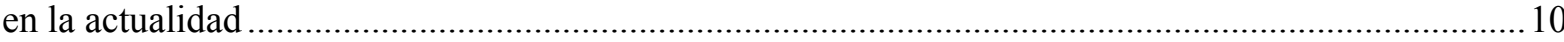

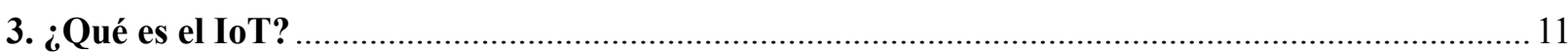

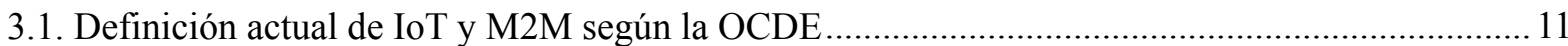

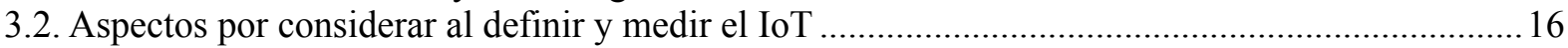

4. Otras definiciones de IoT y estimaciones actuales del tamaño del IoT ......................................... 18

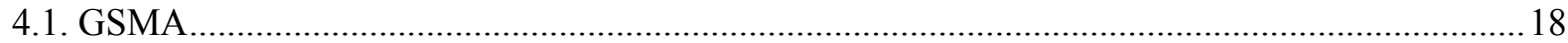

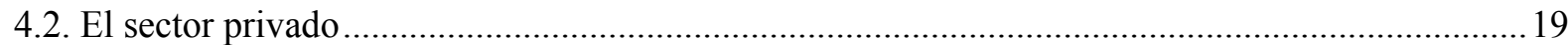

4.3. Autoridades en materia de telecomunicaciones en países miembros de la OCDE..........................20

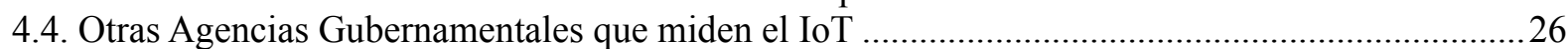

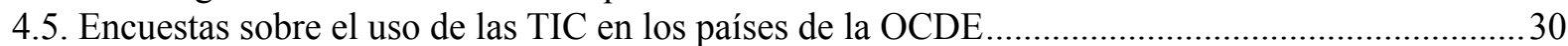

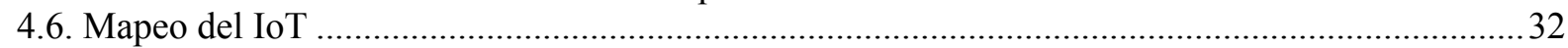

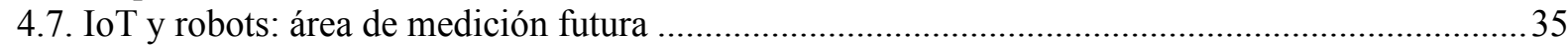

4.8. El IoT y el medio ambiente: sensores M2M y medidores inteligentes ..........................................35

5. ¿Es necesario dar prioridad a algunas categorías de dispositivos de IoT en términos

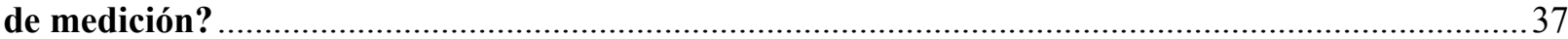

5.1. ¿Algunos dispositivos de IoT, como los vehículos automatizados, generarán

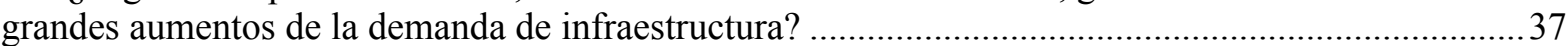

5.2. ¿Qué se necesita en términos de despliegue de infraestructura (p. ej., ITS, 5G)?........................44

6. Desafíos emergentes en materia regulatoria y de creación de políticas relativos al IoT

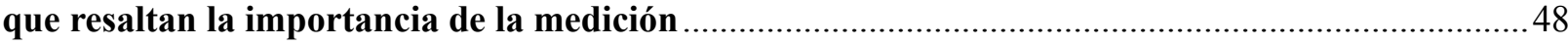

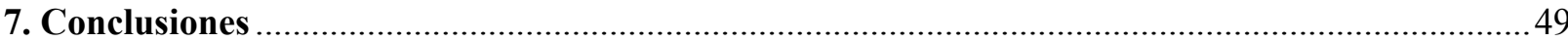

7.1. Sugerencias con respecto a los criterios para la medición del IoT ..................................................49

7.2. Propuesta de definición y taxonomía del IoT de la OCDE ........................................................50

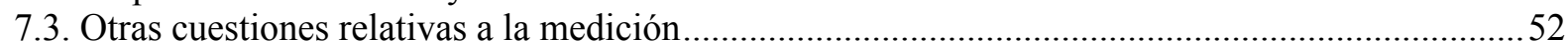

Anexo A. Principales preguntas/cuestiones pendientes relativas a la medición del IoT ....................54

Anexo B. Algunos ejemplos de otras definiciones de IoT .................................................................57

Anexo C. Preguntas detalladas relacionadas con el IoT en las encuestas de uso de las TIC

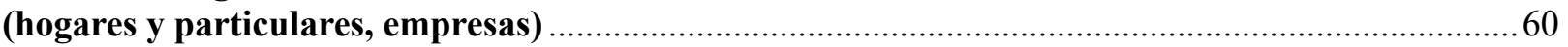

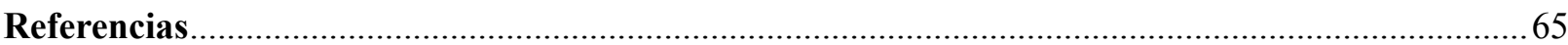

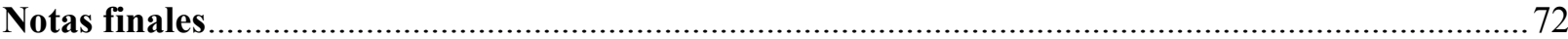




\section{Tablas}

Tabla 1. Mercado de telecomunicaciones en el Reino Unido: estadísticas clave (indicadores seleccionados)...

Tabla 2. Subgrupos de Familias de Patentes de IoT según la Clasificación Internacional de Patentes (IPC).

Tabla 3. Pregunta relativa al IoT en los cuestionarios de la encuesta de uso de las TIC: ejemplos recientes seleccionados para hogares y particulares.

Tabla 4. Pregunta relativa al IoT en los cuestionarios de la encuesta de uso de TIC: ejemplos recientes seleccionados para negocios

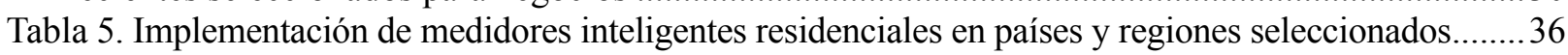

Tabla 6. Comparación de las tecnologías LTE-M y LoRA, Corea .........................................................46

Tabla A C.1. Preguntas relacionadas con el IoT en los cuestionarios de la encuesta sobre el uso de las TIC

Tabla A C.2. Preguntas relativas al IoT en los cuestionarios de las encuestas sobre uso de las TIC

\section{Figuras}

Figura 1. Entorno propicio para el IoT 12

Figura 2. Dispositivos en línea por cada 100 habitantes, países líderes de la OCDE................................. 14

Figura 3. Abonos de telefonía celular M2M/embebidos por cada 100 habitantes .................................... 15

Figura 4. Proporción de tarjetas SIM M2M del total de tarjetas SIM en países de la UE, octubre de 2016

Figura 5. Conexiones M2M por cada 100 habitantes, datos de la GSMA para países de la OCDE ............ 18

Figura 6. Componentes de ARCEP que deben considerarse en el ecosistema de IoT ............................22

Figura 7. Marco de clasificación del mercado de IoT y distribución de datos en Japón ............................24

Figura 8. Tráfico mensual de datos M2M por abono (MB) en Suecia ....................................................25

Figura 9. Ingresos mensuales por abonos M2M (USD) en Suecia y Noruega .......................................26

Figura 10. Principales participantes en IoT, big data y tecnologías de cómputo cuántico,

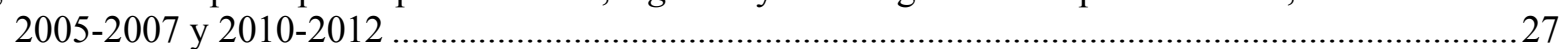

Figura 11. Patentes de la nueva generación de tecnologías relativas a TCI, 2005-2012 _.......................28

Figura 12. Cantidad de dispositivos de Internet de las Cosas en el Reino Unido en 2016, por tipo ............31

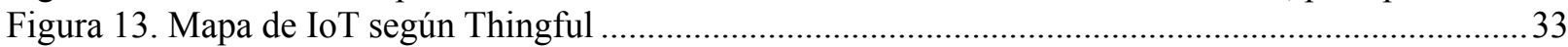

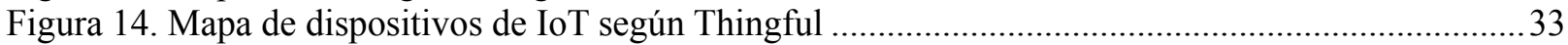

Figura 15. "Mapa de calor" IoTUK Nation de empresas en el sector de IoT .........................................34

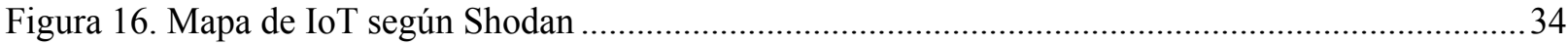

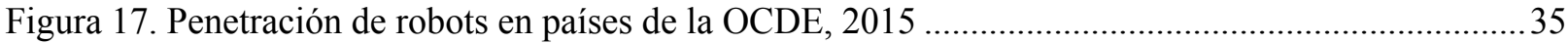

Figura 18. Uso de datos a bordo en vehículos Chevrolet conectados....................................................38

Figura 19. Volumen de datos generados por un vehículo autónomo: Intel ................................................39

Figura 20. Niveles de automatización de acuerdo con la Sociedad de Ingenieros Automotrices.................41

Figura 21. Tráfico total de datos móviles pasado a Redes Wi-Fi Fijas, CISCO ........................................47

Figura 22. Taxonomía propuesta del IoT para efectos de medición ........................................................51 


\section{Resumen ejecutivo}

La declaración de la reunión Ministerial de Cancún sobre Economía Digital destacó la importancia de desarrollar indicadores del IoT que permitan evaluar sus efectos en distintas áreas de políticas $\left(\mathrm{OCDE}, 2016_{[1]}\right)$. Por ello, en el presente informe se revisan distintas definiciones del IoT en el contexto de establecer una definición operativa para el trabajo del CDEP, y se propone una taxonomía para su medición. Asimismo, en este informe se exploran los posibles desafíos para las infraestructuras de telecomunicaciones derivados del crecimiento exponencial de los dispositivos de IoT mediante la aplicación en vehículos conectados y autónomos. Se eligió esta aplicación del IoT ya que los requisitos para la transmisión de datos de los vehículos totalmente automatizados podrían tener implicaciones importantes para las infraestructuras de red, y, por lo tanto, podrían ser prioritarias en términos de medición.

El informe respalda la actual definición que la OCDE asigna al IoT con la salvedad de aquellos dispositivos que ya se consideran en los indicadores de la OCDE (es decir, teléfonos inteligentes [smartphones], tabletas y computadoras personales), y propone añadir subcategorías para fines de medición. La definición general de IoT según la OCDE sería, "el Internet de las Cosas incluye todos los dispositivos y objetos cuyo estado puede ser alterado a través de Internet, con o sin la participación activa de personas. Mientras que los objetos conectados pueden requerir la participación de dispositivos que se consideran parte del "Internet tradicional", esta definición excluye las laptops, las tabletas y los teléfonos inteligentes ya considerados en los indicadores actuales de banda ancha de la $O C D E ”$.

Con la intención de informar mejor a los responsables de la elaboración de políticas, este informe propone un marco de trabajo (taxonomía) con una clasificación del IoT en categorías, dado que muchos dispositivos conectados tendrán requisitos de red diferentes. Por ejemplo, las aplicaciones críticas de IoT, como cirugías a distancia y los vehículos autónomos, requerirán una alta fiabilidad y una conectividad de baja latencia, mientras que los sensores masivos y dispersos de máquina a máquina (M2M) utilizados para aplicaciones agrícolas podrían no ser tan sensibles a la latencia o a las velocidades de la red.

Dentro del marco de medición propuesto para el IoT, se proponen las dos categorías principales de IoT: IoT de Área Amplia e IoT de Corto Alcance. La categoría de IoT de Área Amplia incluye los dispositivos que se conectan a través de tecnología celular, así como aquellos conectados a través de Redes de Área Amplia de Baja Potencia, mientras que la categoría de IoT de Corto Alcance incluye los dispositivos que utilizan espectros no licenciados con un alcance normal de hasta 100 metros. Se sugieren dos subcategorías para el IoT de Área Amplia: 1) Dispositivos M2M masivos (p. ej., sensores para agricultura o ciudades inteligentes) y 2) Aplicaciones críticas de IoT (p. ej., aplicaciones de cirugía a distancia, vehículos totalmente automatizados y otras aplicaciones de robótica industrial). 


\section{Medición y aplicaciones del IoT}

\section{Introducción}

El término Internet de las Cosas (IoT) se refiere a la conexión de un creciente número de dispositivos y objetos a Internet. Como se destacó en la Reunión Ministerial de Cancún, tras la convergencia entre las redes fijas y móviles, y entre las telecomunicaciones y la radiodifusión, el IoT representa el siguiente paso en la convergencia entre las Tecnologías de la Información y las Comunicaciones (TIC) y las economías y sociedades a una escala sin precedentes. Tiene la promesa de contribuir de forma sustancial a la innovación, el crecimiento y la prosperidad social y, al igual que en cualquier otro ámbito de desarrollo, los responsables políticos y demás partes interesadas necesitan pruebas que les permitan fundamentar las decisiones que tomarán en los próximos años. Como tal, la Declaración de Cancún invitaba a la OCDE a seguir desarrollando el trabajo sobre estas tecnologías emergentes, incluido el Internet de las Cosas, con el fin de aprovechar plenamente sus beneficios y fortalecer la recopilación de estadísticas comparables a escala internacional.

Se espera que el IoT crezca de forma exponencial, conectando miles de millones de dispositivos en un periodo relativamente corto (OCDE, 2015 $5_{[2]}$ ). Algunos de estos dispositivos conectados estarán en residencias privadas y se relacionarán con algunas funciones como gestión de energía, seguridad o entretenimiento. Otros se relacionarán a avances en áreas como transporte, salud y manufactura. Una cuestión clave, por lo tanto, es la forma de priorizar los esfuerzos de medición de aquellos elementos del IoT que son de mayor relevancia para los responsables de las políticas. Por ejemplo, en el caso del uso del IoT en la manufactura, en ocasiones llamado Industria 4.0 o la próxima revolución de la producción, es probable que los responsables de la toma de decisiones deseen saber no solo cuántos robots están funcionando en su país, sino también cuántos están conectados. Al mismo tiempo, no solo necesitarán saber cuántos automóviles y camiones están conectados, sino, en el caso de los vehículos totalmente automatizados, cuáles son sus demandas potenciales sobre las infraestructuras de comunicación en términos de generación de grandes cantidades de datos.

Los avances en torno a la conectividad o las implicaciones de las nuevas demandas que se plantean a las redes no son, por supuesto, nuevos para las partes interesadas en los mercados de la comunicación. No obstante, la omnipresencia de estos acontecimientos plantea interrogantes sobre las mejores formas de reunir la información que, en última instancia, resulta necesaria para fundamentar las políticas. Por ejemplo, ¿cuál es la mejor fuente para recabar datos sobre robots conectados? ¿Los productores de robots o los proveedores de la conectividad? De forma similar, ¿cuál es la mejor manera de recabar información sobre vehículos autónomos? ¿En los registros vehiculares que existen en todos los países o con los productores de esos vehículos o con los proveedores de conectividad?

También habrá cuestiones de alta prioridad para las políticas y la regulación de las comunicaciones, especialmente cuando las demandas del IoT se desarrollen de manera que tengan fuertes implicaciones para la localización, la implementación y las capacidades de las infraestructuras. Dado que un solo vehículo totalmente automatizado, por ejemplo, 
puede generar muchos más datos que varios miles de usuarios móviles inalámbricos, esto puede tener profundas implicaciones para las decisiones en áreas como el espectro, los derechos de paso, la ubicación de los centros de datos, los requisitos para un acceso de banda ancha más rápido y enlace terrestre, por nombrar solo algunos. $\mathrm{Al}$ mismo tiempo, otros buscarán información que incluya consideraciones en ámbitos como la privacidad y la seguridad, así como la interoperabilidad, numeración y estandarización. Por lo tanto, las definiciones estadísticas y los indicadores del IoT deberían reflejar, en la medida de lo posible, los diferentes intereses y objetivos políticos en este ámbito.

Además de estar mejor informados sobre la demanda futura de infraestructuras de comunicación, incluidas aquellas en las que podría haber inversión pública, existe una segunda medición de la razón crítica en esta área que es importante para los responsables de las políticas. Es la capacidad de medir los efectos del IoT sobre la productividad, el PIB y el crecimiento, como parte de la Economía Digital. Sin embargo, para evaluar cualquier medida de la influencia del IoT en el PIB, el primer paso consiste en disponer de un indicador adecuado del tamaño del IoT. Este último punto quedó claro en una reciente publicación (2018) de la Oficina de Análisis Económico de los Estados Unidos (BEA, por sus siglas en inglés), que se encargó de medir la influencia de la economía digital en el PIB. Aunque la BEA reconoció que el IoT $^{1}$ era un elemento importante de la economía digital, se excluyó debido a las dificultades inherentes a su medición, así como a la complejidad de asignar el componente "digital" de los dispositivos conectados al considerar el valor añadido (Barefoot et al., 2018 $\left.\left.{ }_{[3]}\right]\right)^{2}$

La Declaración de la Reunión Ministerial de Cancún identifica una serie de áreas en las que las partes interesadas pueden participar para promover la implementación del IoT. En particular, se destacó la importancia de elaborar parámetros para medir los efectos de la adopción del IoT en diversos ámbitos de la creación de políticas (OCDE, 2016 ${ }_{[1]}$ ). Al respecto, el objetivo de este informe es doble. Primero, revisar las distintas definiciones del IoT en el contexto de una definición operativa para el trabajo del CDEP. En segundo lugar, explorar formas viables de medir el IoT y sus implicaciones, en particular para la infraestructura y las redes. Los desafíos potenciales para la infraestructura serán analizados en un estudio de caso: el desarrollo de vehículos conectados y autónomos.

La estructura de este informe es la siguiente. La Sección 2 ofrece un panorama general de las principales cuestiones de la medición del IoT que han surgido durante los años recientes entre los países miembros de la OCDE. En la Sección 3 se resume la definición de IoT empleada por la OCDE a la fecha y las metodologías de medición que ha empleado la OCDE para las comunicaciones máquina a máquina (M2M, por sus siglas en inglés) desde 2012. La Sección 4 ofrece un panorama general de las definiciones seleccionadas y los esfuerzos de medición emprendidos por varias autoridades gubernamentales, organizaciones así como de integrantes del mercado. La Sección 5 aborda la cuestión de si ciertas categorías de dispositivos de IoT requieren una priorización en términos de medición, dadas sus posibles implicaciones para la infraestructura de comunicación (p. ej., vehículos autónomos). La Sección 6 ofrece una breve descripción general de los nuevos retos regulatorios y políticos relacionados con el IoT que resaltan la importancia de la medición. Por último, la Sección 7 concluye destacando algunos criterios que deben considerarse en términos de medición del IoT, y con una propuesta de definición de trabajo de IoT para los países de la OCDE, con sus subcategorías correspondientes. 


\title{
2. Preguntas/cuestiones relativas a la medición
}

\begin{abstract}
A la fecha, la OCDE ha recabado datos de muchas conexiones máquina a máquina (M2M) en redes inalámbricas celulares. Muchas de estas conexiones M2M han sido utilizadas para aplicaciones heredadas creadas directamente en las redes de telefonía celular. Sin embargo, a medida que los dispositivos de IoT se van convirtiendo cada vez más en dispositivos basados en el Protocolo Internet (IP) y no dependientes de una plataforma (es decir, que funcionan en redes móviles, fijas y de otro tipo), ¿cómo deberían intentar los países de la OCDE medir el número de estos dispositivos y sus implicaciones para las redes de telecomunicaciones?
\end{abstract}

La mayoría de los dispositivos de IoT residenciales no están conectados directamente a una red de operadores de telecomunicaciones, sino que se conectan a través de un "concentrador doméstico inteligente" o a través de redes inalámbricas residenciales. Existen, no obstante, diferencias significativas entre estos dispositivos, tanto en términos de número de dispositivos y usos de red, como en los dispositivos habilitados para Internet, que han proliferado en las residencias privadas en los últimos años y que tienden a estar centrados en el usuario (computadoras personales, tabletas, teléfonos inteligentes, dispositivos portátiles, etc.).

Al mismo tiempo, muchas aplicaciones del IoT, como los servicios públicos o gubernamentales, utilizan redes privadas y, por lo tanto, podrían no aparecer en los datos relativos a la oferta (es decir, los suministrados por el operador de telecomunicaciones). Es probable que los proveedores de servicios relacionados proporcionen los datos en un área como, por ejemplo, las conexiones para medidores inteligentes, incluso si las redes de telecomunicaciones proporcionan la conectividad subyacente. Por otra parte, es probable que siga siendo necesario que los operadores de red proporcionen algunos datos como una categoría aparte.

Es probable que aplicaciones de IoT distintas (es decir, comunicaciones M2M masivas y dispersas frente a las aplicaciones críticas de IoT) tengan necesidades de red diversas. Por ejemplo, Ericsson declaró que los vehículos autónomos requerirán una latencia baja (es decir, menos de $5 \mathrm{~ms}$ ) y una fiabilidad y cobertura de red del $100 \%$. Al mismo tiempo, afirman que los objetos M2M conectados masivamente y dispersos, como los sensores, requerirán una cobertura de red del $100 \%$, una vida útil de la batería de 10 años, pero no son realmente sensibles a la latencia (Ericsson, $\left.2017_{[4]}\right) .{ }^{3}$ Esto pone de manifiesto la necesidad de dar prioridad a la medición en función de los objetivos de las políticas.

Aunque el uso de datos del IoT ha sido relativamente modesto hasta la fecha, cabe preguntarse cómo se espera que las aplicaciones de próxima generación, como los vehículos totalmente automatizados, los dispositivos industriales de IoT, etc., cambien el perfil de uso de datos de estos dispositivos en el futuro. A manera de ejemplo, según algunas estimaciones, un solo vehículo autónomo producirá $4000 \mathrm{~GB}$ de datos por día, es decir, el equivalente a los datos producidos por 3000 teléfonos inteligentes (Intel, 2016 $[5]$ ), o incluso $100 \mathrm{~GB}$ de datos por segundo $\left(\mathrm{CNBC}\right.$ Autos, $\left.2017_{[6]}\right)$. Según otras estimaciones, un vehículo conectado genera 20 GB de datos al día (Seminconductor Engineering, 2017 ${ }_{[7]}$ ).

Una pregunta sería, entonces, ¿cómo afectará un aumento sustancial de los datos a los requisitos de infraestructura? ¿Qué cantidad de datos recabados se transferirá realmente y qué tanta capacidad de red adicional se necesitará? Al mismo tiempo, ¿son sus categorías de dispositivos que utilizan tarjetas SIM las que merecen ser incluidas en los datos recogidos por las autoridades dadas las diferentes exigencias que imponen a las infraestructuras? En 
otras palabras, la información sobre los vehículos autónomos podría ser más crítica que la de los objetos como el equipaje, los sensores ambientales o los miles de diferentes tipos de cosas que un día pueden estar conectadas a través de tarjetas SIM (simplemente porque generan menos tráfico).

\subsection{Preguntas específicas relativas a los indicadores de M2M que se emplean en la actualidad}

A medida que empiezan a surgir tecnologías nuevas, como el eSIM (SIM embebido) en dispositivos portátiles (wearables), puede plantearse la cuestión de cómo considerar estas nuevas tarjetas SIM en la medición de las conexiones M2M. La serie 3 de Apple Watch, por ejemplo, utiliza eSIM, mientras que muchos relojes Android Wear 2. 0 han utilizado una "Nano SIM" independiente hasta la fecha. ¿Deben considerarse tales dispositivos como una conexión única o múltiple? En otras palabras, si uno de estos dispositivos está conectado a una cuenta de servicio de teléfono inteligente existente y el otro es potencialmente transferible a otras cuentas distintas, ¿deberían contarse de forma diferente?

Si tales dispositivos se registran como conexiones múltiples, ¿deberían contarse en las conexiones de banda ancha móvil tradicionales (por ejemplo, teléfonos inteligentes, tabletas) o en los dispositivos conectados, como los automóviles y los sensores? En términos del elemento relacionado con una o varias conexiones, se entiende que los proveedores de telecomunicaciones cuentan un solo vehículo como una sola conexión, incluso si tiene dos tarjetas SIM, lo que tal vez ofrezca un camino a seguir.

Los tipos especiales de dispositivos conectados mejorados que actualmente utilizan tarjetas M2M SIM, como los vehículos autónomos, ¿necesitarán una categoría aparte para realizar un seguimiento del elevado consumo de datos de estos dispositivos (a diferencia, por ejemplo, del consumo de datos de los dispositivos conectados que se basan únicamente en sensores) con el fin de adaptar la arquitectura de la red y la infraestructura de comunicaciones en consecuencia?

Además, otra pregunta que podría plantearse a los fabricantes de dispositivos y a los operadores móviles es: cuando un dispositivo, como un teléfono inteligente, tiene aproximación múltiple (multihoming) de conectividad (por ejemplo, puede utilizar redes LTE-M y LoRa), ¿se hace una contabilización doble de los dispositivos M2M que utilizan tarjetas SIM y son dispositivos conectados a la LPWA?

En el Anexo A se presenta una lista completa de preguntas y cuestiones relativas a la medición del IoT y, en particular, a la medición actual de M2M. 


\section{3. ¿Qué es el IoT?}

\subsection{Definición actual de IoT y M2M según la OCDE}

La OCDE define IoT en términos generales "incluidos todos los dispositivos y objetos cuyo estado puede ser alterado a través de Internet, con o sin la participación de las personas. Esto incluye laptops, enrutadores, servidores, tabletas y teléfonos inteligentes, a menudo considerados parte del "Internet tradicional". Sin embargo, estos dispositivos son parte integral del funcionamiento, la lectura y el análisis del estado de los dispositivos del IoT y con frecuencia constituyen el "corazón y el cerebro" del sistema. Por ello, no sería correcto excluirlos" (OCDE, 2015 $[2]$ ).

Además del IoT, las comunicaciones máquina a máquina (M2M), como subconjunto del IoT, se caracterizan por una comunicación de datos autónoma con poca o ninguna interacción humana (OCDE, 2015 [2] ). De hecho, el informe de la OCDE de 2012 sobre el tema definió el M2M como "Dispositivos que se comunican activamente a través de redes alámbricas e inalámbricas que no son computadoras en el sentido tradicional y que utilizan Internet de una forma u otra. La comunicación M2M es solo un elemento de los medidores inteligentes, las ciudades y la iluminación. Es cuando se combina con la lógica de los servicios en la nube, la operación remota y la interacción que este tipo de aplicaciones se convierten en "inteligentes". La tecnología RFID puede ser otro elemento de un entorno más inteligente que puede utilizarse junto con la comunicación M2M y los servicios en la nube" (OCDE, 2012 $[8]$ ).

En términos de la definición de IoT de la OCDE, hasta la fecha se ha utilizado principalmente para informar el debate político y regulatorio, más que para definir el IoT para la recopilación de datos. Por lo tanto, es amplia por razones prácticas. Por otra parte, las autoridades que recopilan estos datos (por ejemplo, los reguladores en materia de telecomunicaciones), así como la GSMA, han definido M2M.

Los primeros retos para llegar a una definición del IoT para la medición consisten en considerar cuestiones tales como aquello que pudiera ser práctico, cuáles pueden ser las prioridades, etc. Este concepto podría, por ejemplo, tomar en cuenta los elementos facilitadores clave (es decir, las comunicaciones M2M, big data, cómputo en la nube y los sensores) que conducen a las aplicaciones de inteligencia artificial (OCDE, 2015 [2] $)$. Además, realizar la medición de la cantidad de "dispositivos conectados" cuando se conectan varios dispositivos en un sistema integrado puede resultar una tarea complicada. Las siguientes tecnologías subyacentes son elementos clave requeridos para que los dispositivos del IoT funcionen correctamente:

- semiconductores (es decir, sensores, circuitos integrados, procesadores, memoria y otros)

- módulos y dispositivos (es decir, software/API para conectar los dispositivos IoT)

- plataformas de IoT (es decir, los sistemas operativos y soluciones de IoT de soporte existentes)

- la red (es decir, conectividad cuando las cuestiones de interoperabilidad y estandarización son relevantes).

Los distintos componentes del entorno propicio del IoT pueden ilustrarse en un diagrama (Figura 1). 
Figura 1. Entorno propicio para el IoT

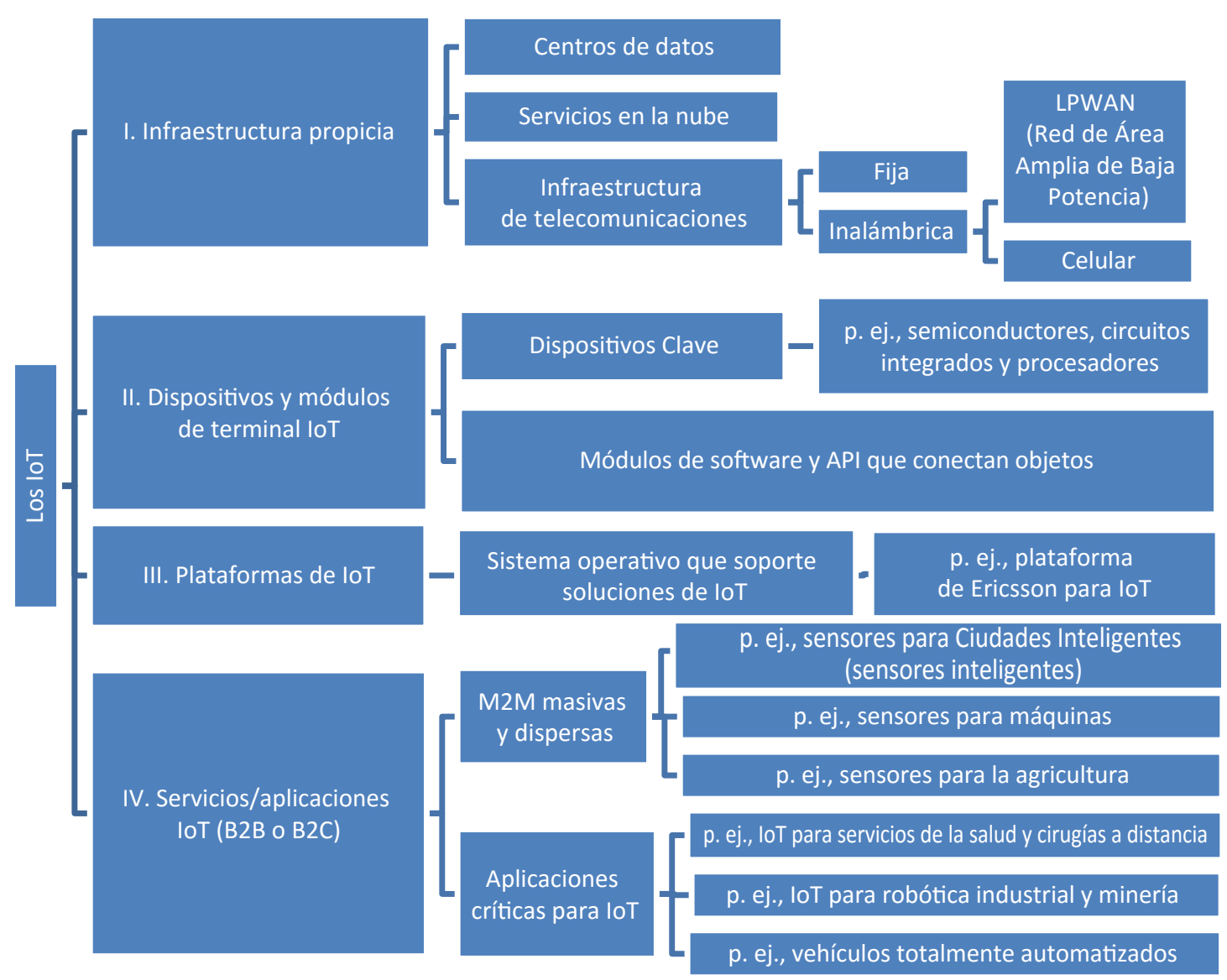

Nota: Este diagrama se desarrolló tomando en consideración los marcos de trabajo para el IoT de Japón, Francia y Corea.

Fuente: Elaboración propia.

En cada uno de los niveles clave del IoT participan numerosos agentes económicos. Esto puede influir en la definición del IoT para efectos de medición y, en última instancia, en la forma en que pueden recabarse los datos. Por ejemplo, algunos de los actores involucrados son los siguientes:

- los diseñadores y productores de dispositivos conectados que se venden a los consumidores (por ejemplo, un televisor Samsung conectado o el asistente virtual de Amazon, Alexa)

- los proveedores de módulos de IoT (es decir, circuitos, procesadores, software y API)

- proveedores de equipo para red (p. ej., Ericsson, Cisco, Huawei)

- proveedores de servicios en la nube para IoT (p. ej., Amazon, Google)

- proveedores de servicios de plataforma para IoT (es decir, el software de soporte integral que lo conecta todo a un sistema de IoT mediante la facilitación de la comunicación, el flujo de datos y la gestión de los dispositivos)

- proveedores de servicios de conectividad (p. ej., LoRa, SigFox, operadores de telefonía celular, proveedores de servicios fijos y satelitales). 
El trabajo futuro sobre la medición del IoT podría centrarse en el mapeo de los distintos agentes desde la perspectiva de la oferta para efectos de la recolección de datos. Este mapeo podría incluir a las partes interesadas que definen los protocolos de conectividad, las que construyen su propia red IoT LPWAN y la ponen a disposición de los clientes, las que actúan como intermediarios mediante la conectividad basada en redes de terceros, etcétera.

Dado que el IoT forma parte de un ecosistema con facilitadores clave, ha sido complicado encontrar una definición lo suficientemente precisa para efectos de medición. No obstante, muchas de las definiciones existentes utilizadas para el IoT son adecuadas para respaldar los conceptos generales de los debates sobre políticas (véanse ejemplos seleccionados en el Anexo B). ${ }^{4}$ En algunos casos, diversos organismos intergubernamentales han abordado cuestiones regulatorias relacionadas con el IoT sin definirlo. Por ejemplo, el Organismo de Reguladores Europeos de Comunicaciones Electrónicas (ORECE) ha trabajado durante los últimos años en estudiar el impacto del IoT en la regulación y en cómo fomentar un entorno propicio para el IoT sin comprometerse con una definición (ORECE, 2016 $\left.{ }_{[9]}\right) .5$

Las organizaciones intergubernamentales y los organismos internacionales de normalización se encuentran realizando esfuerzos para armonizar una definición del IoT para efectos de medición. Un ejemplo es el del Programa de Trabajo y Presupuesto del ORECE para 2018. El ORECE tiene previsto evaluar el tipo de medición del IoT que ya llevan a cabo las autoridades regulatorias nacionales (ARN) desde la perspectiva de la oferta o de la demanda, y evaluar si, en esta fase, existe un conjunto común de indicadores relacionados con el IoT que el ORECE podría recopilar periódicamente en el futuro (posiblemente a partir de 2019). ${ }^{6}$ Otro ejemplo notable es la Organización Internacional de Normalización (ISO), que está trabajando actualmente en la definición y el vocabulario del IoT, así como en la interoperabilidad de los sistemas (plataformas) de IoT como parte de sus proyectos de normas tecnológicas (ISO, 2018 ${ }_{[10]}$ ).

En trabajos anteriores de la OCDE se ha destacado la dificultad de medir el IoT (OCDE, $2017_{[11]}$; OCDE, 2015 [2]; OCDE, 2016 ${ }_{[1]}$ ). Se ha subrayado que "la medición del número de dispositivos de IoT conectados a Internet ha resultado complicada de obtener, y los países apenas ahora comienzan a recopilar datos". A falta de estadísticas oficiales, una opción ha sido examinar las fuentes privadas de recopilación de datos.

Una de las fuentes (p. ej., CISCO, Ericsson, y otros) que se ha utilizado en publicaciones anteriores de la OCDE, son los datos proporcionados por Shodan, que se describe como un motor de búsqueda de dispositivos conectados a Internet. En 2015, según la definición de Shodan, había 363 millones de dispositivos visibles en línea y se registraron unos 84 millones en la República Popular China (en lo sucesivo "China") y 78 millones a Estados Unidos (Figura 2). Si bien se reconoce que dicha recopilación de datos es incipiente y que hasta la fecha no se ha llegado a un consenso sobre las definiciones, estos enfoques ofrecen una opción para el futuro. 
Figura 2. Dispositivos en línea por cada 100 habitantes, países líderes de la OCDE

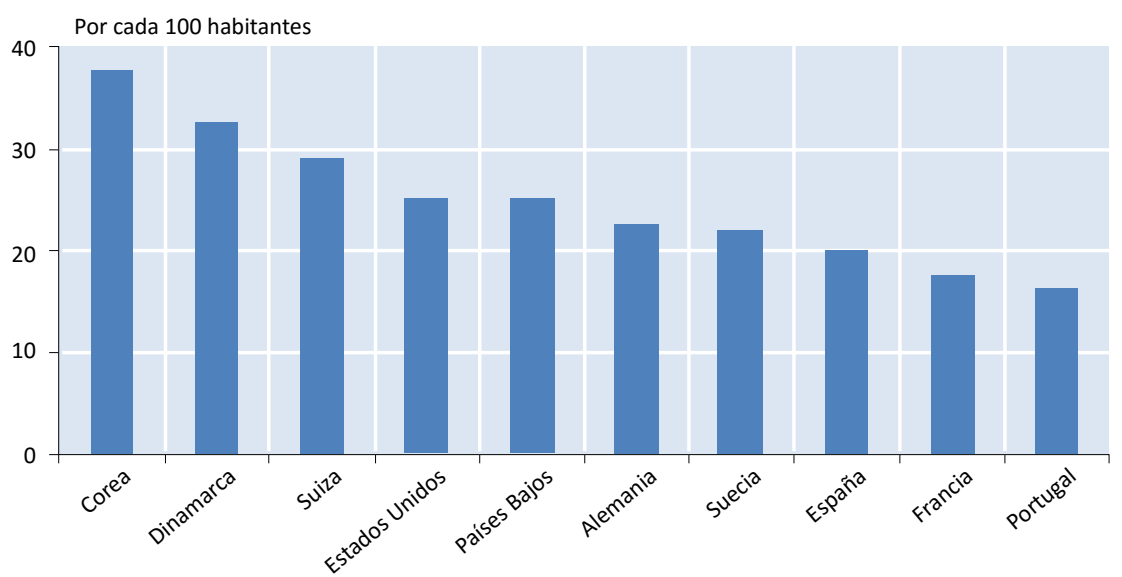

Nota: Última actualización: 29 de mayo de 2015.

Fuente: Perspectiva de la Economía Digital de la OCDE para 2015, http://dx.doi.org/10.1787/888933473770 con datos de Shodan.

Un enfoque para la medición del IoT es centrarse en un subconjunto o subcategoría. La OCDE ha recopilado datos de las autoridades de comunicaciones sobre las tarjetas SIM M2M embebidas desde 2012. Asimismo, la GSMA recopila datos M2M de sus miembros. Aunque es una parte muy importante del IoT, esta categoría es solo una pequeña parte de todos los dispositivos que ahora están conectados o lo estarán en el futuro.

\subsubsection{Medición de los datos de M2M de la OCDE}

El Portal de Banda Ancha publica información sobre indicadores clave del mercado de las telecomunicaciones de los reguladores de las comunicaciones y de los organismos oficiales de estadística de la zona de la OCDE. Dentro del conjunto de indicadores, la mayoría de los países de la OCDE recopilan actualmente datos sobre las tarjetas SIM M2M.

Para calcular el número de abonados al servicio móvil celular M2M/embebido, la OCDE define M2M en las redes móviles como "el número de tarjetas SIM asignadas para su uso en máquinas y dispositivos (automóviles, sensores inteligentes y electrónica de consumo) y que no forman parte de una suscripción de consumo". Esto significa que los adaptadores (dongles) para datos móviles y los abonos a tabletas deben contabilizarse por los países bajo la definición de banda ancha móvil, mientras que las tarjetas SIM en dispositivos de navegación personal, medidores inteligentes, trenes, automóviles, etc., deben contabilizarse en la categoría M2M.

Es posible observar una tendencia creciente en los abonos a tarjetas SIM M2M en el área de la OCDE cuando se comparan los datos más recientes (junio de 2017) con los datos de penetración de M2M para los años 2012 y 2014 (Figura 3). 
Figura 3. Abonos de telefonía celular M2M/embebidos por cada 100 habitantes

Años 2012, 2014 y 2017

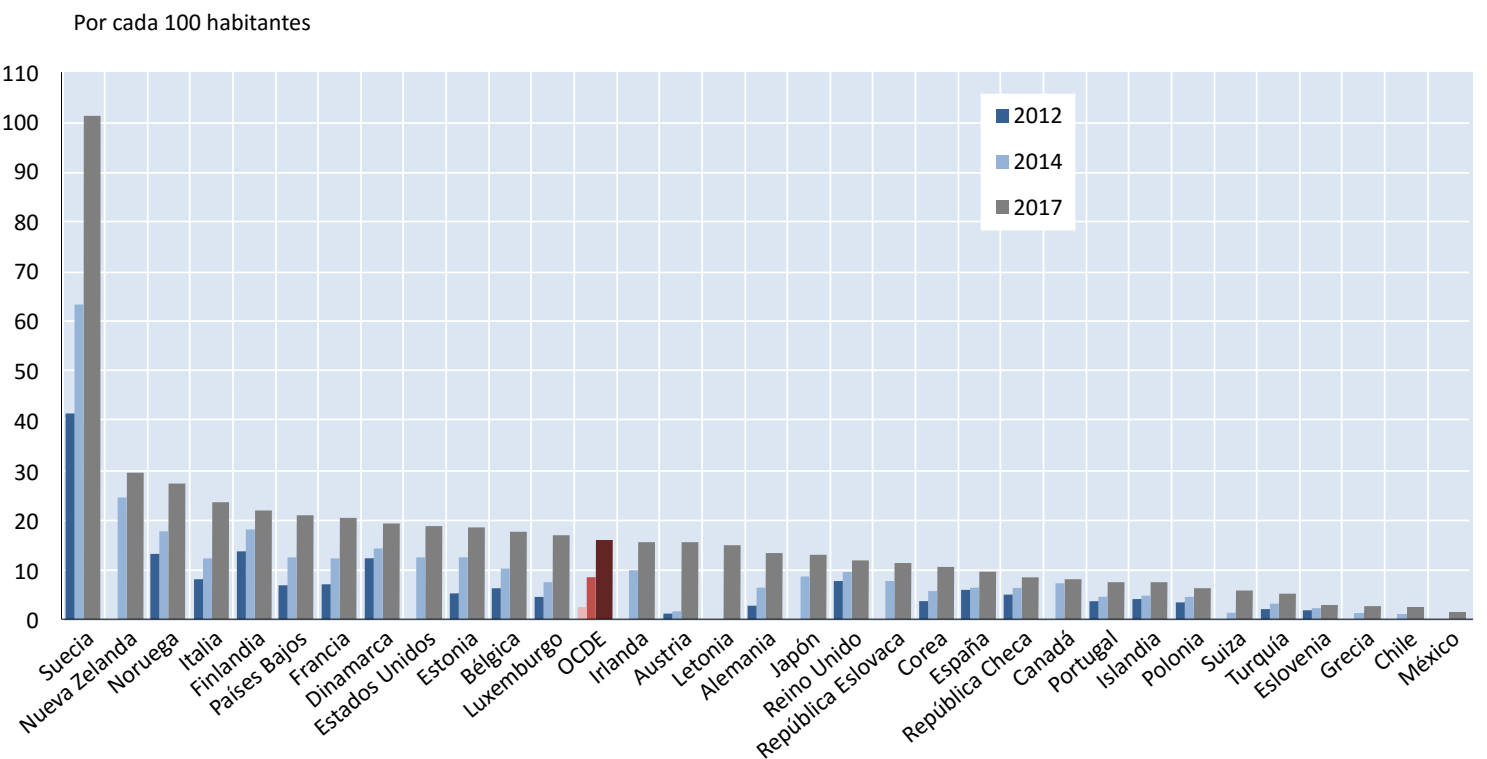

Nota: Para Corea, los datos proporcionados no incluyen algunos dispositivos (dispositivos de navegación personal, entre otros) ya que se basan en tecnologías diferentes a las tarjetas SIM.

Fuente: Portal de Banda Ancha, OCDE, www.oecd.org/sti/broadband/oecdbroadbandportal.htm

Los datos de M2M solo muestran el origen las tarjetas SIM (es decir, donde se asignan los números o de qué Operador de Red Móvil (ORM) u Operador de Red Móvil Virtual (ORMV) nacional se asigna la SIM al usuario final), pero no donde se utiliza el dispositivo conectado. Por lo tanto, podría darse el caso de que un país que presente una alta tasa de tarjetas SIM M2M conectadas refleje el hecho de que un operador ORM o ORMV nacional es fuerte en el mercado internacional IoT-M2M (p. ej., Telenor en Suecia). Por ejemplo, Telenor Connexion, que poseía el 81\% del mercado sueco de M2M (diciembre de 2016), utiliza su numeración (números IMSI) no solo para Suecia, sino también para sus clientes en todo el mundo. ${ }^{7}$

Un factor que probablemente aumentará estas cifras de penetración de M2M es la tendencia de las Autoridades Regulatorias Nacionales (ARN) de varios países de permitir el uso de números M2M extraterritoriales (p. ej., Alemania, Países Bajos y Bélgica). Históricamente, los ORM han utilizado su numeración IMSI en el país que proporcionó los números. En los últimos años, sin embargo, los reguladores de países como Bélgica y los Países Bajos han adoptado políticas más abiertas en relación con el uso de la numeración y M2M. En este sentido, cabe destacar que ambos países tienen grandes cuotas del mercado de M2M de la UE, muy por encima de las cuotas equivalentes de otros países de la Unión Europea, y se sitúan en segundo y tercer lugar detrás de Suecia (Figura 4). 
Figura 4. Proporción de tarjetas SIM M2M* del total de tarjetas SIM en países de la UE, ** octubre de 2016

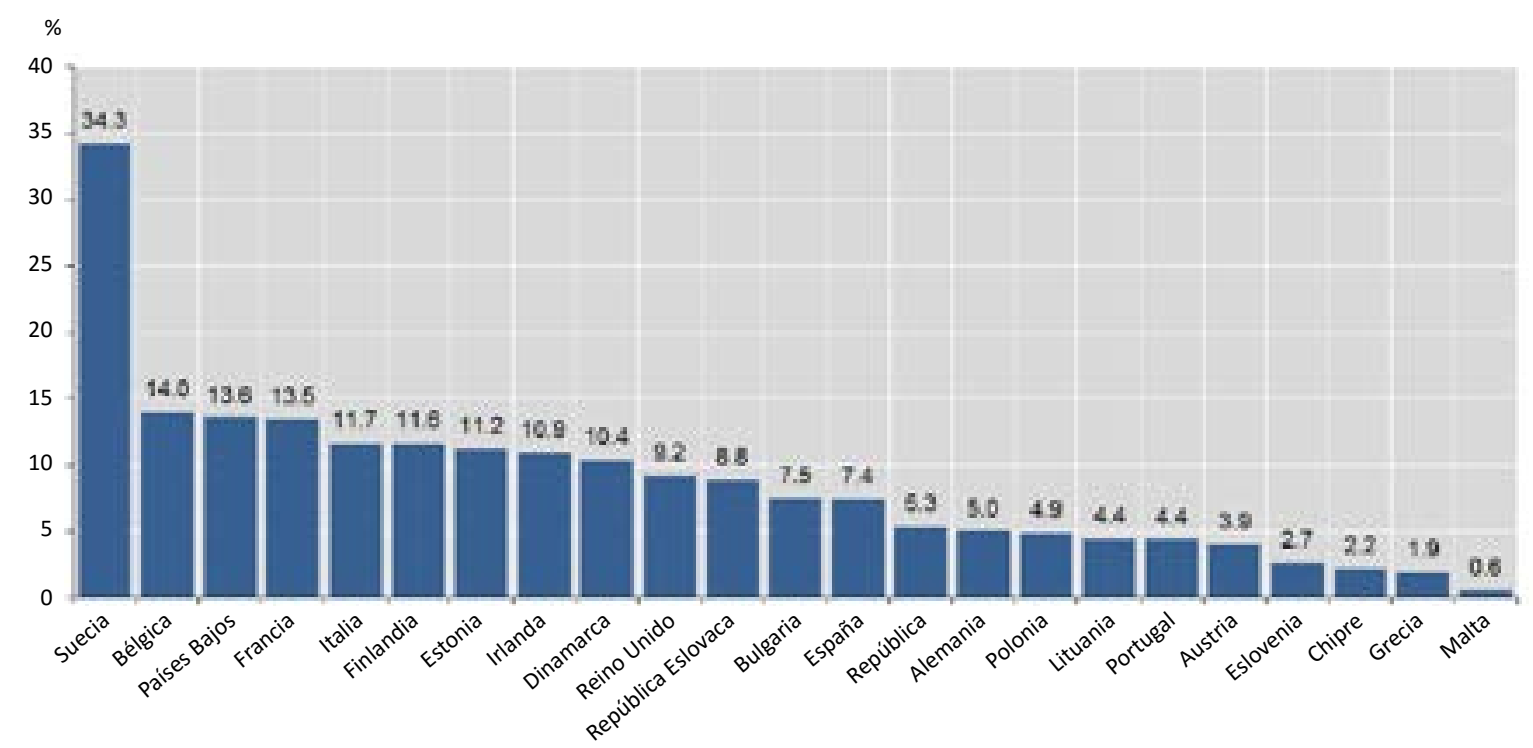

Nota: *Definición de las tarjetas SIM M2M según el CE: "M2M se trata de permitir el flujo de datos entre máquinas y, en última instancia, entre máquinas y personas. Independientemente del tipo de máquina o de datos, la información normalmente fluye de la misma manera general, desde una máquina a través de una red y luego a través de una puerta de enlace a un sistema en el que se puede revisar y actuar en consecuencia". - www.m 2 mcomm.com.

**Nota por parte de Turquía: La información contenida en el presente documento con referencia a "Chipre" se refiere a la parte sur de la isla. No existe una autoridad única que represente a los turcochipriotas y a los grecochipriotas en la isla. Turquía reconoce a la República Turca de Chipre Septentrional (RTCN). Hasta que se encuentre una solución duradera y equitativa en el contexto de las Naciones Unidas, Turquía mantendrá su posición sobre la "cuestión chipriota".

Nota por parte de todos los Estados de la Unión Europea Miembros de la OCDE: La República de Chipre está reconocida por todos los miembros de las Naciones Unidas, a excepción de Turquía. La información que figura en el presente documento se refiere a la zona bajo el control efectivo del Gobierno de la República de Chipre. Fuente: Datos del Mercado Único Digital de la Comisión Europea, EU 28, "Financial indicators, fixed and mobile telephony, broadcasting and bundled services indicators - 2016". (Comisión Europea, 2017 [12]), https://ec.europa.eu/digital-single-market/en/connectivity

\subsection{Aspectos por considerar al definir y medir el IoT}

Algunas de las primeras cuestiones a considerar en relación con una definición del IoT son si es práctica para efectos de medición y los elementos que debería incluir. Este concepto podría tomar en cuenta los elementos facilitadores clave (es decir, las comunicaciones M2M, big data, cómputo en la nube y los sensores) que conducen a las aplicaciones de inteligencia artificial (OCDE, 2015 $5_{[2]}$ ). Dicho esto, cuando hay varios dispositivos en un sistema, la medición de la cantidad de "dispositivos conectados" puede ser compleja. La siguiente lista no es exhaustiva, pero destaca algunos aspectos clave que deben considerarse en relación con la medición del IoT:

I. Medición de "dispositivos conectados" según las características (que permiten, entre otras cosas, distinguir el tráfico de datos M2M del tráfico de comunicaciones móviles). Estas características incluyen:

a. Dispersión o concentración de dispositivos/aplicaciones;

b. Movilidad (objetos estacionarios o portátiles), 
c. Volumen de datos y desempeño de la red (ancho de banda), y

d. QoS incluyendo estándares de seguridad y sensibilidad a la latencia.

II. Clasificación del IoT según las opciones tecnológicas para su uso y adopción:

a. Sensores y concentradores simples (es decir, los sensores recogen y analizan la información del entorno, y los concentradores conectan estos sensores a una red más amplia como la de aire acondicionado, electricidad y sistemas de seguridad);

b. Integración de concentradores (es decir, un sistema que conecta concentradores simples creando dispositivos más complejos como el HomeKit de Apple que agrupa en un solo sistema la energía eléctrica, la seguridad del hogar y las persianas de las ventanas);

c. Aplicaciones mejoradas (es decir, servicios que recopilan y analizan datos de dispositivos conectados y del entorno en tiempo real, como los "vehículos autónomos").

III. Tomar en consideración la infraestructura para IoT subyacente que permite la comunicación entre los dispositivos (es decir, servicios en la nube, cómputo cuántico y de borde, almacenamiento de datos, redes móviles, redes LPWA, conectividad de enlace terrestre y de red principal, entre otros).

La definición actual que la OCDE da al IoT proporciona un marco conceptual que sirve de guía para los debates políticos, ya que abarca el universo de los dispositivos de IoT conectados (es decir, la definición menciona "todos los dispositivos u objetos cuyo estado puede modificarse a través de Internet, con o sin la participación activa de las personas"). Sin embargo, podría ser más útil si se añadieran subcategorías para efectos de medición. Estas subcategorías podrían basarse en diferentes características de los dispositivos: i) la gama de dispositivos de IoT (es decir, de área amplia o de corto alcance), o ii) el tipo de conexión M2M (es decir, sensores simples o dispositivos de IoT críticos "activos", como los vehículos autónomos). Los beneficios de complementar la definición de la OCDE añadiendo subcategorías podrían ser múltiples. A saber, aquí se mencionan dos beneficios principales. En primer lugar, haría más manejable la cuestión de la medición del IoT, y en segundo lugar, permitiría establecer prioridades en la recopilación de datos en determinadas categorías (o subcategorías) del IoT que podrían tener más influencia en la infraestructura de comunicación.

En el futuro, es probable que diferentes aplicaciones IoT-M2M generen patrones de uso muy diferentes. Los sensores ambientales, por ejemplo, pueden generar cantidades muy pequeñas de datos relativos a bicicletas y robots conectados, hasta quizás las cantidades más grandes en el caso de vehículos autónomos. Así pues, una clasificación del IoT en varias subcategorías, como "comunicaciones masivas entre máquinas" (p. ej., sensores como el M2M) y aplicaciones críticas de IoT (p. ej., vehículos autónomos), parece un avance deseable para informar mejor a los responsables políticos.

En resumen, en lo que respecta a las métricas del IoT, hay una cuestión de definición y una cuestión de medición. En la sección siguiente se ofrece un panorama general de las definiciones de varias partes interesadas (incluido el sector privado), así como una descripción de cómo han utilizado estas definiciones para medir el IoT. 


\section{Otras definiciones de IoT y estimaciones actuales del tamaño del IoT}

\subsection{GSMA}

La GSMA afirma que, aunque el IoT es un ecosistema muy complejo y diverso con muy pocos datos reportados, lo define como "dispositivos habilitados para IP capaces de transmisión bidireccional de datos (excluidos los sensores de comunicación unidireccionales y las etiquetas RFID). Incluye todas las tecnologías de acceso, p. ej., celular, de corto alcance, fijo y satelital".

La GSMA también tiene una definición de trabajo de la conexión celular M2M, que utilizan para calcular el número de objetos M2M conectados a lo largo de los años por país. Su definición M2M es "Una tarjeta SIM única registrada en la red móvil al final del periodo, que permite la transmisión de datos móviles entre dos o más máquinas. Excluye los dispositivos informáticos de la electrónica de consumo, como los lectores electrónicos, los teléfonos inteligentes, los accesorios de conexión y las tabletas". Esto significa que ciertas aplicaciones que se consideran como IoT/M2M según otras definiciones no se cuentan en los datos de la GSMA. ${ }^{8}$ Conforme a los datos de la GSMA sobre la penetración de M2M, el número de tarjetas SIM M2M en cada país de la OCDE ha aumentado entre 2012 y 2017 (Figura 5).

\section{Figura 5. Conexiones M2M por cada 100 habitantes, datos de la GSMA* para países de la $\mathrm{OCDE}^{* *}$}

Teclee el subtítulo aquí. Si no necesita un subtítulo, favor de eliminar esta línea.

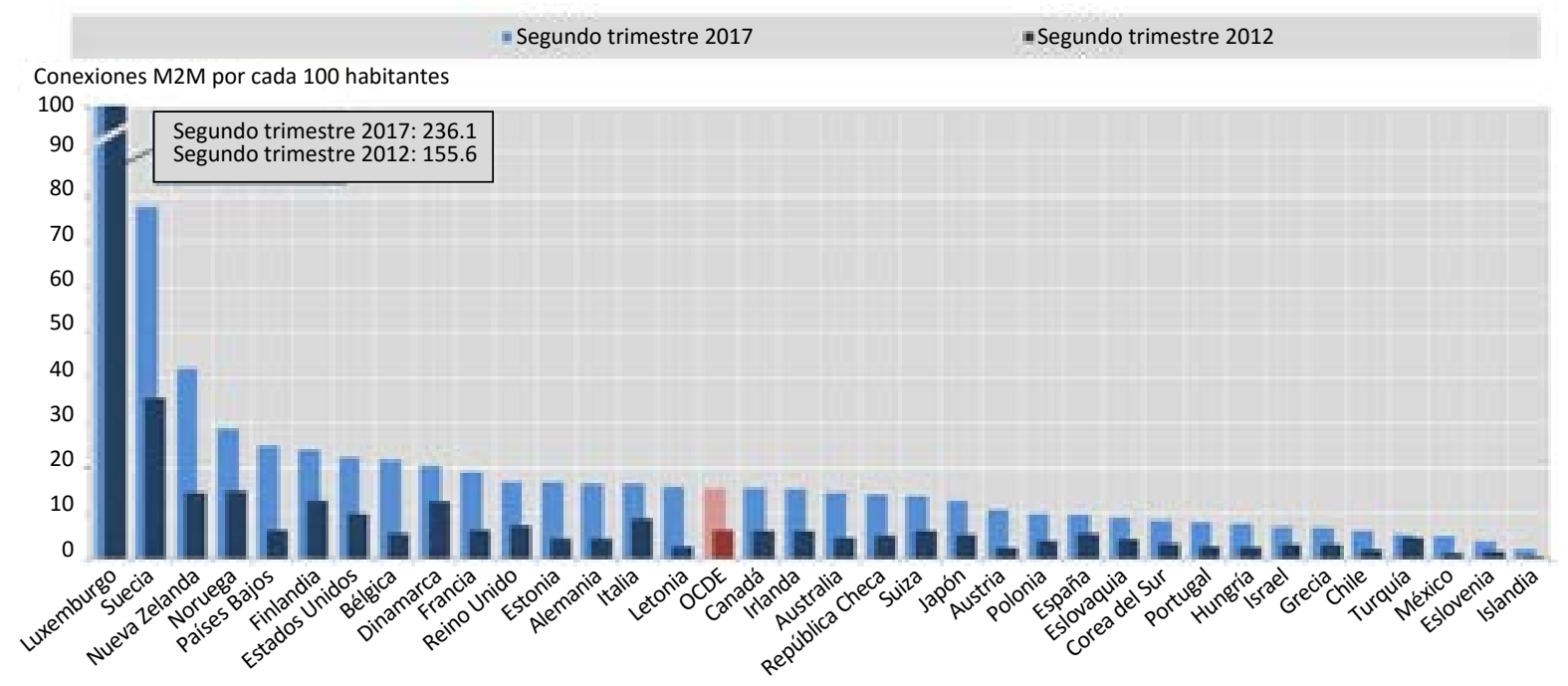

Nota: *Datos poblacionales de OECDstat y datos M2M de GSMA Intelligence. **Luxemburgo no aparece en la gráfica. Según el regulador de comunicaciones, el Institut Luxembourgeois de Régulation, a finales de 2016 había 89400 tarjetas SIM M2M, mientras que la GSMA informa de 1377000 tarjetas SIM M2M en el segundo trimestre de 2017.

Fuente: Elaboración propia a partir de datos de la base de datos de GSMA Intelligence. 


\subsection{El sector privado}

McKinsey (2015) define el IoT como "sensores y actuadores conectados mediante redes a sistemas informáticos. Estos sistemas pueden supervisar o gestionar el estado y las acciones de los objetos y máquinas conectados. Los sensores conectados también pueden monitorear el mundo natural, las personas y los animales". Su definición excluye los "sistemas en los que el propósito principal de todos los sensores consiste en recibir información humana intencionada, como las aplicaciones de los teléfonos inteligentes, en las que la información se introduce principalmente a través de una pantalla táctil, u otro software informático en red en el que los sensores están formados por el teclado y el ratón estándar" (McKinsey Global Institute, $\left.2015_{[13]}\right)$. El McKinsey Global Institute utilizó esta definición en un informe en el que se intentaba hacer una estimación de los posibles efectos económicos totales del IoT en nueve entornos diferentes (p. ej., vehículos, hogares, ciudades, fábricas, logística, salud, etc.). Según este informe, los efectos potenciales oscilaron entre los 3 billones de dólares estadounidenses y los 11.1 billones por año en 2025 (McKinsey Global Institute, $2015_{[13]}$ ). ${ }^{9}$

Ericsson midió 16000 millones de dispositivos conectados en 2016, de los cuales 5600 millones correspondían a la categoría de IoT. Estiman que para 2022 habrá 29000 millones de dispositivos conectados, de los cuales 18000 millones estarán relacionados con el IoT (Barboutov et al., 2017 ${ }_{[14]}$ ). Una característica relevante de la definición de IoT de Ericsson es que se excluyen las computadoras personales, las laptops, las tabletas, los teléfonos móviles y los teléfonos fijos. Como se ha indicado anteriormente con la definición de M2M según la GSMA, esto significa que ciertas aplicaciones que se consideran de IoT/M2M no se cuentan en los datos de Ericsson. Además, Ericsson divide el IoT en dos subcategorías: IoT de área amplia e IoT de corto alcance. El segmento de corto alcance se refiere principalmente a los dispositivos conectados mediante espectro sin licencia (p. ej., dispositivos que utilizan Wi-Fi, Bluetooth y Zigbee con un alcance común de hasta 100 metros). Esta categoría también incluye dispositivos conectados a través de redes de área local (o LAN) de línea fija y tecnologías de línea eléctrica. ${ }^{10} \mathrm{El}$ segmento de área amplia consiste en dispositivos que utilizan conexiones celulares (p. ej., tecnologías NB-IoT y Cat M1), así como tecnologías de baja potencia sin licencia como Sigfox, LoRa y RPMA. ${ }^{11}$

Conforme a la definición de Ericsson, la tecnología más común actualmente en el segmento de IoT de área amplia es GSM/GPRS, y según ellos, la tasa de crecimiento anual compuesta (TCAC) entre 2016 y 2022 para el IoT de área amplia y el IoT de corto alcance se espera que sea del 30\% y el 20\%, respectivamente (Barboutov et al., 2017 ${ }_{[14]}$ ). Cabe destacar que el Informe de Movilidad 2017 de Ericsson ha cambiado la definición de estos dos segmentos con respecto a su informe de 2016, que solo se refería al IoT celular y no celular. ${ }^{12}$

Adicionalmente, dadas las necesidades de datos de las distintas aplicaciones del IoT, Ericsson señala que dentro del segmento de IoT de área amplia han surgido dos subsegmentos distintos: las aplicaciones masivas y las críticas. Por una parte, las conexiones masivas de IoT requieren grandes volúmenes de conexión (pero poco tráfico de datos), suelen ser de bajo coste y requieren un bajo consumo de energía (p. ej., edificios inteligentes, servicios logísticos de transporte, gestión de flotillas, medidores inteligentes y sensores agrícolas). Por otra parte, las conexiones críticas de IoT requieren fiabilidad y disponibilidad máximas de la red, una conectividad de baja latencia y un elevado caudal de datos (p. ej., seguridad de tráfico, automóviles autónomos, aplicaciones industriales, de manufactura y servicios de salud a distancia, incluidas las cirugías a distancia).

El Informe de Movilidad de Ericsson señala además que a principios de 2017 se lanzó la primera red celular de IoT que soporta aplicaciones masivas de IoT desplegadas en redes LTE (basadas en tecnologías LTE-Cat-M1 o LTE-M y Narrow Band-IoT) (Barboutov et al., $\left.2017_{[14]}\right)$. 
CISCO publica regularmente el Pronóstico de Datos Móviles Globales del Virtual Network Index (VNI), que proyecta el tráfico móvil por tipos de datos. CISCO trata la definición de M2M y IoT como sinónimos. Definen M2M como tecnologías que "permiten que los sistemas se comuniquen con otros dispositivos de la misma capacidad, como la medición de servicios públicos, la seguridad y la vigilancia, la gestión de flotas, el GPS y la navegación, el seguimiento de activos y los dispositivos de registros de salud" (CISCO, 2017 ${ }_{[15]}$ ).

En la última publicación del VNI de CISCO se realizó un cambio metodológico. En la actualización de febrero de 2016, dentro de la categoría M2M, actualizaron la proyección para incluir conexiones de red de área amplia (LPWAN) de baja potencia "que es una alternativa emergente de conectividad M2M de banda ultra estrecha para una variedad de aplicaciones de IoT". La definición M2M según CISCO incluye los dispositivos portátiles, que son "dispositivos capaces de conectarse y comunicarse con la red, ya sea directamente a través de la conectividad celular integrada o a través de otro dispositivo (principalmente un smartphone) a través de Wi-Fi, Bluetooth, etc." (CISCO, 2017).

Conforme a la definición de IoT de CISCO, en 2016 había 780 millones de conexiones M2M en todo el mundo, de las cuales 325 millones eran dispositivos portátiles (p. ej., relojes inteligentes, gafas inteligentes, rastreadores de salud y fitness, dispositivos de navegación portátiles, ropa inteligente, etc.). De estos dispositivos portátiles, 11 millones ya tenían conexiones celulares integradas (eSIM) en 2016. Su proyección es que para 2021 habrá 3300 millones de dispositivos M2M conectados; es decir, un crecimiento cuatro veces mayor en cinco años. Además, es probable que aumente la proporción de conexiones M2M como parte del total de conexiones móviles.

Según los datos del VNI de CISCO, en 2016 los dispositivos M2M representaban el 9.7\% de los dispositivos móviles conectados a nivel mundial (un total de 8000 millones de dispositivos móviles, incluidos los módulos M2M en 2016), y esta proporción crecerá hasta el 28.4\% en 2021 (de los 11600 millones de conexiones móviles previstas para 2021). Un factor que influye en la creciente adopción del IoT es la aparición de dispositivos portátiles (CISCO, 2017 ${ }_{[15]}$ ).

Algunos operadores de telefonía móvil ahora reportan a sus accionistas la cantidad de dispositivos de IoT conectados a sus redes en sus estados financieros anuales. En Estados Unidos, AT\&T fue una de las primeras compañías en reportar el número de dispositivos conectados, y para 2017 tenía 39 millones (AT\&T, 2017 [16]). Más recientemente, otros grandes actores se han unido a la hora de informar sobre estos datos, como los operadores de China. En 2017, China Telecom y China Mobile reportaron 44.3 y 229 [sic] dispositivos de IoT, respectivamente (China Telecom, 2017 $[17]$; China Mobile, $2017_{[18]}$ ).

\subsection{Autoridades en materia de telecomunicaciones en países miembros de la OCDE}

\subsubsection{ANACOM, el regulador de servicios de comunicación de Portugal}

La Autoridad Nacional de Comunicaciones de Portugal (ANACOM) ha estado recopilando datos M2M desde 2012 (p. ej., número de dispositivos M2M con tarjetas SIM, tráfico e ingresos), de la misma manera que muchos otros reguladores en el área de la OCDE. En 2016, por primera vez, ANACOM trató de recopilar datos sobre las tecnologías de comunicaciones de área amplia de baja potencia (LPWA) (p. ej., ingresos, número de dispositivos, clientes y tráfico). La tasa de respuesta de esta encuesta fue bastante baja; sin embargo, con base en el número muy limitado de respuestas, encontraron que: 1) hay un pequeño número de clientes corporativos, 2) un gran número de dispositivos, y 3 ) niveles muy bajos de tráfico en las redes LPWA. 
En lo que respecta a la cuestión de la definición y medición del IoT, el punto de vista de ANACOM es que es preferible una metodología armonizada. En cuanto a los indicadores, además del uso (ingresos, datos, dispositivos, clientes), ANACOM considera que también debería estudiarse la cobertura del IoT. A este respecto, la ANACOM observa que el ORECE está elaborando un informe sobre las obligaciones de cobertura de las 5G ("Informe de mejores prácticas sobre las obligaciones de cobertura con vistas al estándar 5G").

En su opinión, el enfoque de la GSMA es un ejemplo de cómo se pueden recabar datos sobre M2M de forma armonizada a través de varias geografías utilizando datos del lado de la oferta. Podría tener sentido dividir estos indicadores por tecnología/norma con el fin de obtener algunas ideas sobre los tipos de aplicaciones que se ofrecen (es decir, conexiones de IoT críticas o no críticas).

Sin embargo, los datos de los operadores móviles solo cubrirán las aplicaciones del segmento de área amplia del IoT basadas en el espectro licenciado. En cuanto a las aplicaciones basadas en espectro sin licencia, la sugerencia de ANACOM consiste en ponerse en contacto directamente con los proveedores de LPWA (p. ej., Sigfox, LoRa), que son en su mayoría empresas trasnacionales, a fin de recopilar información sobre la comunicación de LPWA.

En cuanto al segmento del IoT de corto alcance, las aplicaciones industriales y las aplicaciones domésticas implicarán probablemente diferentes indicadores y fuentes de datos. Según la experiencia previa de ANACOM, las posibles fuentes de datos para servicios y dispositivos residenciales no están conectadas directamente a la red de un operador de telecomunicaciones. Estas fuentes incluyen:

- Cifras de los puntos de venta y de los vendedores de dispositivos: Desde hace varios años, la ANACOM recoge datos de estas fuentes sobre dispositivos de televisión digital (a través de un tercero) con buenas tasas de respuesta y que cubren la mayor parte del mercado portugués.

- Encuestas de hogares: La ANACOM ha estado estudiando el uso de los servicios de OTT durante varios años basándose en encuestas de hogares.

Además, la ANACOM, el regulador portugués en materia de comunicaciones, destaca la necesidad de perfeccionar los indicadores de M2M. Señalan que muchas aplicaciones de IoT se basarán en redes celulares, por lo que es posible basarse en fuentes de datos tradicionales (es decir, los operadores móviles) para recopilar datos sobre el número de conexiones, el tráfico e incluso los ingresos asociados a M2M. Para la ANACOM, tendría sentido refinar aún más los indicadores $\mathrm{M} 2 \mathrm{M}$ de las siguientes maneras:

- Recolección de datos por red/tecnología (p. ej., 2G, 3G, 4G y 5G).

- Recogida de datos por subcategorías de diferentes redes/tecnologías asociadas con diferentes aplicaciones M2M e IoT (p. ej., área amplia/corto alcance, críticas/no críticas);

- Recopilación de estadísticas M2M para aplicaciones específicas (p. ej., vehículos autónomos).

Asimismo, en su opinión, es posible seguir un enfoque idéntico para los servicios de la LPWA. Una cuestión conexa se refiere a la medición de la penetración móvil. La ANACOM afirma que los dispositivos conectados a M2M deben ser excluidos, entre otras cosas porque, de lo contrario, hacen que las medidas de penetración sean menos útiles.

Por último, la ANACOM expresa que tendría sentido medir la adopción de tecnologías y aplicaciones relacionadas con el IoT entre las empresas, especialmente en el caso de las aplicaciones de corto alcance y las redes privadas para las que no se disponga de fuentes de 
datos alternativas. Un ejemplo de ello es la encuesta de Eurostat sobre el uso de las TIC en las empresas, que incluía un módulo sobre el uso de los servicios en la nube.

\subsubsection{ARCEP, el regulador de servicios de comunicación de Francia}

Según el ARCEP, es necesario considerar varios componentes en el ecosistema del IoT. Estos incluyen los objetos físicos mismos, los agentes económicos, la conectividad (es decir, la "columna vertebral" del IoT) y los flujos de datos entre los objetos conectados (Figura 6).

\section{Figura 6. Componentes de ARCEP que deben considerarse en el ecosistema de IoT}

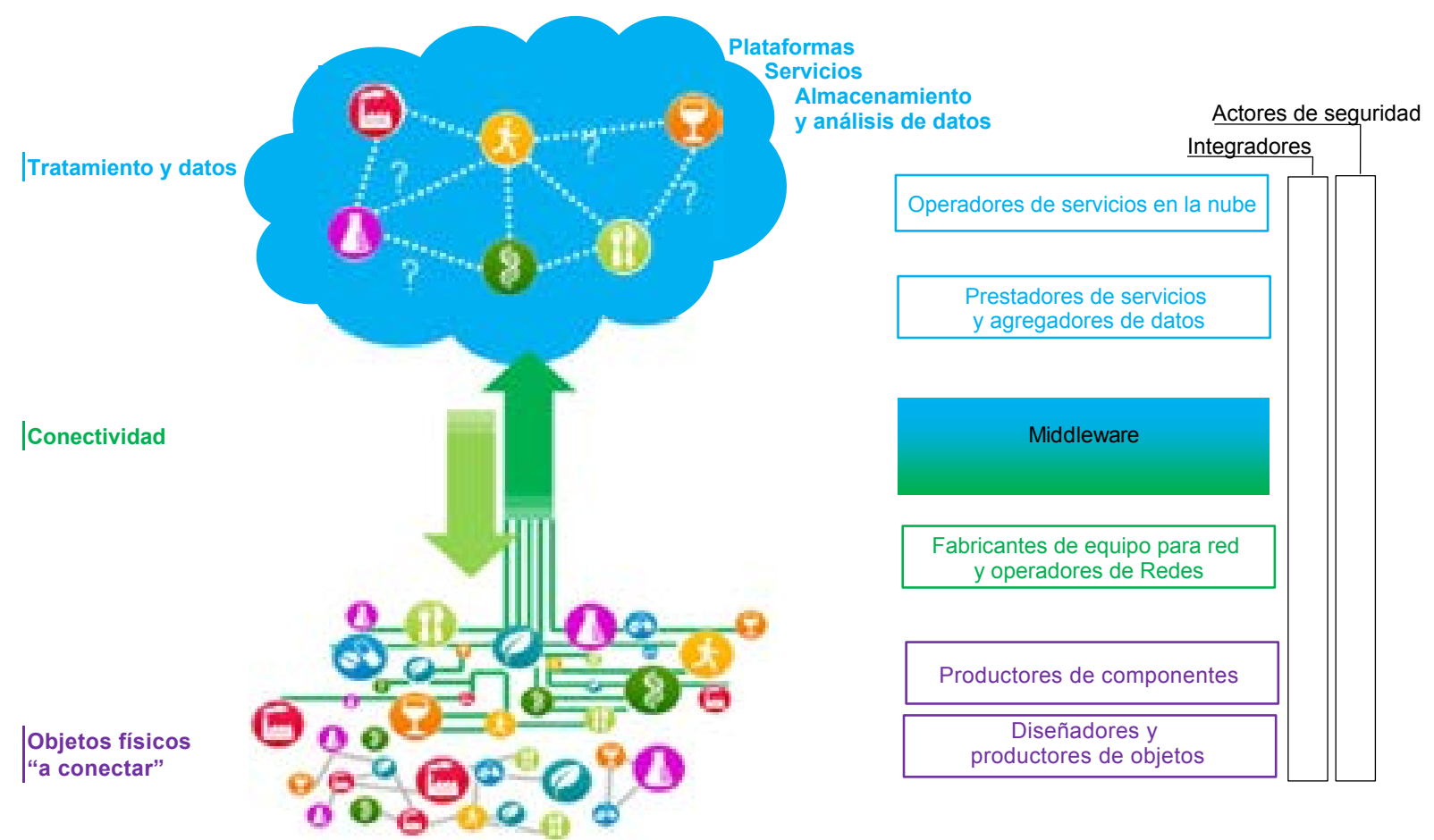

Fuente: «Le Livre Blanc: Préparer la révolution de l'Internet des objets», (ARCEP, 2016 $[19]$ ).

Como tal, el ARCEP considera el IoT como un ecosistema, y desde 2016 ha publicado varios informes sobre el IoT (ARCEP, 2016 $[19])$. En su opinión, los objetos físicos que se conectarán a Internet pueden diseñarse para una gran variedad de aplicaciones, que van desde "dispositivos inteligentes" (es decir, equipos domésticos) hasta componentes elementales sencillos. Los agentes económicos que producen estos objetos van desde los diseñadores y productores de objetos hasta los fabricantes de equipos de red. La capa de red es crucial, aseguran, ya que garantiza la calidad de la conexión necesaria para transmitir los datos entre los objetos. A este respecto, ARCEP observa que, además de las redes de comunicación tradicionales existentes, están surgiendo nuevas redes dedicadas (p. ej., proveedores de redes de área amplia de baja potencia [LPWAN] como Sigfox, LoRa, etc.).

Desde la perspectiva de los agentes y sectores del mercado del IoT, el ARCEP ha señalado varios mercados en los que las aplicaciones concretas del IoT se encuentran en expansión actualmente. Por ejemplo, algunas aplicaciones incluyen: i) "territorios inteligentes", que se 
relacionan (dentro de los proyectos de desarrollo de las comunidades) con las infraestructuras de comunicación (transporte, energía, agua) y la optimización de su gestión; ii) edificios conectados (hogar y trabajo); iii) industria $4.0 ; i v$ ) vehículos autónomos y conectados; v) salud digital; y vi) empresas agrícolas (ARCEP, 2016 ${ }_{[19]}$ ).

\subsubsection{BNetzA, el regulador de los servicios de comunicación en Alemania}

BNetzA definió M2M por primera vez en el plan de numeración relativo a las IMSI (BNetzA, 2016 ${ }_{[20]}$ ). Definió M2M como "el intercambio predominantemente automatizado de información entre dispositivos técnicos tales como máquinas, máquinas expendedoras, vehículos o equipos de medición (por ejemplo, medidores de electricidad, gas y agua) o entre los dispositivos y una unidad central de tratamiento de datos. Las comunicaciones pueden ser alámbricas o inalámbricas. Por lo general, un humano no participa en las comunicaciones, aunque la limitada participación humana no excluye su clasificación como comunicaciones M2M. Si la participación humana limitada forma parte de un servicio, esto no excluye su clasificación como comunicaciones M2M a efectos del plan de numeración, al menos en los siguientes casos:

- activación/operación/control/monitoreo de una aplicación M2Mo de un dispositivo M2M utilizando equipos técnicos como una computadora, un teléfono inteligente, una tableta, etc., por parte de una persona en un entorno privado (p. ej., una casa inteligente) o industrial;

- activación de una aplicación que permite la comunicación individual en el sentido de una comunicación punto a punto preseleccionada, pero no una llamada a un número de libre elección. Ejemplos de ello son las llamadas electrónicas (eCalls) en vehiculos, las llamadas de emergencia privadas en ascensores y/o vehiculos y los servicios de conserjería en vehículos.

Esta lista no es exhaustiva y debe entenderse sin perjuicio de una evaluación de los nuevos modelos de negocio" (BNetzA, 2016 $[20]$ ). Una definición similar se utiliza en el Plan de Numeración para Números Móviles (BNetzA, 2017 [21]). Según el BnetzA, en Alemania la cantidad de tarjetas SIM M2M ha aumentado de 1.6 millones en 2010 (BNetzA, 2011 [22] a 7.7 millones a finales de 2016 (BnetzA, 2017 [23]).

\subsubsection{MIC, el Ministerio del Interior y Comunicaciones de Japón}

El MIC sigue un marco cuando realiza su análisis del desarrollo del IoT, el cual está conformado por varios niveles (Figura 7). 
Figura 7. Marco de clasificación del mercado de IoT y distribución de datos en Japón

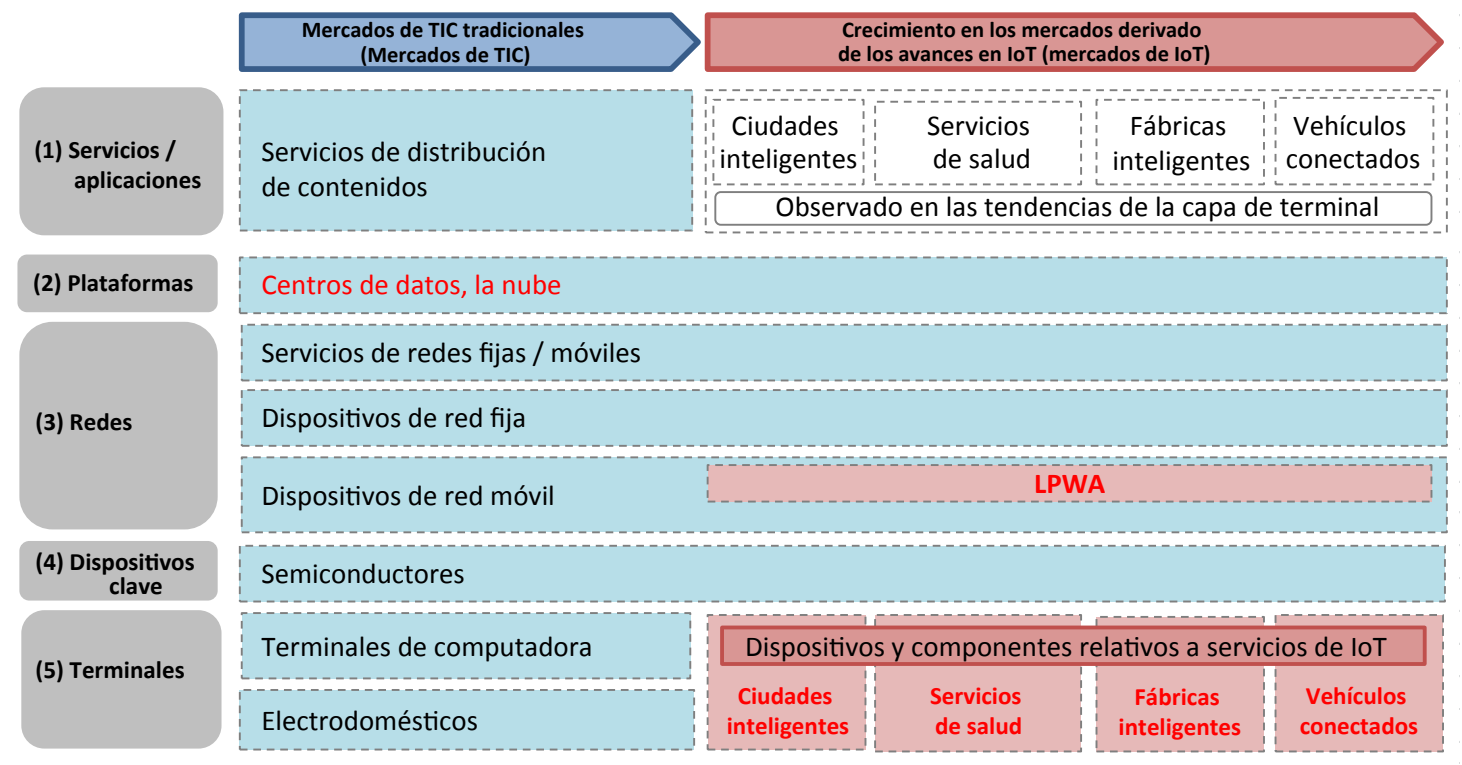

Fuente: “2017 White Paper, Information and Communication in Japan” (MIC, 2017 [24] $)$.

Japón clasifica los dispositivos IoT conforme al sistema de comunicaciones inalámbricas que lo soporta, dentro de una doble dimensión de distancia y consumo de energía. ${ }^{13}$ En un enfoque similar, un informe de McKinsey de 2017 presentó una conexión matricial multidimensional entre las soluciones de conectividad del IoT(desglosada por segmentos tecnológicos detallados y posibles dispositivos relacionados con el IoT), la distancia, el consumo de energía, el ancho de banda y trece amplios sectores económicos (McKinsey, 2017 ${ }_{[25]}$ ).

El marco desarrollado en Japón también incluye una clasificación del mercado caracterizada por un crecimiento previsto del IoT. Se han identificado cuatro mercados principales para el futuro desarrollo del IoT: ciudades inteligentes, servicios de salud, fábricas inteligentes y automóviles conectados. Los segmentos de mercado seleccionados destacados por Japón coinciden significativamente con los señalados en el marco del IoT desarrollado por el $\operatorname{ARCEP}($ ARCEP, 2016 $[19]$ ).

\subsubsection{OFCOM, el regulador de los servicios de comunicaciones en el Reino Unido}

En el Informe sobre el Mercado de las Comunicaciones de 2017 de Ofcom se define una conexión M2M como "una conexión entre dispositivos, frecuentemente inalámbrica, en la que no se requiere necesariamente la intervención humana". Ejemplos de uso común de M2M son la medición inteligente (donde el medidor reporta el uso de energía a una base de datos de facturación central) y las alarmas antirrobo, que pueden contener una tarjeta SIM para permitir la comunicación con las centrales de monitoreo. Las máquinas expendedoras son otro ejemplo común, ya que algunos usan M2M para mantener una computadora central actualizada con los niveles de inventario". (Ofcom, 2017 $[26]$ ) Es notable que los abonos móviles activos medidos por Ofcom incluyan conexiones M2M. Sin embargo, aunque su definición abarca un alcance más amplio del IoT, Ofcom únicamente mide los abonos celulares M2M, es decir, un subconjunto de IoT y M2M, y no hace un seguimiento de las conexiones NB-IoT o LTE-M. 
De acuerdo con esta medida de Ofcom, en el Reino Unido, los abonados de M2M han aumentado de 4.1 millones en 2011 a 7.6 millones en 2016 (Tabla 1).

Tabla 1. Mercado de telecomunicaciones en el Reino Unido: estadísticas clave (indicadores seleccionados)*

\begin{tabular}{|c|c|c|c|c|c|c|}
\hline Año & 2011 & 2012 & 2013 & 2014 & 2015 & 2016 \\
\hline Promedio mensual de datos móviles por conexión activa $(\mathrm{GB})^{\star *}$ & 0.1 & 0.2 & 0.4 & 0.5 & 0.9 & 1.3 \\
\hline Abonos móviles activos (millones) ${ }^{* * *}$ & 86.5 & 88.4 & 88.8 & 90.3 & 91.9 & 92 \\
\hline Abonos 4G (millones) & & & 2.7 & 23.6 & 39.4 & 52.4 \\
\hline Abonos M2M (millones) & 4.1 & 5 & 5.7 & 6.3 & 6.7 & 7.6 \\
\hline
\end{tabular}

Nota: * Indicadores seleccionados tomados de la Figura 4.1 del Informe del Mercado de Telecomunicaciones de 2017 (Ofom, 2017 $[26]$ ); ** Promedio mensual de datos móviles por conexión activa en 2011 a marzo y de 2012-2016 a junio de cada año; *** abonos móviles activos incluyendo abonos máquina a máquina.

Fuente: Ofcom / operadores / Informes de Naciones Conectadas de Ofcom 2011-2016 (Ofcom, 2017 [26] ${ }_{\text {[ }}$.

\subsubsection{PTS, el regulador de los servicios de comunicación de Suecia}

Suecia cuenta con algunos de los sistemas de recopilación de datos M2M más avanzados que reúnen información sobre la cantidad de ingresos que generan al año los abonos M2M. Además, desde 2010, PTS ha recopilado datos sobre la magnitud del tráfico M2M. Aunque sigue siendo relativamente pequeño cuando se mide por abonos M2M, en comparación con los teléfonos inteligentes, dicho tráfico creció de menos de $1 \mathrm{MB}$ por abono M2M en 2010 a 23 MB en 2016 (Figura 8). Notable, sin embargo, fue el fuerte aumento en 2016. Hay dos posibles explicaciones para esta tendencia. La primera se refiere a un error de medición, ya que PTS informa de que los datos facilitados por Telia hasta 2015 eran incorrectos, lo que significa que los volúmenes de datos hasta 2015 podrían ser superiores a los indicados en la Figura 8. La segunda razón del aumento podría ser la evolución en el mercado de M2M con alguna aplicación de la tecnología que se utiliza en áreas que generan mayores cantidades de tráfico, como los automóviles conectados.

Figura 8. Tráfico mensual de datos M2M por abono (MB) en Suecia

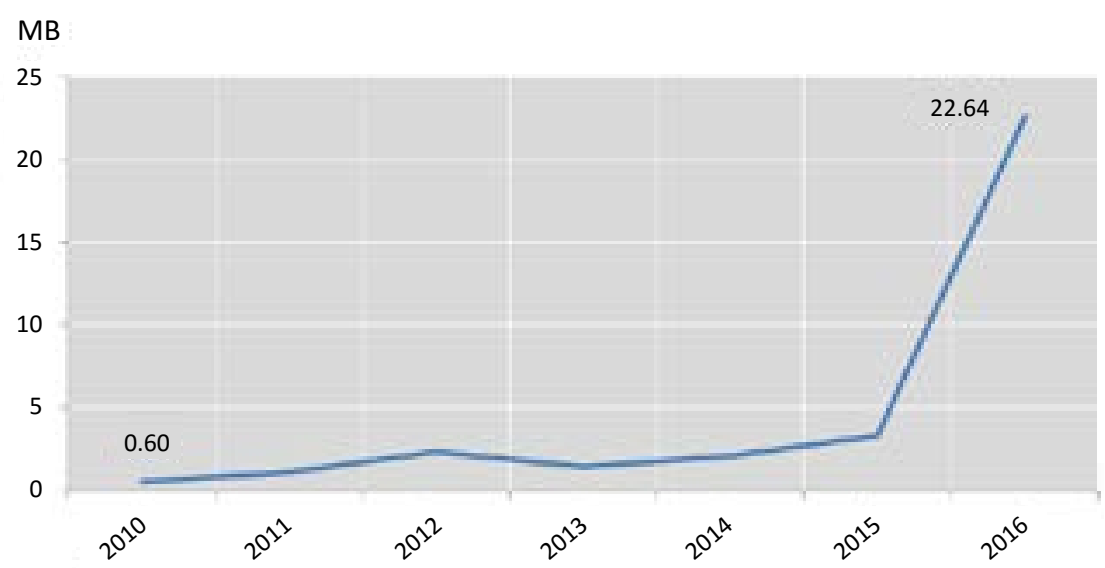

Nota: PTS define las conexiones máquina a máquina como la comunicación entre máquinas utilizadas para telemática y telemetría. PTS define los abonos como abonos de contrato más las tarjetas de prepago. Las tarjetas de prepago se reportan de acuerdo con la regla de los 3 meses. El aumento del tráfico de los servicios de datos entre 2015 y 2016 depende de los informes de Telia. Telia reportó aproximadamente 2000 Tbytes para 2016 y 76 Tbytes para 2015. Telia dice que los datos de 2015 son muy bajos, pero no se dispone de un valor real. Fuente: La Autoridad Sueca de Correos y Telecomunicaciones, 22 de mayo de 2017. 
Figura 9. Ingresos mensuales por abonos M2M (USD) en Suecia y Noruega

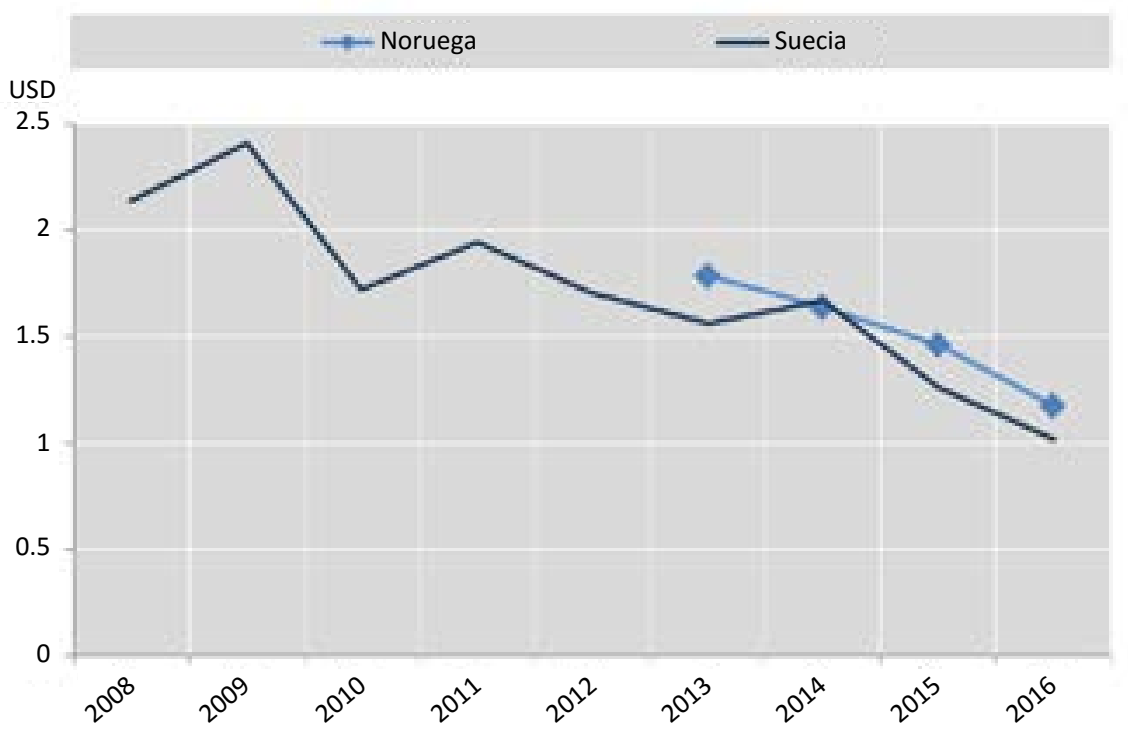

Nota: Por "máquina a máquina" se entiende la comunicación entre máquinas utilizadas para telemática y telemetría. En el caso de Suecia, "Abonos" equivale a abonos por contrato + tarjetas de prepago. Las tarjetas de prepago se reportan conforme a la regla de los 3 meses. Los datos de abonos M2M de ambos países proceden de "Telecommunication Markets in the Nordic and Baltic Countries", junio de 2017, Tabla 1,

http://statistik.pts.se/en/nordic-baltic-telecommarket/tables/mobile-call-and-data-services/table-1-subscriptions/. Fuente: Cálculo propio utilizando datos de la Autoridad Sueca de Correos y Telecomunicaciones, 22 de mayo de 2017, y de la Autoridad Nacional de Comunicaciones de Noruega,

https://ekomstatistikken.nkom.no/\#/statistics/details?servicearea=Mobiltjenester\&label=Maskin-tilmaskin\%20 - $\% 20$ omsetning.

PTS también recopila datos sobre el monto de los ingresos generados por los abonos M2M. Por abono, estos han disminuido desde 2008, pasando de un poco más de 2 USD al mes en 2008-2009 a aproximadamente 1 USD en 2016 (Figura 9). Otra autoridad nórdica de comunicaciones que recoge datos sobre los ingresos de M2M se encuentra en Noruega, donde la experiencia ha sido similar a la de Suecia, ya que los ingresos mensuales por abonos de M2M han disminuido en los últimos tres años. Esto puede deberse al gran aumento de los dispositivos M2M y a los planes tarifarios nuevos.

Aunque los países de la OCDE han podido presenciar un alto crecimiento de los dispositivos M2M conectados, en términos de ingresos, M2M sigue siendo un mercado incipiente. Por ejemplo, según PTS, M2M solo generó 106.05 millones de dólares en ingresos en 2016, lo que representa el $1.7 \%$ del total del mercado sueco de telecomunicaciones. No obstante, el M2M como subconjunto del IoT tiene el potencial de crecer en un futuro próximo con la aparición de nuevos casos de negocio. Aunque en la actualidad M2M no es grande en términos de ingresos, con el crecimiento del IoT y la evolución de los modelos de negocio, se espera que se convierta en la mayoría de las conexiones con implicaciones para la infraestructura con la llegada de los vehículos autónomos y la 5G.

\subsection{Otras Agencias Gubernamentales que miden el IoT}

\subsubsection{Definiciones de las Oficinas de Propiedad Intelectual}

El Cuadro de Indicadores para 2015 de la OCDE publicó información sobre patentes de IoT con base en el trabajo realizado por expertos de la Oficina de Propiedad Intelectual 
del Reino Unido (IPO, por sus siglas en inglés) (Figura 10). En su informe “Ocho Grandes Tecnologías: Un resumen de la serie de informes sobre el panorama de las patentes" [Eight Great Technologies: A summary of the series of patent landscape reports], la IPO trazó un mapa de la actividad inventiva en relación con novedosas tecnologías de las TIC durante el período comprendido entre 2004 y 2013 mediante el análisis de los documentos de patente publicados en todo el mundo.

Figura 10. Principales participantes en IoT, big data y tecnologías de cómputo cuántico, 2005-2007 y 2010-2012

Cuota de las economías en las familias de patentes IP5 presentadas ante la USPTO y la OEP, tecnologías TIC seleccionadas.

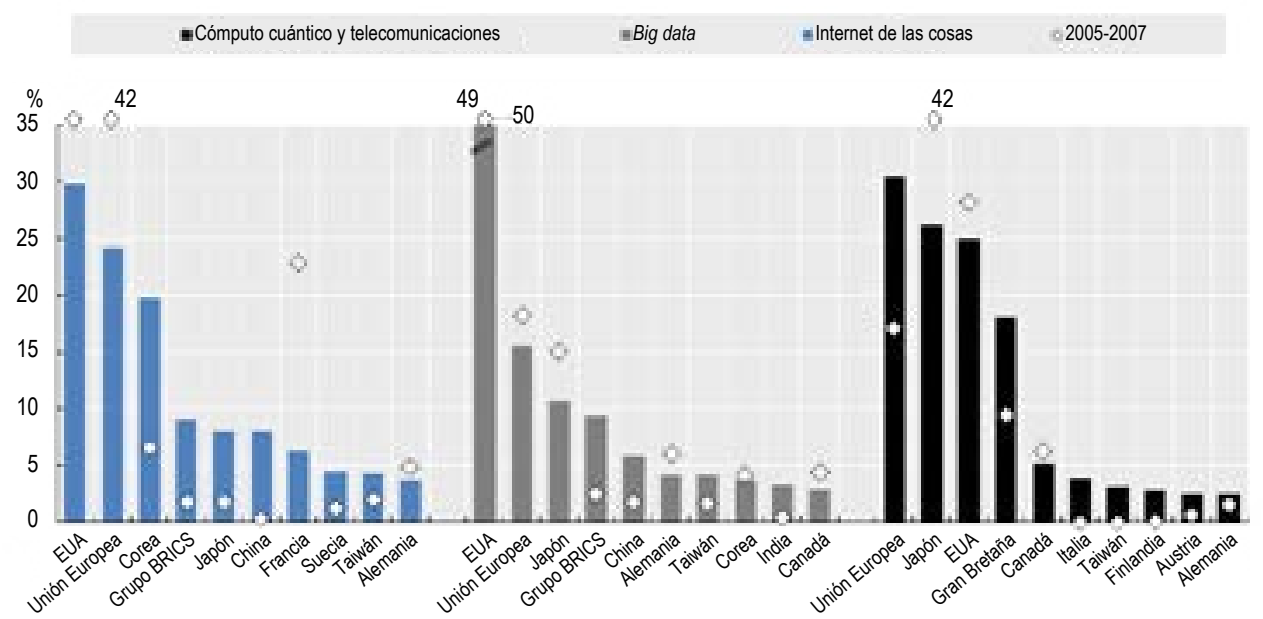

Nota: Los datos se refieren a familias de patentes IP5 con miembros registrados en la OEP o en la USPTO, por fecha de primera presentación y según la residencia del solicitante, utilizando recuentos fraccionados. La Oficina de Propiedad Intelectual (IPO) del Reino Unido ha asignado documentos de patente a campos tecnológicos. Para más detalles sobre los informes de la Oficina Internacional de Patentes sobre las ocho grandes tecnologías (octubre de 2014), consultar

www.gov.uk/government/publications/eight-great-technologies-the-patent-landscapes.

Fuente: Cálculos de la OCDE basados en el informe de IPO (2014), Eight Great Technologies: the Patent Landscapes, United Kingdom and STI Micro-data Lab: Intellectual Property Database, http://oe.cd/ipstats, junio de 2015.

La IPO identificó las tecnologías de capacitación que forman la base de la nueva generación de TIC: la informática y las telecomunicaciones cuánticas, el Internet de las cosas y el big data. La definición de Internet de las Cosas (IoT) del presente documento es: "redes de objetos fisicos cotidianos a las que se puede acceder a través de Internet y que son capaces de identificarse automáticamente con otros dispositivos. Algunos ejemplos son los dispositivos de control remoto, la optimización de las congestiones de tráfico, la sanidad electrónica (e-health) y el autodiagnóstico industrial" (IPO, 2014 ${ }_{[27]}$ ). Se encontró que los países europeos, especialmente el Reino Unido, han liderado el desarrollo del cómputo cuántico, mientras que Estados Unidos ha liderado el desarrollo tanto del IoT como de las grandes tecnologías relacionadas con el big data (OCDE, 2015 [28] $)$.

Las actividades en materia de patentes relacionadas con el Internet de las Cosas (IoT) aumentaron entre 2005 y 2012. En 2012, la tasa de crecimiento anual del IoT alcanzó el $126 \%$ (Figura 11) (OCDE, 2015 [28] $)$. 
Figura 11. Patentes de la nueva generación de tecnologías relativas a TCI, 2005-2012

Número de familias de patentes IP5 y tasas de crecimiento anual.

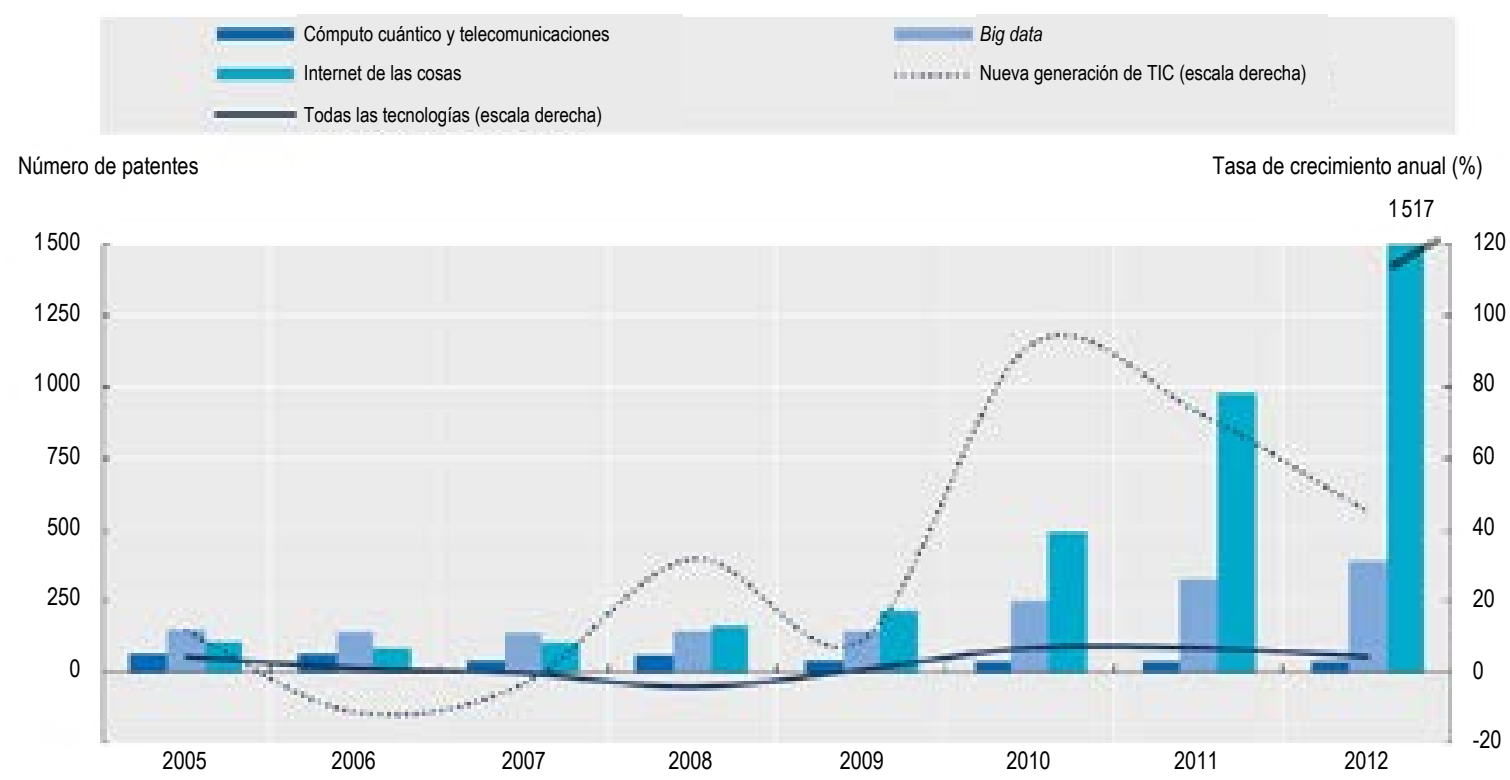

Nota: Los datos de patentes se refieren a las familias de patentes IP5 por primera fecha de presentación. La Oficina de Propiedad Intelectual (IPO) del Reino Unido ha asignado documentos de patente a campos tecnológicos. Para más detalles sobre los informes de la Oficina Internacional de Patentes sobre las ocho grandes tecnologías (octubre de 2014), consultar www.gov.uk/government/publications/eight-great-technologies-thepatent-landscapes.

Fuente: Cálculos de la OCDE basados en el informe de IPO (2014), Eight Great Technologies: the Patent Landscapes, United Kingdom and STI Micro-data Lab: Intellectual Property Database, http://oe.cd/ipstats, junio de 2015.

\section{Informe de la IPO del Reino Unido sobre el IoT}

Dentro de las tecnologías disruptivas cubiertas, la IPO publicó un informe especial sobre IoT titulado "Ocho grandes tecnologías: El Internet de las Cosas". Este informe indica que desde 2004 hasta 2013, el conjunto de datos mundiales contenía casi 22000 patentes publicadas sobre el IoT (es decir, 10000 familias de patentes). El registro de patentes de elementos relacionados con el IoT ha crecido rápidamente, con una tasa media de crecimiento anual del $40 \%$ entre 2004 y 2013 , frente a un aumento medio del $6 \%$ en todas las tecnologías. Adicionalmente, más del $75 \%$ de las familias de patentes de IoT se presentaron por primera vez en China, los Estados Unidos o Corea (IPO, 2014).

Según este informe de la IPO (2014), la empresa que había presentado más patentes de IoT en 2014 era la empresa china ZTE, en relación principalmente con comunicaciones M2M, la automatización de vehículos y reconocimiento de seguridad de IoT. LG y Samsung también poseían patentes de IoT relacionadas con la transmisión y almacenamiento de datos, pero en ese momento, estaban más interesados en los hogares inteligentes. Hasta 2013, los medios de comunicación habían informado sobre un gran interés en el IoT por parte de empresas como Apple y Google. Sin embargo, Apple ocupaba el puesto 27 en la lista de los principales solicitantes de IoT, y Google el 84. Sin embargo, ese mismo año Google adquirió Nest Labs, especializada en Hogares Inteligentes (IPO, 2014[29]). 
Es posible mostrar los subgrupos del IoT, o el desglose tecnológico de las familias de patentes del IoT que se encuentran en este informe de la IPO (Tabla 2). Los subgrupos se basan en la Clasificación Internacional de Patentes (IPC, por sus siglas en inglés). La mayor proporción de patentes de IoT presentadas durante 2005-2013 se refiere a las tecnologías M2M, y la segunda se refiere a los medidores inteligentes (IPO, 2014 ${ }_{[29]}$ ).

Tabla 2. Subgrupos de Familias de Patentes de IoT según la Clasificación Internacional de Patentes (IPC)*

\begin{tabular}{|c|c|}
\hline H04L29/08 & $\begin{array}{l}\text { Control de la comunicación; procesamiento de la comunicación } \rightarrow \text { caracterizado por un protocolo } \rightarrow \text { Procedimiento de control } \\
\text { de la transmisión, p. ej., procedimiento de control a nivel de enlace de datos }\end{array}$ \\
\hline H04L & $\begin{array}{r}\text { ledes de conmutación de datos } \rightarrow \text { caracterizadas por una configuración de ruta, p. ej. LAN (Redes de Área Local) o WAN (Redes } \\
\text { de Área Amplia) }\end{array}$ \\
\hline H04L29/06 & Control de la comunicación; procesamiento de la comunicación $\rightarrow$ caracterizado por \\
\hline G06F15/16 & $\begin{array}{r}\text { Computadoras digitales en general; Equipo de procesamiento de datos en general } \rightarrow \text { Combinaciones de dos o más computadoras } \\
\text { digitales, cada una con al menos una unidad aritmética, una unidad de programa y un registro, p. ej., para el procesamiento } \\
\text { simultáneo de varios programas }\end{array}$ \\
\hline G05B1 & $\begin{array}{r}\text { Sistemas de control de programas } \rightarrow \text { eléctricos } \rightarrow \text { Control total de fábrica, es decir, control central de una variedad de máquinas, } \\
\text { p. ej., control numérico directo o distribuido (DNC), sistemas de fabricación flexibles (FMS), sistemas de fabricación integrados } \\
\text { (IMS), fabricación integrada de computadoras (CIM) }\end{array}$ \\
\hline H04W84/18 & Topologías de red $\rightarrow$ Redes autoorganizadas. P. ej., redes ad hoc o redes de sensores \\
\hline H04W4/00 & as redes de comunicación \\
\hline G08C17/02 & Arreglos para la transmisión de señales caracterizados por el uso de un enlace eléctrico inalámbrico $\rightarrow$ con un enlace de radio \\
\hline H04W72/04 & $\begin{array}{r}\text { Gestión de recursos locales, p. ej., selección o distribución de recursos inalámbricos o programación de tráfico inalámbrico } \rightarrow \\
\text { distribución de recursos inalámbricos }\end{array}$ \\
\hline H04B7/26 & $\begin{array}{r}\text { Sistemas de transmisión por radio, es decir que utiliza campos de radiación } \rightarrow \text { para la comunicación entre dos o más puertos } \rightarrow \\
\text { al menos uno de los cuales es móvil }\end{array}$ \\
\hline
\end{tabular}

Nota: *La IPC establece un sistema jerárquico de símbolos independientes del idioma para la clasificación de las solicitudes de patente en función de los distintos ámbitos tecnológicos a los que se refieren. Sin embargo, las clasificaciones no son mutuamente excluyentes y cada familia de patentes puede tener varias clasificaciones aplicadas.

Fuente: Informe sobre el panorama de las patentes de la Oficina de Propiedad Intelectual (IPO) del Reino Unido (IPO, 2014): Eight Great Technologies: The Internet of Things (agosto de 2014), consultar https://www.gov.uk/government/publications/new-eight-great-technologies-internet-of-things.

\subsubsection{La Conferencia Europea de Administraciones Postales y de Telecomunicaciones (CEPT)}

El CCE, dentro de la CEPT, ha publicado un informe sobre "Numeración y direccionamiento en las comunicaciones máquina a máquina (M2M)" con el objetivo de ayudar a las ARN a considerar soluciones de numeración y direccionamiento para las aplicaciones M2M. La CEPT define M2M como "una tecnología de comunicación en la que los datos pueden transferirse de forma automatizada con poca o ninguna interacción humana entre dispositivos y aplicaciones" (CEPT, 2010 [30] $)$.

En 2010, la CEPT llegó a cuatro conclusiones importantes. En primer lugar, basándose en su análisis, proyectaron que la tasa de crecimiento anual esperada requerida para el número de M2M durante 2010-2020 era de aproximadamente el 20\%. También destacaron que a largo plazo, el direccionamiento IPv6 se convertirá en una alternativa clave a los recursos de numeración, al menos para una parte de las aplicaciones M2M. 
También mencionaron que un número significativo de países de la CEPT no contaban con la capacidad suficiente en su plan de numeración para acomodar el crecimiento de M2M. Por último, pidieron un enfoque armonizado sobre las posibles soluciones de numeración en Europa (CEPT, 2010 [30] $)$.

\subsection{Encuestas sobre el uso de las TIC en los países de la OCDE}

Desde el punto de vista de la demanda, las encuestas recientes o futuras sobre el uso de las TIC en empresas, hogares y particulares incluyen un número limitado de preguntas relacionadas con el IoT. Las preguntas relacionadas se encuentran en el Anexo C a detalle.

En cuanto a las encuestas para hogares y particulares, las preguntas se limitan generalmente a determinados electrodomésticos inteligentes, ${ }^{14}$ dispositivos sanitarios o portátiles, ${ }^{15} \mathrm{o}$ servicios de almacenamiento en nube (Tabla 3 ).

Tabla 3. Pregunta relativa al IoT en los cuestionarios de la encuesta de uso de las TIC: ejemplos recientes seleccionados para hogares y particulares

\begin{tabular}{|c|c|c|c|c|c|c|c|}
\hline Artículos & Australia & Canadá & Eurostat & Japón & Corea & México & Estados Unidos \\
\hline Electrodomésticos & 2014-2015 & 2018 & $\begin{array}{l}2014 \\
2016 \\
2019\end{array}$ & $\begin{array}{l}2015 \\
2016\end{array}$ & 2017 & 2016 & 2017 \\
\hline Dispositivos portátiles & $2016-2017$ & & & 2016 & $\begin{array}{l}2016 \\
2017\end{array}$ & & 2017 \\
\hline Salud & & 2018 & & & & & \\
\hline Nube & & & $2014-17$ & $\begin{array}{l}2015 \\
2016\end{array}$ & $\begin{array}{l}2015 \\
2016\end{array}$ & 2016 & 2017 \\
\hline
\end{tabular}

Nota: consultar las preguntas detalladas en la Tabla A C.1 del Anexo C.

Fuente: Elaboración propia, con información tomada de Eurostat y fuentes nacionales.

Con respecto a las encuestas de negocios, los servicios RFID y en la nube han sido objeto de seguimiento durante varios años (Tabla 4). Los dispositivos de IoT, los dispositivos inteligentes o los sensores se han introducido más recientemente en estas encuestas, aunque hasta la fecha se han empleado con relativamente poca frecuencia (por ejemplo, en el uso de grandes cantidades de datos, o sobre la percepción de las tecnologías digitales, etc.).

Tabla 4. Pregunta relativa al IoT en los cuestionarios de la encuesta de uso de TIC: ejemplos recientes seleccionados para negocios*

\begin{tabular}{rrrrrr}
\hline \multicolumn{1}{c}{ Artículos } & \multicolumn{1}{c}{ Australia } & \multicolumn{1}{l}{ Canadá } & \multicolumn{1}{l}{ Eurostat } & \multicolumn{1}{l}{ Japón } & \multicolumn{1}{l}{ Corea } \\
\hline RFID & $2015-2016$ & 2014 & 2011 & 2014 & $2014-1206$ \\
& & & 2014 & 2016 & \\
loT, dispositivos Inteligentes, sensores & $2015-2016$ & 2014 & 2016 & 2014 & $2015-2016$ \\
& & & 2018 & 2016 & \\
Servicios en la nube & $2014-2016$ & 2012 & 2014 & $2010-16$ & $2012-2016$ \\
& & & 2016 & & \\
\hline
\end{tabular}

Nota: *Todas son encuestas sobre TIC, salvo por Canadá (es decir, encuesta de tecnología avanzada). Consultar las preguntas detalladas en la Tabla A C.2 del Anexo C.

Fuente: Elaboración propia, con información tomada de Eurostat y fuentes nacionales. 
Eurostat tiene previsto introducir una pregunta en la Encuesta Comunitaria sobre el Uso de las TIC en los hogares y por parte de los particulares (Cuestionario 2019), como se indica a continuación: “¿En los últimos 3 meses utilizó Internet para interactuar con equipos domésticos o aparatos conectados a Internet, como termostatos, focos o sistemas de seguridad?" Para el Cuestionario Eurostat 2020 se prevé un conjunto de preguntas más exhaustivas sobre el Internet de las cosas. La redacción de la pregunta de Eurostat de 2019 es similar a la desarrollada por la NTIA en los Estados Unidos (NTIA, 2017 ${ }_{[31]}$ ). ${ }^{16}$

\subsubsection{Otras fuentes de encuestas: Asociación de Auditoría y Control de Sistemas de Información (ISACA)}

Se están empezando a realizar varias encuestas sobre la propiedad y el uso del IoT. ISACA, por ejemplo, encuestó a 1000 particulares en el Reino Unido en 2016 (Figura 12)

\section{Figura 12. Cantidad de dispositivos de Internet de las Cosas en el Reino Unido en 2016, por tipo}

Porcentaje de cada tipo de dispositivos de Internet de las Cosas (IoT) poseídos por particulares en el Reino Unido (UK) en 2016

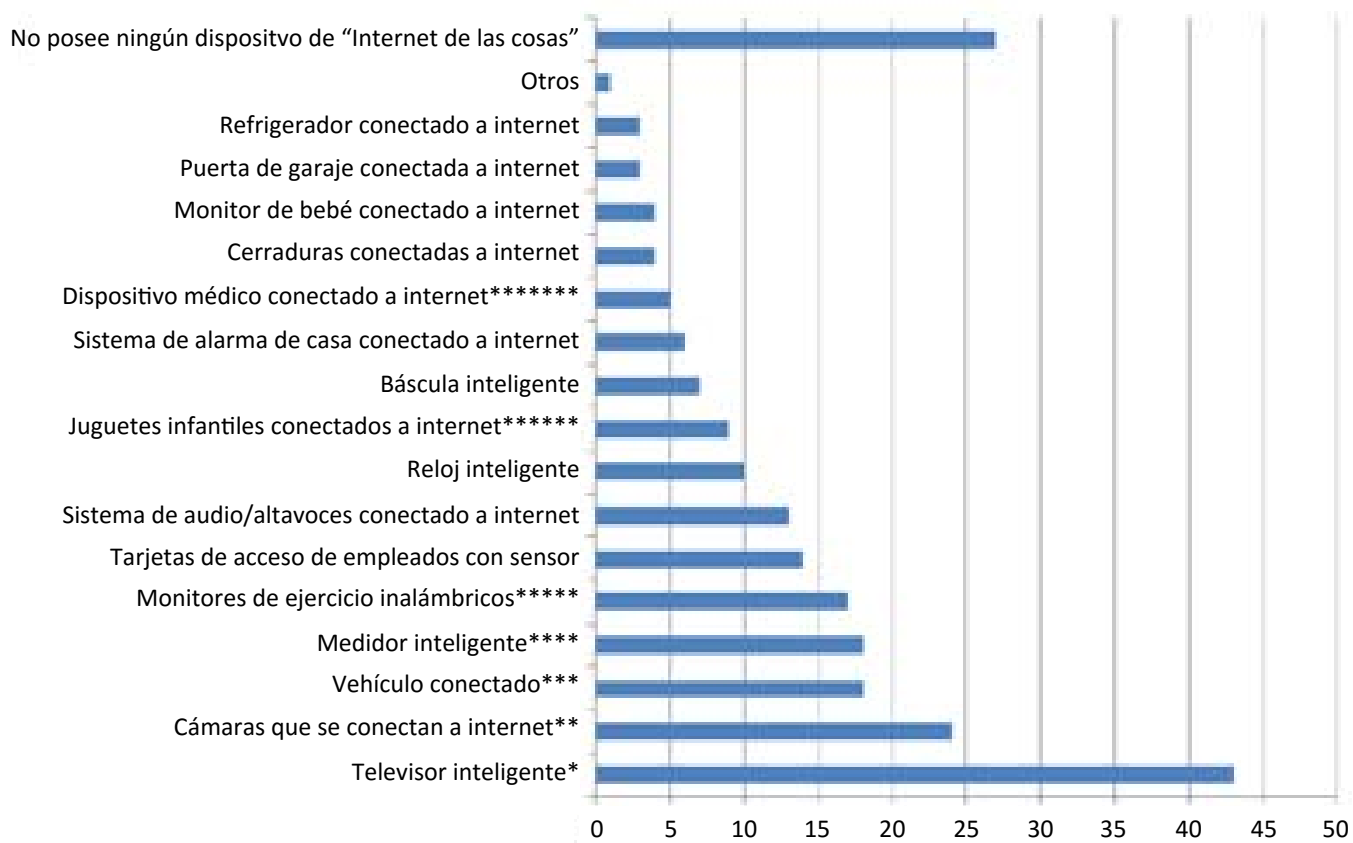

Nota: *p.ej., Apple TV, Samsung Smart TV), **p. ej., cámaras de video o digitales habilitadas para Wi-Fi que puedan subir fotos directamente a Internet o a la nube, ***p. ej., un coche con conexión a Internet, un sistema GPS o un dispositivo de cobro de peaje electrónico, ${ }^{* * *}$ p. ej., un termostato o medidor de servicios públicos conectado a Internet, *******p. ej., Fitbit, Fuel Band, ******p. ej., juguetes con conexión Wi-Fi que puedan grabar y hablar con los niños y que puedan disponer de micrófonos, cámaras, altavoces y motores, $* * * * * * * *$ p. ej., un monitor cardíaco.

Fuente: ISACA, 12 de agosto de 2016 al 23 de agosto de 2016.

Sin embargo, es necesario ser precavidos con las encuestas, dado el carácter novedoso del IoT y el hecho de que algunas aplicaciones podrían no ser reconocidas por los usuarios. 
Por ejemplo, una encuesta realizada a 3700 conductores europeos en 2015 reveló que el 39\% de los propietarios de automóviles desconocían que sus coches eran "vehículos conectados" (TNS y Bearing Point, 2016 $6_{[32]}$ ). Incluso si el 60\% restante de los propietarios de automóviles supieran que compraron un vehículo conectado, podrían no saber que su automóvil puede tener varias tarjetas SIM (es decir, una para el sistema de entretenimiento y otra para la telemetría). La pregunta natural que surge desde una perspectiva métrica es cómo contar este dispositivo. ¿Se trata de dos dispositivos conectados M2M en el caso de tener dos tarjetas SIM o un solo abono?

Otra cuestión planteada en relación con los dispositivos portátiles de consumo es cómo contar los dispositivos conectados. En otras palabras, ¿cuál es el papel de las nuevas tarjetas SIM portátiles integradas, que, según CISCO, en 2016 ya representaban 11 millones de dispositivos? Esto plantea la cuestión de si el consumidor que responde a una encuesta es consciente de que su dispositivo tiene una eSIM en lugar de una tarjeta SIM normal. Además, plantea la cuestión de la implicación de este tipo de tarjetas SIM a la hora de medir dispositivos conectados a M2M. Por ejemplo, en el caso de la serie 3 de Apple Watch, la tecnología interna eSIM está asociada a un plan de comunicaciones móviles. Por último, esto plantea la cuestión de si este dispositivo portátil se contabilizará como un dispositivo móvil o como una conexión M2M.

\subsection{Mapeo del IoT}

Otra forma de medir el IoT es a través de los llamados motores de búsqueda de IoT, como Thingful o Shodan, que exploran el mundo de los dispositivos conectados en Internet y los indizan. Es decir, estos motores de búsqueda hacen 'ping' a dispositivos conectados que están "abiertamente disponibles", y los geolocalizan. La forma en que clasifican los dispositivos como sensores ambientales u otros, depende de las definiciones que establezcan en sus códigos de programación.

\subsubsection{Thingful}

Thingful se describe a sí mismo como un motor de búsqueda para el Internet de las Cosas y proporciona mapas de los dispositivos conectados descubribles que están "abiertamente disponibles", lo que significa que tienen los certificados de propiedad de datos adecuados. En términos generales, solo indizan los recursos que:

- generan datos de series temporales que se actualizan al menos una vez al día

- tienen una sola geolocalización

- tienen una URL o identificador único donde se puede acceder a ellos.

La definición de Thingful de un "dispositivo conectado" es: "Un dispositivo genérico de IoT que genera un conjunto de medidas. Las mediciones pueden ser directamente de sensores físicos o por cálculo." Su definición de vehículo conectado es: "un vehículo equipado con acceso a Internet, y normalmente también con una red de área local inalámbrica. Esto permite que el vehículo comparta el acceso a Internet con otros dispositivos tanto dentro como fuera del vehículo".

Siguiendo su definición de dispositivos conectados, Thingful puede mostrar aquellos detectados en una región en particular o en un mapa del mundo (Figura 13). Los distintos colores que se pueden observar en la Figura 13 indican categorías de dispositivos conectados. Estas "categorías de dispositivos" incluyen: 1) energía (p. ej., termostatos, medidores eléctricos), 2) salud (p. ej., Fitbit, monitores cardíacos), 3) hogar, 4) flora, 5) medio ambiente (p. ej., sensores de calidad del aire) y 6 ) transporte (p. ej., buques, embarcaciones, camiones, 
automóviles). Aquí se puede mostrar un ejemplo de los dispositivos que se encuentran en la clasificación de Thingful para dispositivos domésticos de casi todo el mundo (Figura 14).

Figura 13. Mapa de IoT según Thingful

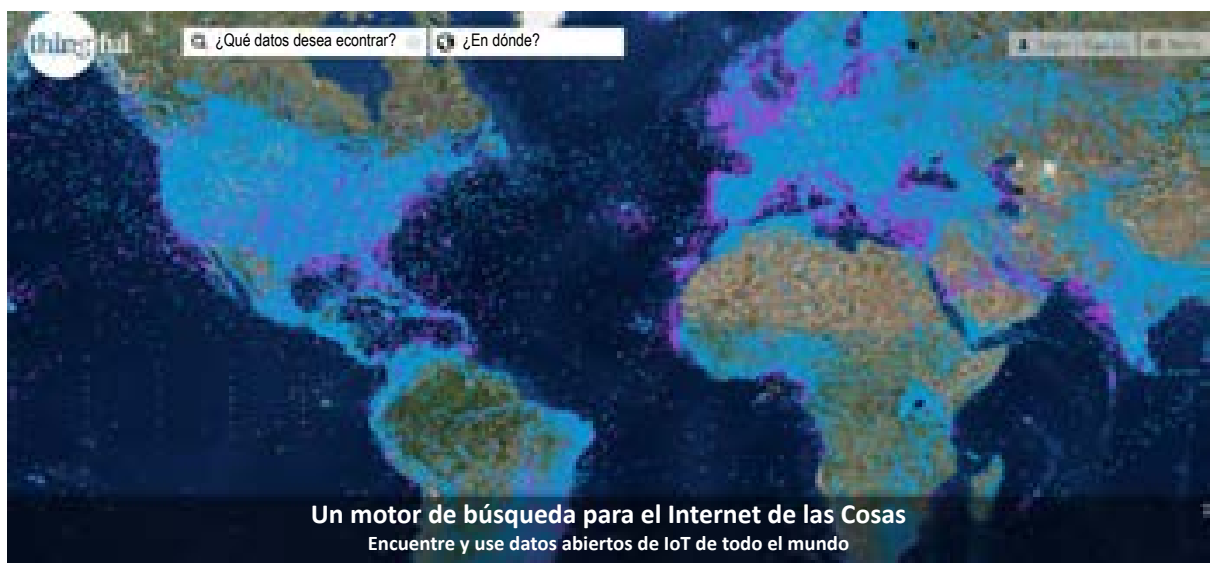

Fuente: www.thingful.net

Figura 14. Mapa de dispositivos de IoT según Thingful

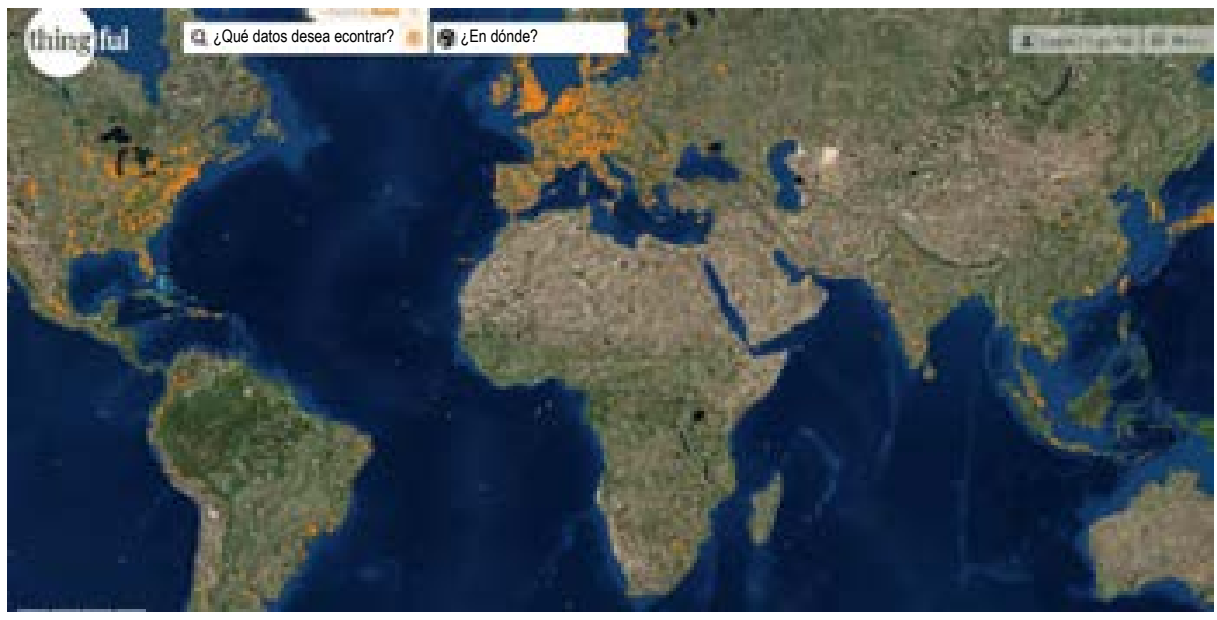

Fuente: www.thingful.net

\subsubsection{Base de Datos de IoTUK Nation}

La Base de datos de IoTUK Nation presenta un panorama de las empresas y organizaciones que componen el sector del IoT en el Reino Unido con datos abiertos para reunir y cruzar información de diversas fuentes. Para ilustrar dónde están ubicadas las organizaciones, crearon una representación hexagonal de regiones, donde cuanto más intenso es el color de un hexágono, más organizaciones hay en esa región (IoTUK Nation, 2017 [33]). En la región de Camden y Londres, por ejemplo, este enfoque encontró 50 organizaciones de IoT (Figura 15). 
Figura 15. "Mapa de calor" IoTUK Nation de empresas en el sector de IoT

Ejemplo: Área de Camden y Londres

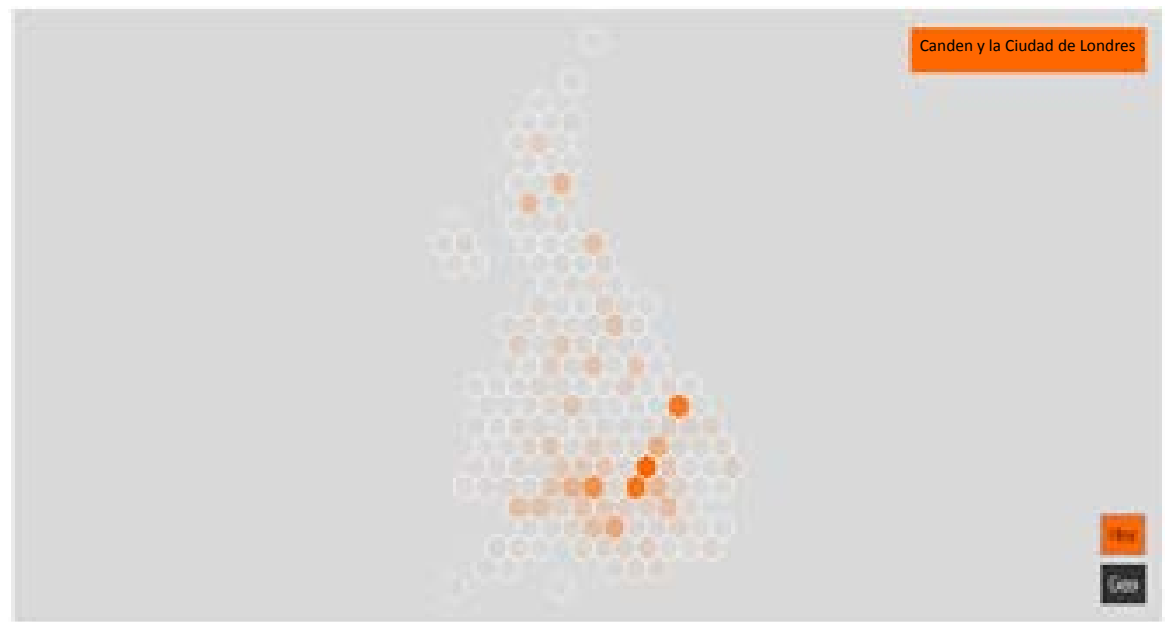

Nota: La representación hexagonal de áreas pretende dar el mismo peso visual a aquellas áreas con poblaciones similares $(150000-800000)$.

Fuente: https://odileeds.org/projects/iot

\subsubsection{Shodan, un motor de búsqueda para el IoT}

Shodan fue lanzado en 2009 como un motor de búsqueda de dispositivos conectados. Actualmente, Shodan rastrea casi cuatro mil millones de dispositivos a través de la red IPv4, así como diversos dispositivos conectados a IPv6 (Alex Wright, 2017 [34] $)$. A diferencia de los navegadores web que utilizan el protocolo de transporte de hipertexto (HTTP), Shodan examina otros puertos conectados a TCP/IP, incluidos los puertos FTP, SSH, SNMP, SIP y RTSP, en busca de servidores con capacidad de respuesta (Alex Wright, 2017 [34] $)$. Cuando recibe un mensaje de bienvenida (o un 'ping', según la expresión de Shodan), el motor de búsqueda obtiene los metadatos del dispositivo conectado que entonces pueden ser mapeados (Figura 16).

Figura 16. Mapa de IoT según Shodan

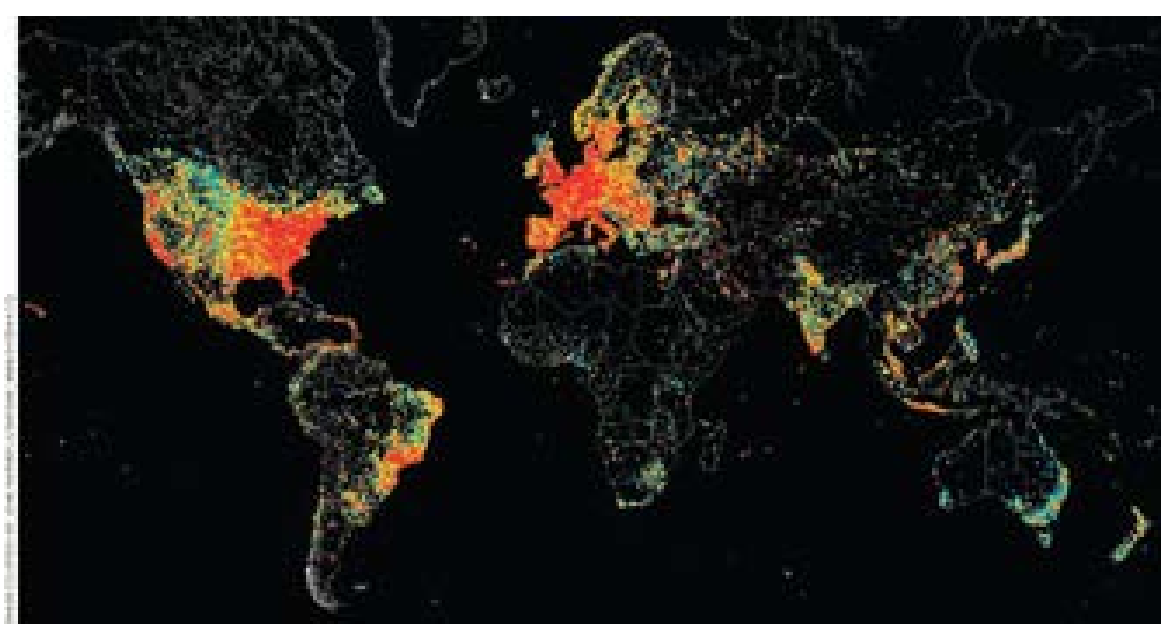

Fuente: $\underline{\text { www.shodan.io }}$ 


\subsection{IoT y robots: área de medición futura}

Existen datos sobre el grado de penetración de los robots en los países de la OCDE (Figura 17). La Federación Internacional de Robótica (IFR, por sus siglas en inglés) recopila estos datos y el conjunto de datos se construye mediante la consolidación de la información de casi todos los proveedores de robots industriales del mundo, y ha sido utilizado por la OCDE durante algún tiempo. ${ }^{17}$ Los datos de la IFR contienen una medida de las existencias de robots en aproximadamente 100 ubicaciones geográficas e industrias entre 1993 y 2015 (OCDE, 2017 $[35]$ ).

En la actualidad, los datos de la IFT sobre el despliegue de robots no incluyen el número de robots conectados. La IFT, no obstante, planea comenzar a recopilar estos datos a partir de 2018. Esto podría brindar un valioso conjunto de datos para esta categoría de conectividad del IoT.

Figura 17. Penetración de robots en países de la OCDE, 2015

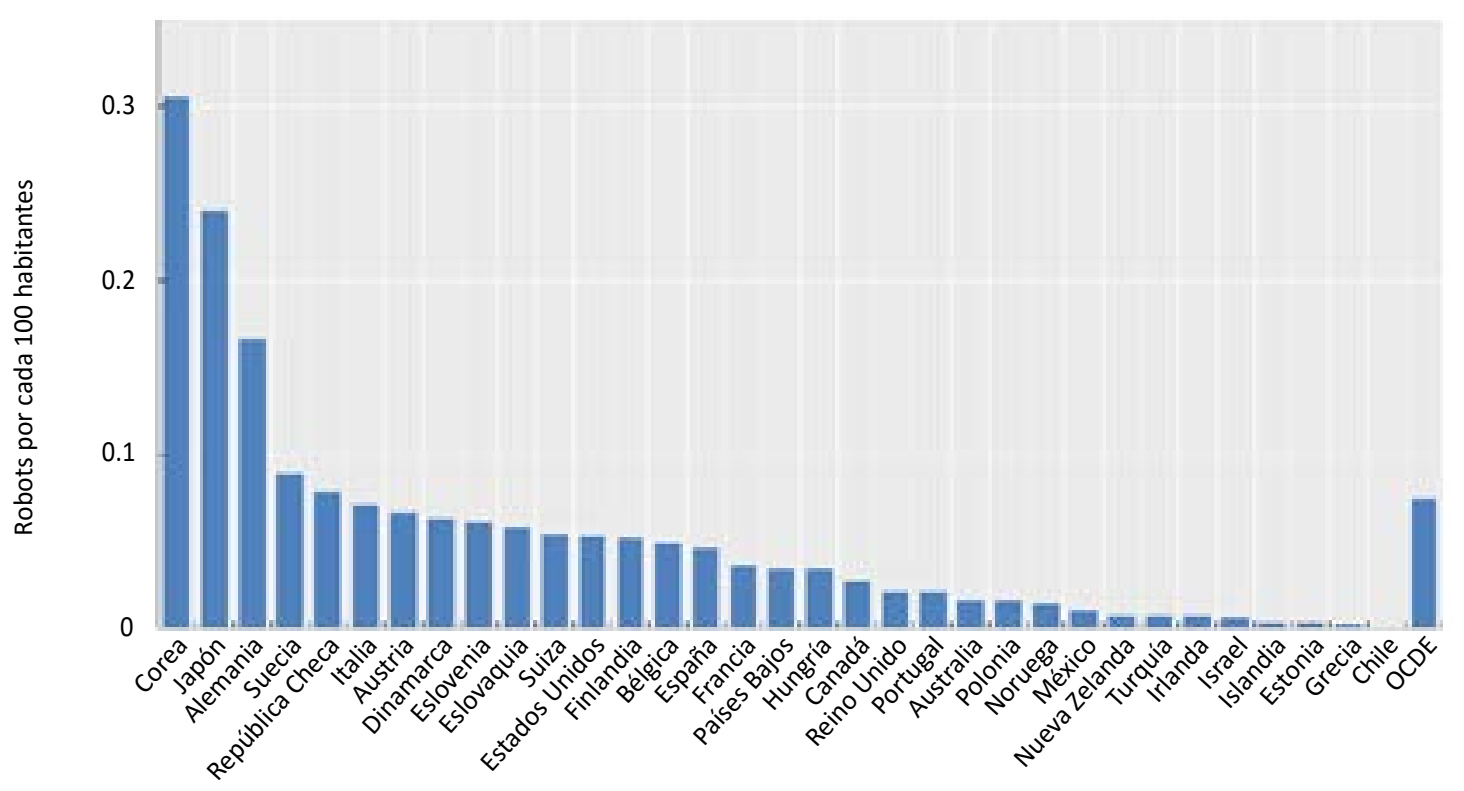

Nota: Datos de 2013 en lugar de 2015 para Finlandia y Eslovenia

Fuente: Federación Internacional de Robótica (IFR).

\subsection{EI IoT y el medio ambiente: sensores M2M y medidores inteligentes}

Los servicios masivos de comunicación M2M comprenden la enorme cantidad de sensores que se utilizarán en las ciudades (p. ej., redes eléctricas y carreteras), en la industria (p. ej., sensores dentro de las máquinas) y en el sector agrícola (p. ej., sensores que miden los niveles de humedad para mejorar la eficiencia del agua o predecir mejor el rendimiento de los cultivos). ${ }^{18}$ Una característica de este tipo de dispositivos M2M es que su despliegue será masivo, en el sentido de que se trata de millones de sensores dispersos en áreas amplias (en términos de $\mathrm{km}^{2}$ ). Sin embargo, la cantidad de datos transmitidos por dispositivo puede ser menor (en comparación con las aplicaciones críticas de IoT) y tienden a ser menos sensibles a los problemas de latencia. 
Se han llevado a cabo algunas mediciones de los sensores en términos de "medidores inteligentes". Un informe reciente de la Dirección de Medio Ambiente de la OCDE sobre los medidores inteligentes y el comportamiento de los consumidores destacó que en muchos países del mundo está en marcha la implementación de los medidores inteligentes entre los clientes residenciales (Tabla 5). Para 2016, por ejemplo, en Canadá y Estados Unidos, aproximadamente la mitad de todos los medidores residenciales han sido reemplazados por medidores inteligentes. ${ }^{19}$ Este informe afirma, sin embargo, que en el Reino Unido y Francia, el despliegue de medidores inteligentes en los hogares va a la zaga de Norteamérica (Rivers, 2018 $[36]$.

Tabla 5. Implementación de medidores inteligentes residenciales en países y regiones seleccionados

\begin{tabular}{lcccc}
\hline Región & $\begin{array}{c}\text { Número de medidores } \\
\text { inteligentes }\end{array}$ & $\begin{array}{c}\text { Numero de cuentas } \\
\text { residenciales }\end{array}$ & $\begin{array}{c}\text { Penetración de los } \\
\text { medidores inteligentes }\end{array}$ & Año \\
\hline Francia & 1500000 & 29000000 & $5 \%$ & 2016 \\
Alemania & 1600000 & 40000000 & $4 \%$ & 2014 \\
Italia & 26000000 & 26000000 & $100 \%$ & 2015 \\
\hline Ontario Canadá & 5000000 & 5000000 & $100 \%$ & 2016 \\
Reino Unido & 3500000 & 27000000 & $13 \%$ & 2016 \\
\hline Estados Unidos & 57107785 & 131864192 & $43 \%$ & 2015 \\
\hline
\end{tabular}

Nota: Datos de Francia: metering.com, https://www.metering.com/reports/linky-smart-meter-enedis/; Alemania: Zhou y Brown (2017); Italia: Uribe-Pérez et al (2016); Francia, Italia, Alemania (número de hogares): Eurostat (2016); Ontario: Oficina del Auditor General de Ontario (2014); Reino Unido: Departamento de Estrategia Comercial, Energética e Industrial [Department for Business, Energy and Industrial Strategy] (2016), Oficina de Estadísticas Nacionales [Office for National Statistics] (2016); Estados Unidos: Administración de Información de Energía de los Estados Unidos (2017).

Fuente: Informe de la OCDE "Leveraging the Smart Grid: The Effect of Real-Time Information on Consumer Decisions" (Rivers, 2018 [36]).

Otra aplicación medioambiental que depende cada vez más del IoT, y en particular del uso de sensores masivos y dispersos, es la ganadería inteligente (SLF, por sus siglas en inglés). Esta última se refiere al uso de las Tecnologías de la Información y las Comunicaciones (TIC) aplicadas en las cadenas de valor pecuarias para impulsar la productividad del sector agropecuario mediante la integración de diferentes procesos como la Ganadería de Precisión (PLF, por sus siglas en inglés), los Sistemas de Información de Gestión (MIS, por sus siglas en inglés), la automatización agrícola y la robótica. La integración de todos estos procesos tiene como objetivo mejorar la gestión y la toma de decisiones. En este sentido, el IoT utilizado para la SLF tiene por objeto proporcionar una cobertura completa de los procesos mediante la recopilación y transmisión de datos de todo el agroecosistema. Esto significa que la SLF puede establecer contacto con cada uno de los participantes de una cadena ganadera, recopilando información sobre sus procesos y aumentando las posibilidades de control y de mejora de la eficiencia de sus tareas. En términos de medición de estos dispositivos, la cuestión sigue siendo si sería mejor ponerse en contacto con los propietarios de SLF para obtener indicadores, o con los proveedores de conectividad de dichos sistemas. 


\title{
5. ¿Es necesario dar prioridad a algunas categorías de dispositivos de IoT en términos de medición?
}

\author{
5.1. ¿Algunos dispositivos de IoT, como los vehículos automatizados, generarán \\ grandes aumentos de la demanda de infraestructura?
}

Si bien los "coches conectados" han sido habituales durante varios años, es probable que los crecientes niveles de autonomía de los conductores impongan nuevas exigencias a las infraestructuras de comunicación. Los vehículos totalmente automatizados, en ocasiones llamados vehículos sin conductor o autónomos, generan grandes cantidades de datos, lo que plantea cuestiones como las siguientes:

- ¿Cuántos datos generará un vehículo totalmente automatizado?

- ¿Qué tanta de esta transmisión de datos debe ser en tiempo real?

- ¿Cuánta de esta información es on-net y off-net?

- ¿A qué distancia deberán transmitirse los datos para la comunicación de vehículo a vehículo o de otro tipo?

- ¿Qué cantidad de datos será necesario cargar y descargar cuando un vehículo está parado, por ejemplo, en un garaje con una conexión de banda ancha fija?

Los requisitos de transmisión de datos de los vehículos totalmente automatizados podrían tener grandes implicaciones para la infraestructura de la red y, por lo tanto, es necesario establecer prioridades en términos de medición para poder seguir los acontecimientos. Al mismo tiempo, el crecimiento exponencial de las necesidades de datos en los vehículos automatizados puede presentar desafíos políticos considerables (es decir, de seguridad, protección, privacidad, etc.) que pueden explorarse en futuros trabajos de la OCDE.

Antes de examinar más de cerca estos diferentes aspectos, pueden ser útiles algunas observaciones generales con respecto a la terminología relativa a los automóviles totalmente automatizados, autónomos y conectados:

- La conducción autónoma se basa en el uso de sensores y radares en el propio vehículo (es decir, el vehículo funciona de forma "autónoma").

- La conducción conectada utiliza conectividad y soporta la conducción autónoma. La mayor parte de la conducción conectada utiliza ITS (es decir, la tecnología de corto alcance), que establece la comunicación de vehículo a vehículo, y la conectividad del vehículo con la infraestructura vial. En el caso de los vehículos conectados a redes móviles, se trata únicamente de características especiales de "valor añadido" del vehículo, como la telemática y el "infoentretenimiento" (es decir, en este caso, las características de conducción relacionadas con la seguridad no dependen de la conectividad móvil).

- La conducción automatizada describe el hecho de que el conductor está cada vez menos involucrado en el proceso de conducción.

\subsection{1. ¿Cuánta información?}

Existen distintas estimaciones sobre la cantidad de datos que generará en el futuro un automóvil conectado y sobre la cantidad de datos que se transferirán realmente a través de 
las redes de telecomunicaciones. Las proyecciones difieren, quizá debido a las definiciones o a los avances tecnológicos previstos. No obstante, todas las estimaciones para los vehículos conectados son que producirán una enorme cantidad de datos en comparación con los vehículos actuales.

En la actualidad, los vehículos conectados a Chevrolet en los Estados Unidos utilizan 4220684 gigabytes (GB) de datos en 2016, un aumento de casi el 200\% con respecto a 2015 (Chevrolet Media, 2017 ${ }_{[37]}$ ). Tan solo los propietarios de Tahoe y Suburban utilizaron 713669 GB de datos en 2016, lo que equivale aproximadamente a 3 millones de horas de transmisión de video, o 1800 millones de canciones, juegos o descargas de aplicaciones (Chevrolet Media, 2017 [37]). Es decir, si se suman los datos trimestrales de la compañía, el uso de datos a bordo en los vehículos conectados a Chevrolet creció de 1455 terabytes (TB) en 2015 a 4224 TB en 2016 (Chevrolet, 2016 ${ }_{[38]}$ ) (Figura 18). Para responder a la creciente demanda, en mayo de 2017, AT\&T introdujo el "plan de datos 4G LTE ilimitado" para vehículos conectados, tales como para los propietarios de Chevrolet, con un precio de 20 dólares al mes, con la reserva de que después de 22 GB de uso, AT\&T podría reducir las velocidades (Chevrolet Media, 2017 [39]).

Figura 18. Uso de datos a bordo en vehículos Chevrolet conectados

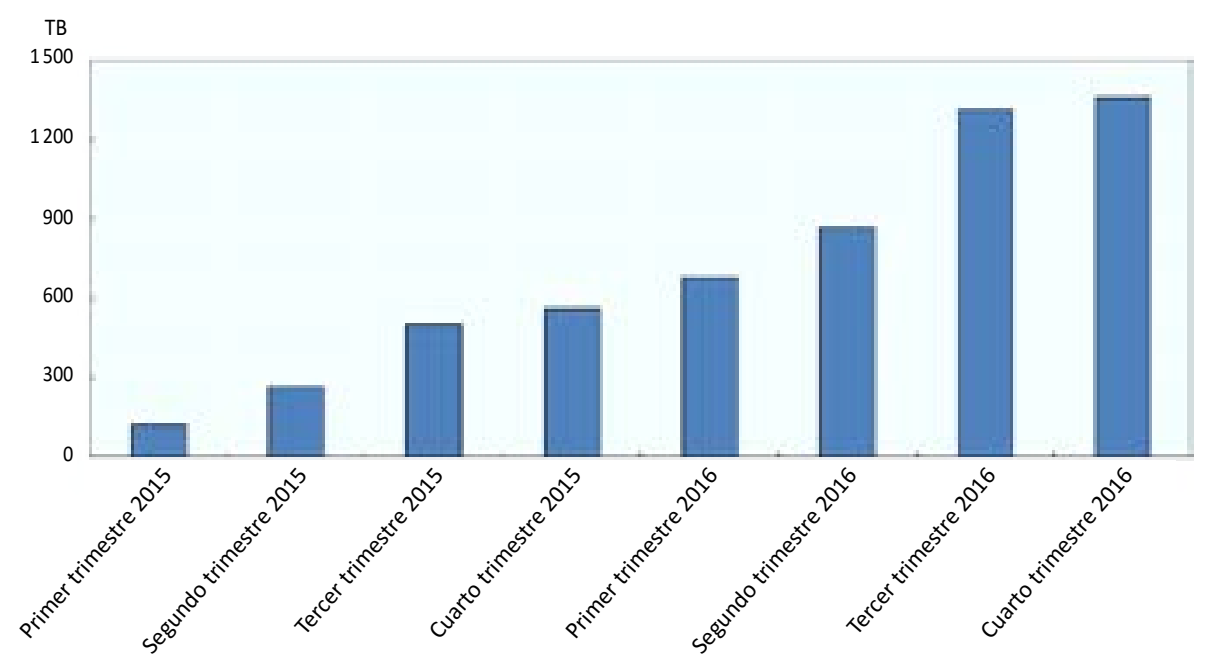

Nota: $\mathrm{TB}=$ Terabytes

Fuente: Chevrolet (2016) "Chevrolet lowers 4G LTE data pricing up to 50 percent", http://media.chevrolet. com/media/us/en/chevrolet/home.detail.html/content/Pages/news/us/en/2016/jun/0629-onstarData.html.

Según el responsable de marketing de Tuxera, una empresa que produce gestión de archivos para vehículos, un vehículo nuevo de 2017 generará unos 20 GB de datos al día, suponiendo que el coche tiene dos cámaras, 16 sensores y es conducido una o dos horas al día (Seminconductor Engineering, 2017 ${ }_{[7]}$ ). Además, según Intel, la estimación es de 4000 GB por día. No todos estos datos, por supuesto, necesitan ser transmitidos, lo que es un factor importante a la hora de pensar en los requisitos de las redes para adaptarse a este crecimiento exponencial de los datos.

De acuerdo con el analista de Barclays, Brian Johnson, un solo vehículo totalmente automatizado (es decir, de nivel 4/5 de automatización), dados todos sus sensores, cámaras 
y LiDAR, podría generar hasta $100 \mathrm{~GB}$ de datos por segundo (CNBC Autos, 2017 ${ }_{[6]}$ ). Además, este mismo informe de Barclays mencionaba que tan solo en Estados Unidos, "260 millones de autos generarán alrededor de 5800 Exabytes de datos diarios, suficientes para llenar 1.4 millones de centros de datos móviles de camiones de Amazon, o un convoy de 11000 millas de largo" (Automobile Mag, 2017 ${ }_{[40]}$ ).

Un vehículo conectado dispone hoy en día de una o varias tarjetas SIM relacionadas con telemática (datos de los sensores sobre el mantenimiento del vehículo) y con el "infoentretenimiento" (es decir, para el sistema de entretenimiento del vehículo que utiliza un punto de acceso Wi-Fi y conectividad 4G). Aunque la cantidad de datos generados por los vehículos conectados, o sus usuarios, está aumentando rápidamente, no es necesario transmitir todos los datos en tiempo real. Además, el uso de una conexión a bordo por parte de los particulares puede ser menor que el de un smartphone, especialmente si se tiene en cuenta que un teléfono inteligente puede utilizarse en el trabajo y en el tiempo libre, mientras que el tiempo que se pasa en un vehículo puede ser mucho menor. En un futuro próximo, sin embargo, se espera que los vehículos totalmente automatizados generen volúmenes mucho mayores de datos.

Según Intel, en 2020 el usuario medio de Internet producirá 1.5 GB diarios, mientras que un vehículo autónomo generará $4000 \mathrm{~GB}$ diarios de datos (Figura 19) (Intel, 2016 ${ }_{[5]}$ ). En otras palabras, un solo vehículo automatizado en un solo día producirá datos equivalentes a unos 2700 usuarios de Internet. Los requisitos de velocidad de conexión para un vehículo totalmente automatizado se componen de las siguientes características: alrededor de 10$100 \mathrm{Kbps}$ para el $\operatorname{radar}^{20}$ y una cantidad equivalente para el sonar; aproximadamente 50 Kbps para el GPS; alrededor de 10-70 Mbps para el LiDAR, el sistema de teledetección láser, ${ }^{21}$ y 20-40 Mbps para las cámaras. El total de datos generados es de $4000 \mathrm{~GB}$ por día, cada día para cada vehículo autónomo (Intel, 2016 $[5]$ ).

Figura 19. Volumen de datos generados por un vehículo autónomo: Intel

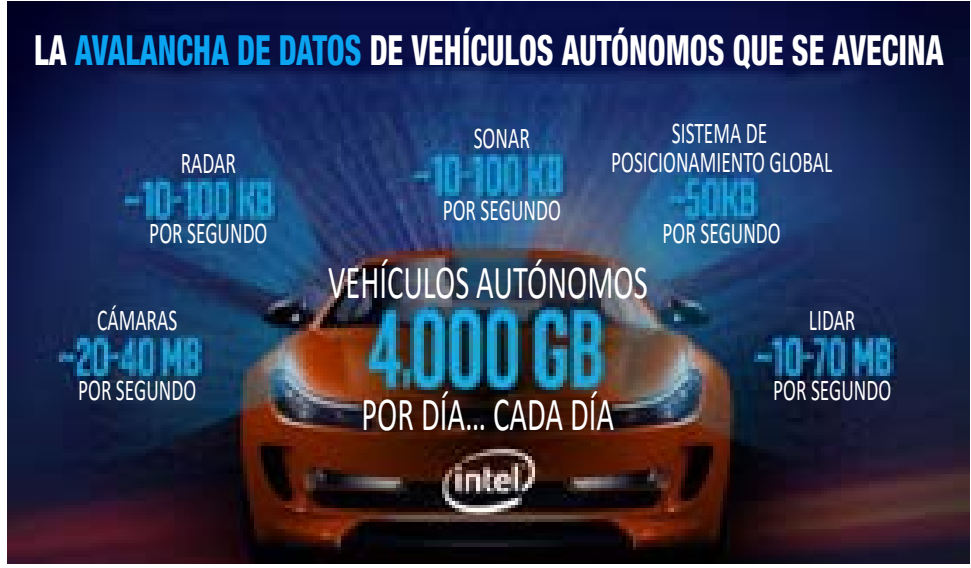

Fuente: Intel,

https://www.networkworld.com/article/3147892/internet/one-autonomous-car-will-use-4000-gb-of-dataday.html

Mientras tanto, según Google Cloud, los vehículos autónomos pueden producir más de 560 GB por vehículo al día (Google Cloud Platform, 2017 ${ }_{[41]}$ ). Muchos fabricantes de automóviles están realizando pruebas para determinar, entre otras cosas, cuáles son los requisitos de datos que deben cumplir los vehículos automatizados para funcionar, así como los requisitos regulatorios que deben adaptarse para que los vehículos automatizados 
se conviertan en una realidad. Por ejemplo, en Suecia, Volvo tiene previsto ofrecer a sus clientes vehículos totalmente automatizados para 2021, y en enero de 2017 comenzó una prueba de 100 vehículos de autoconducción probados por personas del público en general en la ciudad de Gotemburgo (Nordic Business Insider, 2017 ${ }_{[42]}$ ). Otro ejemplo es un reciente proyecto de investigación en Francia que actualmente se dedica a la realización de 64 pruebas de referencia en vehículos conectados y automatizados (VCA) en todo el mundo. Uno de los objetivos de este proyecto consiste en cuantificar las diferentes pruebas (número de vehículos en uso y tamaño del presupuesto). Los resultados aún no han sido publicados (TEVAC, 2017 $[43]$ ). ${ }^{22}$

En lo que se refiere a la recopilación de datos de los vehículos conectados y automatizados, esto podría hacerse de varias maneras. Una opción podría ser la realización de encuestas específicas dirigidas al lado de la oferta (es decir, a los fabricantes de vehículos). Otras opciones podrían ser la recopilación de datos de los registros de vehículos que existen en todos los países, o de aquellos que proporcionan conectividad, o incluso de las compañías de seguros. Lo más probable es que cada una de estas partes interesadas proporcione indicadores de diversas índoles. Por ejemplo, mientras que el proveedor de conexión puede tener una idea de la cantidad de tráfico de datos utilizados por vehículo, los registros de vehículos solo conocerían la cantidad de vehículos conectados por su modelo.

\subsection{2. ¿Diferentes niveles de automatización requerirán diferentes niveles de conectividad?}

Una pregunta abierta es si la cantidad de datos dependerá del grado de automatización. Para responder a esta pregunta, resulta útil revisar los niveles de automatización definidos por la Norma J3016 de la Sociedad de Ingenieros Automotrices. Conforme a esta definición, un humano puede intervenir hasta el nivel tres de automatización (Figura 20). 
Figura 20. Niveles de automatización de acuerdo con la Sociedad de Ingenieros Automotrices

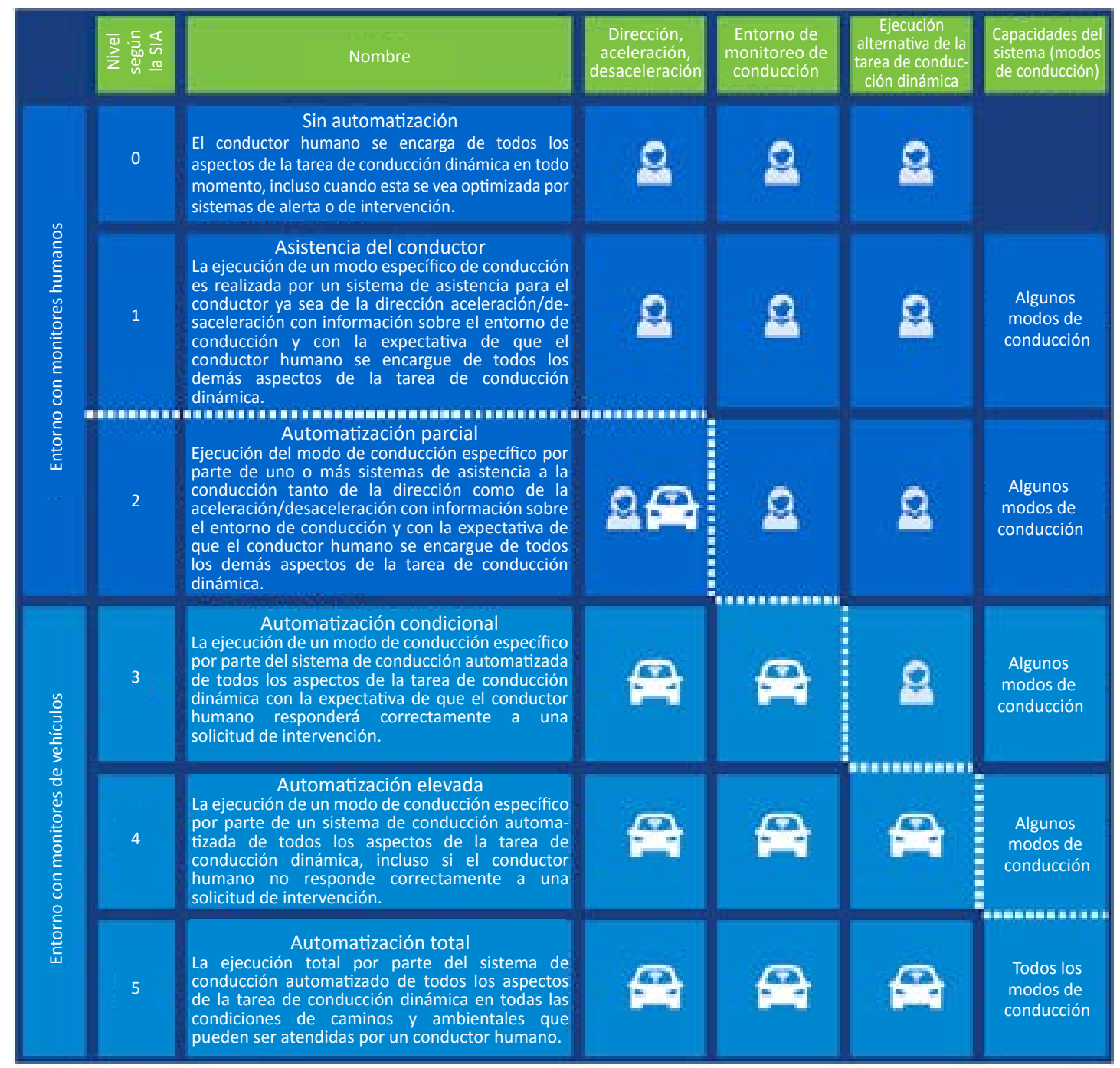

Nota: Figura tomada de la página 14 de "Automated and Autonomous Driving” (OECD/ITF, 2015 [44] $)$.

Fuente: Adaptado de la Norma J3016 de la SAE (SAE, 2014 $\left.{ }_{[45]}\right)$.

Los requisitos de conectividad pueden variar en función del nivel de automatización del vehículo. A este respecto, un informe del Foro Internacional de Transporte señaló que: "Los niveles de automatización más allá de la automatización condicional (Nivel 3) pueden operar en función de las entradas procedentes únicamente de sensores [embebidos] embarcados en el vehículo (autodetección) o mediante una combinación de entradas autodirigidas y entradas procedentes de sensores embarcados en otros vehículos e infraestructuras que se comunican al vehiculo en tiempo casi real" (OCDE/ITF, 2015 [44] $)$.

Además, el enfoque de vehículo conectado y de infraestructura conectada requiere frecuencias de transmisión de datos disponibles, protocolos de transmisión de datos de baja latencia, fiables, seguros y a prueba de fallos, así como una sintaxis de datos armonizada que garantice una interoperabilidad segura (OCDE/ITF, 2015 $\left.{ }_{[44]}\right)$. 


\subsubsection{La naturaleza del tráfico de datos creado por los vehículos automatizados: ¿más carga o descarga de datos?}

En 2017, AT\&T tenía 14.6 millones de autos conectados a su red, añadiendo aproximadamente un millón más cada trimestre. En la actualidad, AT\&T divide la facturación del tráfico de datos de cada fabricante de automóviles utilizando su red entre los datos telemáticos y los datos de infoentretenimiento conectados. Mientras que hoy en día AT\&T reporta que la mayoría de los datos de estas conexiones se relacionan con el entretenimiento, consideran que esta tendencia se invertirá una vez que los automóviles estén totalmente automatizados.

Según Sandvine, una compañía que rastrea el uso de datos entre un panel de usuarios de banda ancha fija en Norteamérica, el entretenimiento en tiempo real representó más del $71 \%$ de la descarga durante los períodos pico en 2016, lo que representó un ligero aumento con respecto al 70\% reportado en 2015 (Sandvine, 2016 ${ }_{[46]}$ ). En ese momento, Sandvine reportó que el uso de Netflix representaba la mayor proporción del tráfico de descarga (es decir, el 35\%), con un 17.53\% para YouTube. Aunque los patrones de uso de datos móviles pueden diferir de los de las redes fijas, también se cree que, en general, implican que se descargan más datos de los que se cargan. Esto plantea la cuestión de si el IoT invertirá esta tendencia. Es decir, ¿la prevalencia del IoT y de los vehículos automatizados creará más datos ascendentes que descendentes?

\subsection{4. ¿Qué datos o aplicaciones son más sensibles a los problemas de latencia?}

Algunos de los datos utilizados por los vehículos automatizados pueden ser extremadamente sensibles al tiempo (es decir, decisiones en tiempo real que debe tomar en cuestión de milisegundos el vehículo totalmente automatizado mientras circula). Otras aplicaciones en vehículos conectados o autónomos no serán tan sensibles a los problemas de tiempo o latencia (es decir, datos de sensores telemáticos para el mantenimiento de vehículos). Con respecto a los datos que no son requeridos inmediatamente por un vehículo automatizado, estos pueden seguir siendo muy valiosos por otras razones. Por ejemplo, algunos datos sobre las condiciones de las carreteras, como el desgaste, pueden ser útiles para su mantenimiento. Estos datos se pueden cargar cuando un vehículo se encuentra estacionado o en un garaje y, por lo tanto, utilizar una red fija. De la misma manera, las actualizaciones de software para un vehículo, si no son sensibles al tiempo, pueden ocurrir al mismo tiempo. Dicho esto, incluso las redes fijas experimentarían un gran aumento de la demanda de tráfico si fuera necesario cargar una proporción sustancial de los datos generados por los vehículos automatizados.

Otros ejemplos de datos que pueden ser sensibles a problemas de latencia, pero que no requieren la transmisión en tiempo real (y que por lo tanto no son sensibles al tiempo), son algunos productos para ciudades inteligentes. Por ejemplo, AT\&T no solo se aventura en el área de vehículos conectados, sino que también tiene un producto para ciudades inteligentes. En su experiencia, algunos nodos (con muchos sensores conectados a ellos) en una ciudad inteligente pueden llevar datos, lo que no es sensible al tiempo, pero que sería muy sensible a los problemas de latencia. Un ejemplo notable es la transmisión en tiempo real de datos para analizar los patrones de tráfico de las cámaras de las luminarias públicas. Si bien es posible que puedan descargar los datos durante las horas de menor consumo, la medición debe ser fiable y, para ello, requiere una latencia mínima.

\subsection{5. ¿Cómo abordan los fabricantes de automóviles el aumento exponencial de los datos?}

Los fabricantes de automóviles están construyendo centros de datos y adoptando nuevas estrategias y herramientas digitales que les permitan hacer frente al gran crecimiento 
esperado en términos de datos generados por vehículos cada vez más automatizados, para producir mejores productos y servicios y quizá con miras a atender los problemas relacionados con la propiedad de los datos. A modo de ejemplo, Volkswagen actualmente explora el sector del cómputo cuántico, y BMW está construyendo, cerca de Múnich, un centro de datos diez veces más grande que las instalaciones actuales de la empresa (NYT, $2017_{[47]}$ ). En Estados Unidos, Ford anunció una inversión de 200 millones de dólares para construir un nuevo centro de datos en Flat Rock, Michigan, ya que espera un incremento del $1000 \%$ en el uso de datos debido a las conexiones necesarias entre las tecnologías de automoción e informática en un mundo de vehículos parcial y totalmente automatizado (DataCenter Knowledge, 2017 ${ }_{[48]}$ ).

Muchas compañías automotrices están desarrollando estrategias internas que les permitan hacer frente a los desafíos de cómputo, análisis y almacenamiento de datos para que los vehículos autónomos se conviertan en una realidad. Por ejemplo, Bosch invertirá 1100 millones de dólares en una nueva fábrica para producir circuitos integrados para una variedad de aplicaciones, incluyendo sensores en vehículos autopropulsados (NYT, 2017 $\left.{ }_{[47]}\right)$. BMW también desarrolla capacidades digitales en casa y utiliza la inteligencia artificial para analizar la gran cantidad de datos generados por la realización de pruebas de vehículos automatizados. La compañía afirma que la mayoría de los centros de datos deben estar en sus propias instalaciones, ya que la cantidad de datos es tan grande que no puede depender únicamente del cómputo en la nube. Por otro lado, Volvo ha recurrido a proveedores externos como Ericsson para la tecnología informática, e instalará el sistema operativo Android de Google en los autos nuevos a partir de 2019 (NYT, 2017 [47]).

\subsubsection{Plataformas del IoT para vehículos automatizados: interoperabilidad de los datos}

Actualmente se están generando nuevos flujos de datos que permitan garantizar la comunicación vehículo a vehículo (V2V) y vehículo a todo (V2X). Están surgiendo diferentes soluciones que requieren la coordinación de múltiples partes interesadas a través de plataformas comunes.

En una plataforma de IoT para vehículos autónomos, el reto consiste en integrar muchas tecnologías heterogéneas que le permitan al automóvil navegar (Semiconductor Engineering, $\left.2017_{[49]}\right)$. IBM, por ejemplo, está desarrollando una nueva plataforma de IoT, para vehículos autónomos, que utiliza la informática cognitiva $\left(\right.$ IBM, 2017 $\left.{ }_{[50]}\right)$. La patente de IBM para este sistema de cómputo cognitivo ayuda a determinar si una persona $-\mathrm{o}$ el sistema de autoconducción - debe tomar el control del vehículo para evitar colisiones, y el momento para ello (Popular Science, $2017_{[51]}$ ).

La colaboración entre las distintas partes interesadas para crear plataformas de IoT para vehículos automatizados es cada vez mayor. Por ejemplo, hace un año Intel se asoció por primera vez con Mobileye, una empresa israelí que fabrica cámaras y sensores, y después adquirió la empresa en marzo de 2017 por 15300 millones de dólares (Tech Crunch, 2017 $\left.7_{[52]}\right)$. Algunos sugieren que, con esta adquisición Intel desea convertirse en el líder de los sistemas informáticos para automóviles automatizados (NYT, 2017 [53] $)$. Más recientemente, BMW y FIAT-Chrysler se asociaron con Intel (y con su empresa adquirida Mobileye) con el objetivo de crear una plataforma tecnológica para la conducción altamente automatizada (Automotive News, $2017_{[54]}$ ). 


\section{2. ¿Qué se necesita en términos de despliegue de infraestructura (p. ej., ITS, 5G)?}

Uno de los posibles cuellos de botella actuales para que el IoT se convierta en una realidad omnipresente, y para que los vehículos se automaticen plenamente, podría estar relacionado con la conectividad de la red. Un aumento exponencial de los datos generados por los vehículos automatizados podría representar un desafío para las plataformas que conectan y gestionan estos datos. Las implicaciones y las posibles respuestas para cualquier aumento exponencial de los datos dependerán de algunos de los siguientes elementos de la infraestructura de comunicación:

- $5 \mathrm{G}$

- Enlace terrestre

- IXP y centros de datos

- Servicios en la nube

Una solución ideal de red del IoT tendría que cumplir las siguientes condiciones: 1) amplia cobertura y conexión de múltiples dispositivos, 2) bajo consumo de energía, 3) bajo costo y 4) conectividad confiable. En los párrafos siguientes, el informe examinará algunos aspectos de la conectividad de la red que son partes importantes del ecosistema del IoT.

\subsubsection{ITS}

La conducción automatizada y conectada implica una comunicación directa entre los automóviles o entre los automóviles y la infraestructura vial, lo que ocurre a través de la tecnología de Sistema de Transporte Inteligente (ITS, por sus siglas en inglés), una tecnología de corto alcance, en lugar de a través de redes móviles.

La Comisión Europea promueve el uso de una red dedicada, la plataforma C-ITS, para los servicios de automóviles conectados. En 2014, la Comisión Europea decidió desempeñar un papel más destacado en el despliegue de la conducción conectada, mediante la creación de una Plataforma de Despliegue para C-ITS. La Plataforma se concibió como un marco de cooperación entre las autoridades nacionales, las partes interesadas en C-ITS y la Comisión, con miras a desarrollar una visión común sobre el despliegue interoperable de la plataforma C-ITS en la UE. Generará recomendaciones sobre políticas para el desarrollo de una hoja de ruta y una estrategia de despliegue de C-ITS en la UE e identificará posibles soluciones a algunas cuestiones transversales críticas.

En el marco del apoyo al despliegue de C-ITS en las carreteras europeas, hay una serie de proyectos piloto de la vida real de C-ITS financiados en el marco de diferentes programas, que crearán nuevos servicios de ITS para todos los usuarios de carreteras europeas. Estos proyectos pondrán a prueba las interacciones vehículo-infraestructura y vehículo a vehículo mediante el uso de comunicaciones tanto de corto alcance como celulares.

\subsubsection{Estandarización y $5 G$}

Uno de los principales retos que deben abordarse en relación con el IoT es garantizar una conexión fiable que sea interoperable con otros dispositivos y redes de IoT. La conectividad móvil es tan solo un tipo de conectividad que se utiliza para los dispositivos y redes de IoT. El ORECE, con base en datos de Machina Research, encontró que apenas una pequeña fracción de las conexiones M2M se basará en tecnologías celulares, lo que significa que algunos de los dispositivos de IoT podrían requerir una tarjeta SIM, aunque esto no será necesario para la mayoría de los dispositivos de IoT (ORECE, 2016 $[9]$ ). ${ }^{23}$ Otras redes 
de conectividad utilizadas son, por ejemplo, las redes de área amplia de baja potencia (LPWAN, consultar la Sección 5.2.3 siguiente), o las redes fijas.

Con respecto a la conectividad móvil (celular) utilizada para el IoT, el estándar 5G promete convertirse en un elemento central del IoT, gracias a su capacidad para reunir redes heterogéneas como RFID y Bluetooth con la tecnología celular (5G Américas, 2017 [55]). Además, el hecho de que la red $5 \mathrm{G}$ muy probablemente utilice un nuevo espectro en las bandas de alta frecuencia la hace particularmente atractiva como solución para IoT (Fierce Wireless and TelecomAsia, 2016 $\left.{ }_{[56]}\right)$.

Intel ha expresado su opinión respecto de que, para que los vehículos autónomos se conviertan en una realidad, los flujos de datos de entrada y salida de dichos vehículos deben realizarse a un ritmo más rápido que el de las actuales redes móviles LTE. De esta forma, Intel ha señalado que las redes $5 \mathrm{G}$ pueden convertirse en el "oxígeno" de los vehículos totalmente automatizados (VB, 2017 [57] $)$.

BMW ha señalado que uno de los principales desafíos para la conducción autónoma es que, para procesar todos los datos recogidos por los sensores, las redes inalámbricas deben ser más avanzadas, incluso con 5G. Afirman que para los vehículos automatizados de Nivel 5 (es decir, vehículos totalmente autónomos), con al menos 33 sensores que van desde escáneres hasta LiDAR, las redes 5G deberán estar en funcionamiento para 2020 (BMW $\left.\mathrm{Blog}, 2017_{[58]}\right)$. Señalan que la conducción totalmente autónoma requiere descargar mapas muy detallados en tiempo real, y BMW considera que esto podría requerir conectividad 5G. Además, la conectividad puede ser importante por motivos de seguridad y esto puede ser sensible al tiempo. A modo de ejemplo, BMW afirma que sus vehículos deben estar conectados a un servidor para que, en caso de que se detecte un ataque a la seguridad o una vulnerabilidad, se pueda proporcionar de forma automática una actualización de cifrado a más de 10 millones de vehículos en 24 horas (CarAdvice Australia, 2017 [59] $)$.

Las características clave de la 5G serán las siguientes (3GLTEinfo, 2015 $5_{[60]}$ ):

- velocidades de conexión de hasta 20 Gbps (en comparación con el máximo de 1 Gbps alcanzado con LTE actualmente),

- velocidades reales de cobertura experimentadas por los usuarios que oscilan entre 100-1 000 Mbps (en comparación con los 10 Mbps de las redes 4G),

- latencia de 1 milisegundo (ms) (en comparación con 10 ms en 4G), y

- conexiones de dispositivos de 200000 dispositivos $/ \mathrm{km} 2$.

Con el crecimiento del IoT, el estándar 5G tendrá que atender una amplia gama de aplicaciones con distintos requisitos de red. El estándar 5G promete atender la adaptabilidad que la red requerirá para cada una de estas aplicaciones (Ericsson, 2017 $[4]$ ). Como se mencionó anteriormente, Ericsson ha destacado que los vehículos automatizados requerirán una latencia baja (es decir, menos de $5 \mathrm{~ms}$ ) y una fiabilidad y cobertura del $100 \%$ de la red, mientras que los objetos M2M conectados masivamente y dispersos, como los sensores, requerirán una cobertura del $100 \%$ de la red, una duración de la batería de 10 años, pero no serán sensibles a la latencia (Ericsson, 2017 $[4]){ }^{24}$

Se están llevando a cabo varios estudios sobre el estándar 5G. Por ejemplo, Corea lanzó una red piloto 5G para los Juegos Olímpicos de Invierno de Pyeong Chang 2018 en colaboración con Korea Telecom (KT), que ofreció el primer banco de pruebas del mundo de la próxima generación de servicios de comunicación inalámbrica. Esto brindó la oportunidad de probar los autobuses 5G autónomos desde el aeropuerto de Seúl hasta el campus olímpico de Pyeong Chang, así como los drones autónomos 5G. Además, SK Telecom ya ha probado su vehículo autónomo en la autopista Gyeongbu de Corea, recorriendo $26 \mathrm{~km}$ a una velocidad 
de hasta $80 \mathrm{~km} /$ hora, y tiene previsto conectar vehículos autónomos a sus redes de prueba de 5G (Telecom Lead, 2017 [61] $)$. Mientras tanto, en Europa, la República de San Marino será uno de los primeros en implementar 5G, con pruebas también en curso en algunas partes de Italia con la intención de destacar el potencial de uso en áreas como el transporte (Telecom Italia, 2017[62]).

En el futuro, los vehículos automatizados que utilicen las redes $5 \mathrm{G}$ podrían requerir nuevas asociaciones entre países. A la luz de esta necesidad, en abril de 2018, varios países europeos firmaron acuerdos para establecer corredores $5 \mathrm{G}$ transfronterizos para la conducción conectada y automatizada. Esto se basa en los acuerdos existentes (firmados en 2017) entre 27 Estados miembros del CE para llevar a cabo ensayos transfronterizos de 5G (Mobile World Live, 2018 ${ }_{[63]}$ ). ${ }^{25}$

\subsubsection{LPWAN para IoT}

El uso de redes de área amplia de baja potencia (LPWAN) es un aspecto clave de la infraestructura del IoT, y se refiere a un gran número de dispositivos de baja potencia que se encuentran prácticamente en todas partes. Las tecnologías de redes de área amplia se dividen en dos grupos: a) un grupo se centra en el espectro sin licencia, como LoRA y SigFox, y b) un grupo se refiere a las conexiones que operan dentro del espectro con licencia, como LTE-M y NB-IoT (MediaTek Blog, 2017 [64] $)$.

Actualmente, en muchos lugares del mundo están lanzándose tecnologías LPWAN que se basan en el espectro licenciado. En Estados Unidos, operadores como Verizon y AT\&T han mejorado sus redes LTE para soportar los servicios LTE-M, y Deutsche Telekom y Vodafone han desplegado NB-IoT en varios mercados europeos (GSMA, 2017 [65]). En Corea, SK Telecom, KT y LGU+ comenzaron a utilizar LTE-M en 2016, y en la primera mitad de 2017, KT y LGU+ desplegaron NB-IoT. Al mismo tiempo, SK Telecom implementó una red LoRA en junio de 2016.

Hay quienes afirman que las tecnologías 3GPP LPWAN, como NB-IoT y LTE-M son preferibles a otras tecnologías LPWAN existentes como LoRA y Sigfox, ya que se pueden escalar fácilmente en las redes $4 \mathrm{G}$ existentes $\mathrm{y}$, de esta forma, pueden llegar a más clientes a un menor costo (MediaTek Blog, 2017 [64] $)$. La GSMA señala que NB-IoT es la tecnología líder entre las alternativas de $4.5 \mathrm{G}$ o LTE avanzado (es decir, $3 \mathrm{GPP}$ ) para el IoT.

Con respecto a LPWAN, Corea ha compartido una tabla en donde se compara LTE-M con las redes LoRA (Tabla 6).

Tabla 6. Comparación de las tecnologías LTE-M y LoRA, Corea

\begin{tabular}{|c|c|c|}
\hline & LTE-M & LoRA \\
\hline \multirow[t]{4}{*}{ Ventajas } & Se puede escalar a partir de redes LTE existentes & Circuitos integrados y módulos baratos \\
\hline & Mejor CdS en el espectro licenciado & Bajo consumo de energía y batería de 10 años \\
\hline & Ya se cuenta con estándares & Interfaz de usuario sencilla \\
\hline & Seguridad al igual que en LTE & Fácil de instalar en torres móviles \\
\hline \multirow[t]{4}{*}{ Desventajas } & Circuitos integrados y módulos costosos & Requiere el despliegue de una red nueva \\
\hline & Dispositivos con un alto consumo de energía & Se basa en un espectro sin licencia \\
\hline & El servicio abierto es complicado & Problemas de estandarización \\
\hline & No existe un modelo de negocio actual & El ecosistema de los circuitos integrados es limitado \\
\hline
\end{tabular}

Fuente: Elaboración propia con base en la presentación de NIA sobre 5G e IoT. 


\subsubsection{Servicios en la nube}

Las soluciones en la nube también buscan ayudar al flujo de datos generados por los vehículos totalmente automatizados. En este sentido, Google recientemente lanzó "Cloud IoT Core", que es una plataforma informática "que aprovecha el modelo de seguridad integral de Google" (Google Cloud, 2017 ${ }_{[66]}$ ). Con el objetivo de sentar las bases de la comunicación entre vehículos (V2V), Google actualmente diseña una "plataforma de vehículos conectados" que utiliza esta plataforma "Cloud IoT Core" (Google Cloud Platform, 2017 $[41]$ ).

\subsubsection{De vuelta a lo básico: Fibra (enlace terrestre)}

Las redes fijas e inalámbricas siguen siendo muy complementarias. A modo de ejemplo, según CISCO, en 2016 alrededor del $60 \%$ de los datos móviles se descargaron a redes fijas a través de Wi-Fi o femtoceldas, lo que equivale a 10.7 Exabytes al mes (Figura 21) (CISCO, 2017 $[67]$ ). Esta tendencia ilustra cómo es probable que el aumento de datos debido a la mayor cantidad de dispositivos conectados al IoT, dependa de una mayor conectividad de la red troncal y de la fibra de la red troncal.

Figura 21. Tráfico total de datos móviles pasado a Redes Wi-Fi Fijas, CISCO

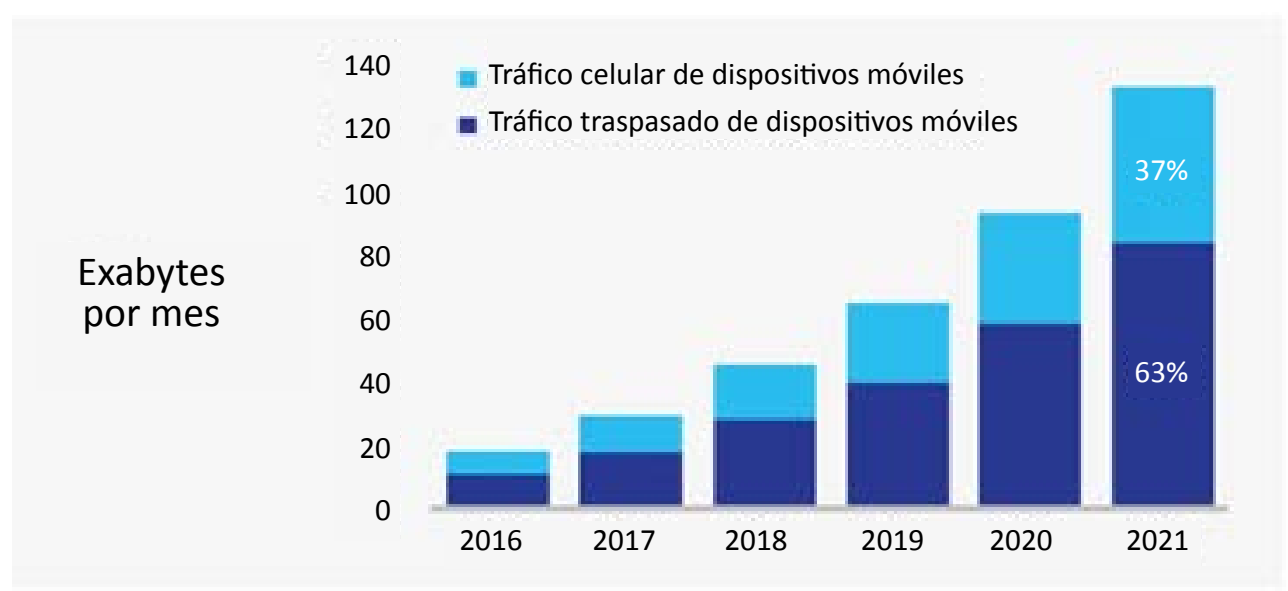

Nota: Traspaso se refiere al tráfico de dispositivos de modo dual (sin incluir laptops) en Wi-Fi y redes de celdas pequeñas.

Fuente: VNI CISCO (2017).

Un estudio reciente de Deloitte señaló que en el caso de Estados Unidos, el acceso de banda ancha fija soporta hasta el 90\% del tráfico inalámbrico (Deloitte US, 2017 [68]). Como tal, afirman que gran parte del éxito de la $5 \mathrm{G}$ en los Estados Unidos dependerá en última instancia del despliegue de fibra. Concluyeron que se necesita una inversión estimada de 130000 a 150000 millones de dólares en fibra para satisfacer las futuras necesidades de banda ancha (Deloitte US, 2017 [68] $)$.

Como ejemplo de las complementariedades entre las redes fijas e inalámbricas, el director ejecutivo de Verizon señaló recientemente en una entrevista que su empresa está comprometida a rediseñar su red para que esté "desde la nube, pasando por la infraestructura de fibra de alta velocidad, hasta llegar a $5 G^{\prime \prime}$ (Seeking Alpha, 2017 [69] $)$. Para ello, además de realizar pruebas de 5G en 11 ciudades, están invirtiendo en el despliegue de 12.5 millones de millas de fibra por año durante los próximos tres años (Seeking Alpha, 2017 [69] $)$. 


\section{Desafíos emergentes en materia regulatoria y de creación de políticas relativos al IoT que resaltan la importancia de la medición}

Junto con los beneficios que el IoT puede aportar, podrían surgir nuevos retos en cuanto a la creación de políticas y de índole regulatoria en algunos ámbitos (p. ej., cuestiones de privacidad/seguridad, así como cuestiones de interoperabilidad, numeración y estandarización). Por ello, la creación de indicadores que sirvan de base para la elaboración de políticas en estos ámbitos es una prioridad. Aunque el principal objetivo del presente informe consiste en examinar la medición del IoT, conviene mencionar las áreas de trabajo futuro, así como recordar los trabajos anteriores de la OCDE sobre el IoT.

Los trabajos anteriores de la OCDE han destacado, entre otras cuestiones regulatorias, la numeración, el direccionamiento y la interoperabilidad del IoT. Por ello, para fomentar el ecosistema del IoT, la interoperabilidad, la gestión del espectro, el uso extraterritorial de los números y las soluciones que faciliten el cambio de proveedor para evitar el bloqueo, se han vuelto cruciales. Además, en trabajos anteriores se ha subrayado la importancia del IPv6 como facilitador clave del IoT (OCDE, 2016 ${ }_{[1]}$ ).

Además de las cuestiones relativas a la interoperabilidad, la numeración y otros estándares, es necesario crear privacidad, seguridad, responsabilidad y fiabilidad en torno al uso del IoT. Por ejemplo, las cuestiones de responsabilidad potencial requieren que se haga una identificación clara de las responsabilidades, específicamente cuando un dispositivo que funciona incorrectamente puede tener resultados sociales o económicos negativos (OCDE, 2016 $[1]$ ).

El desarrollo de métricas sobre seguridad digital, en general, es una tarea relativamente compleja y sigue siendo un área de medición emergente para el IoT. Esto significa que hay méritos para el trabajo futuro centrado en las estadísticas sobre estándares y prácticas de seguridad en torno al IoT, incluso en la OCDE. Es probable que la medición diseñada para informar a los responsables de las políticas en estas áreas cobre más importancia, ya que será necesaria la interoperabilidad de los marcos políticos a través de fronteras y sectores. Esto se encontrará a la vanguardia en áreas como la protección del consumidor, la seguridad, la privacidad y la protección, especialmente cuando los productos se diseñan, fabrican y venden en países con enfoques diferentes (OCDE, 2016 ${ }_{[1]}$ ). 


\section{Conclusiones}

\subsection{Sugerencias con respecto a los criterios para la medición del IoT}

A medida que los dispositivos de IoT se van convirtiendo cada vez más en dispositivos basados en IP y agnósticos a las plataformas (es decir, que funcionan en redes móviles, fijas y de otro tipo), ha aumentado la demanda de enfoques que midan el número de tales dispositivos y mejoren la comprensión de sus implicaciones para las redes de telecomunicaciones. La actual definición de trabajo de la OCDE de IoT, proporciona un marco para orientar los debates sobre políticas y podría resultar más útil si se añadieran subcategorías para efectos de medición.

\subsubsection{Principios generales para establecer prioridades en términos de medición y recopilación de datos de IoT}

Dada su vasta naturaleza, algunas categorías de dispositivos de IoT requieren una priorización en términos de medición. Al determinar prioridades en términos de medición, la pertinencia de las políticas y la viabilidad podrían ser algunas de las principales consideraciones a la hora de tomar la decisión.

Una aplicación notable de IoT que probablemente requerirá una priorización en términos de medición son los vehículos automatizados, ya que generarán enormes volúmenes de datos, lo que probablemente tendrá una influencia importante en la infraestructura de comunicación. En este sentido, la medición de vehículos automatizados se vuelve crucial desde la perspectiva de la planificación urbana, por consideraciones ambientales, para los ministerios de transporte y para los reguladores de las comunicaciones, entre otros.

Es necesario tener en cuenta los aspectos prácticos relacionados con la recopilación de datos para los indicadores de IoT. Un factor clave para la medición, en donde intervienen varias partes interesadas en las cadenas de suministro, es tener en cuenta la propiedad de los datos. ${ }^{26}$ En particular, la medición del IoT puede resultar especialmente complicada para los dispositivos que utilizan bandas de frecuencias sin licencia, ya que no existen procedimientos administrativos de autorización o declaración en estas bandas. En todas estas consideraciones, los responsables políticos deben establecer prioridades y tener un objetivo claro para los datos recopilados.

Aspectos adicionales que deben considerarse en relación con la medición del IoT

Medición de "dispositivos conectados" por características:

- dispersión o concentración de dispositivos/aplicaciones

- movilidad de los objetos (fijos o nómadas),

- volumen de datos y rendimiento de la red (ancho de banda)

- sensibilidad a la latencia.

Clasificación del IoT por opciones tecnológicas para su uso y adopción:

- sensores y concentradores sencillos

- integrar concentradores (es decir, un sistema que conecta concentradores simples creando dispositivos más complejos como el HomeKit de Apple) 
- aplicaciones mejoradas (es decir, servicios que recopilan y analizan datos de dispositivos conectados y del entorno en tiempo real, como los "vehículos automatizados").

Teniendo en cuenta la infraestructura subyacente de IoT que permite la comunicación entre dispositivos:

- Servicios en la nube

- cómputo cuántico y de borde,

- almacenamiento de datos

- redes móviles

- redes LPWA

- conectividad de enlace terrestre y servidores, y otros.

\subsubsection{Medición del IoT en encuestas sobre el uso de las TIC por parte de empresas, hogares y particulares}

Desde el punto de vista del uso, dado que el IoT es de naturaleza evolutiva y que los tipos de dispositivos conectados están cambiando rápidamente, una de las cuestiones difíciles es la de mantener la neutralidad tecnológica. Otra dificultad radica en la conciencia de los consumidores de la naturaleza conexa de los dispositivos que poseen.

Una opción a la hora de concebir las preguntas relacionadas con el IoT que deben incluirse en las encuestas de hogares y empresas, es medir la progresión de los dispositivos conectados entre una familia "genérica" de objetos (p. ej., electrodomésticos, dispositivos portátiles) o bienes más complejos (p. ej., coches, camiones, tractores). Esto puede hacerse desde la perspectiva del productor (utilizando estadísticas de asociaciones o de encuestas específicas sobre la oferta) o desde la perspectiva del usuario (p. ej., desarrollando módulos ad hoc en las encuestas sobre el uso de las TIC).

Las categorías de dispositivos según los ámbitos de aplicación (por ejemplo, el hogar o la salud) podrían implementarse en módulos dentro de las encuestas sobre el uso de las TIC en los hogares y en las personas. Por lo tanto, es muy positivo que Eurostat añada una pregunta relacionada con el IoT (similar a la que incluye Estados Unidos) en su encuesta sobre las TIC en los hogares de 2019. Asimismo, la consideración actual de Eurostat de añadir un módulo sobre IoT para las encuestas de utilización de los hogares es oportuna. Por otra parte, la interacción de los dispositivos de IoT con los procesos empresariales podría medirse mejor utilizando módulos específicos que se aplicarían en las encuestas sobre la utilización de las TIC por las empresas. ${ }^{27}$

\subsection{Propuesta de definición y taxonomía del IoT de la OCDE}

La propuesta que aquí se presenta consiste en respaldar la actual definición de trabajo de la OCDE de IoT, excluyendo los dispositivos que ya se tienen en cuenta en las métricas de la OCDE (es decir, teléfonos inteligentes, tabletas y computadoras personales), y agregando subcategorías a efectos de medición. El desglose del IoT en varias subcategorías, como "comunicaciones masivas entre máquinas" (p. ej., sensores como M2M) y aplicaciones críticas de IoT (p. ej., vehículos automatizados), parece ser una forma razonable de avanzar para crear medidas de IoT que sean adecuadas para informar a la formulación de políticas. 
La definición global de IoT sería:

"Internet de las Cosas incluye todos los dispositivos y objetos cuyo estado puede ser alterado a través de Internet, con o sin la participación activa de las personas. Mientras que los objetos conectados pueden requerir la participación de dispositivos considerados parte de la "Internet tradicional", esta definición excluye las tabletas, las laptops y los teléfonos inteligentes ya contabilizados en las actuales métricas de banda ancha de la OCDE."

Los beneficios de reafirmar la definición de la OCDE y complementarla adoptando subcategorías son múltiples. A saber, aquí se destacan dos beneficios principales. En primer lugar, hace más manejable la cuestión de la medición del IoT y, en segundo, permite establecer prioridades en la recopilación de datos en determinadas categorías (o subcategorías) del IoT que pueden tener más influencia en las futuras demandas de infraestructura de comunicación.

Las subcategorías del IoT deben coincidir con los objetivos políticos, así como con la evolución del mercado del IoT. Por ello, es natural hacer analogías con los conceptos establecidos por la Unión Internacional de Telecomunicaciones (UIT) en su visión de la quinta generación de redes inalámbricas, o la norma IMT 2020, que aún no se ha finalizado en 2019 en la Conferencia Mundial de Radiocomunicaciones de la UIT (UIT, 2015 [70]] $_{\text {. Esta }}$ norma se ha concebido teniendo en cuenta el IoT con tres escenarios de uso principales: banda ancha móvil mejorada, comunicaciones masivas de tipo máquina y comunicaciones/ aplicaciones críticas.

Además, tener en cuenta estas subcategorías (p. ej., las comunicaciones masivas de tipo máquina y aplicaciones críticas de IoT), estaría en consonancia con lo que varias autoridades de los países de la OCDE han destacado (p. ej., Francia, Japón, Corea y Portugal), y coincidiría con la forma en que otras partes interesadas que desarrollan los casos de negocio del IoT, están midiendo actualmente el IoT (p. ej., Ericsson y CISCO).

De esta forma, la propuesta es dividir el IoT en las siguientes subcategorías (Figura 22):

Figura 22. Taxonomía propuesta del IoT para efectos de medición

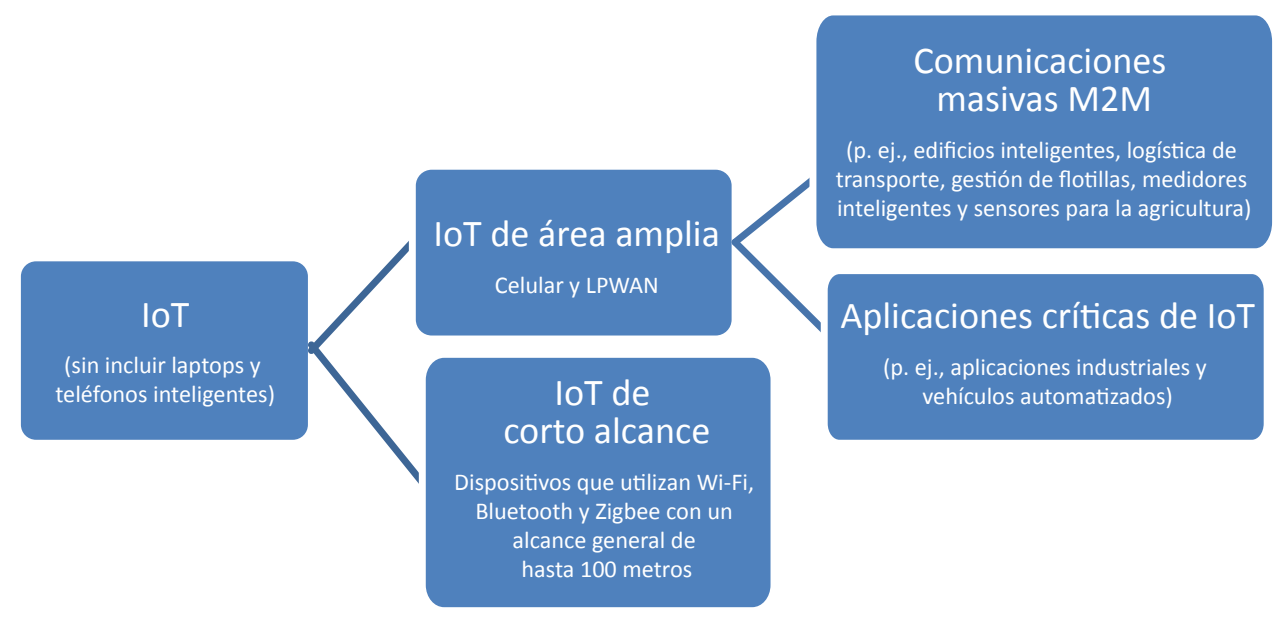

Fuente: Elaboración propia. 
Como se ha señalado anteriormente, las comunicaciones M2M constituyen un subconjunto del IoT. Desde 2012, con el fin de conocer el número de abonados M2M entre los abonados de voz móvil, la OCDE ha medido las tarjetas SIM embebidas M2M, definidas como "el número de tarjetas SIM asignadas para su uso en máquinas y dispositivos (automóviles, contadores inteligentes, electrónica de consumo) y que no forman parte de una suscripción de consumo". Se ha hecho un ejercicio similar cuando se trata de la medición del IoT en sentido amplio. Es decir, los países de la OCDE han optado por separar las laptops y los teléfonos inteligentes (que ya forman parte de la medición de la OCDE) al crear indicadores para las subcategorías del IoT.

Las dos categorías de IoT propuestas son IoT de Área Amplia e IoT de Corto Alcance. La categoría de IoT de Área Amplia incluye dispositivos conectados mediante tecnología celular (NB-IoT o LTE-M) así como los conectados a través de redes de área amplia de baja potencia (por ejemplo, redes SigFox y LoRa), mientras que la categoría de IoT de corto alcance incluye dispositivos que utilizan espectro sin licencia con un alcance típico de hasta 100 metros. Además, el IoT de corto alcance se refiere también a los dispositivos que se conectan a través de redes de área local (o LAN) de línea fija y tecnologías de línea eléctrica. Cabe señalar que esta categoría también puede incluir algunos dispositivos M2M en edificios inteligentes, aplicaciones logísticas o industriales.

Dentro de la categoría de IoT de Área Amplia, se sugieren dos subcategorías: Dispositivos M2M masivos (p. ej., sensores para la agricultura o ciudades inteligentes) y aplicaciones críticas de IoT (p. ej., aplicaciones de cirugía a distancia, vehículos totalmente automatizados y otras aplicaciones de robótica industrial). La justificación para hacer la distinción entre estas dos últimas subcategorías de dispositivos conectados se basa en el hecho de que las aplicaciones críticas de IoT tendrán requisitos de red muy diferentes (es decir, alta fiabilidad y baja latencia), mientras que los sensores M2M masivos y dispersos pueden no ser tan sensibles a la latencia o a las altas velocidades de conectividad.

La principal ventaja de la taxonomía propuesta es la simplicidad para cubrir las aplicaciones de IoT en el espectro licenciado proporcionado por los operadores de redes celulares, así como los dispositivos o aplicaciones desplegados por los proveedores comerciales de LPWAN para poder recopilar los datos de estos en una etapa posterior con fines de medición. Sin embargo, una advertencia para esta definición y marco es que puede no proporcionar una visión integral de todo el mercado y algunas redes privadas pueden quedar fuera del alcance de la definición.

\subsection{Otras cuestiones relativas a la medición}

Este informe propone una taxonomía del IoT para efectos de medición. No obstante, siguen pendientes varios problemas de medición del IoT. Por ejemplo, ¿cómo afectará a los requisitos de infraestructura el aumento sustancial previsto de miles de millones de dispositivos conectados? Para responder a esta pregunta, el primer paso es un marco para evaluar el tamaño de las subcategorías del IoT, que era el objetivo del presente informe. La siguiente lista ilustra algunas preguntas generales que pueden inspirar futuros debates:

- Aunque el uso de datos del IoT (es decir, el tráfico de datos por dispositivo) ha sido relativamente modesto hasta la fecha, ¿cómo cambiará el perfil de uso de datos de estos dispositivos la próxima generación de aplicaciones, como los vehículos automatizados, los dispositivos industriales de IoT, etc.?

- Para las categorías de IoT que merecen especial atención dadas sus implicaciones para la infraestructura (por ejemplo, vehículos automatizados), ¿cuáles son las 
mejores maneras de recopilar la información que, en última instancia, sirve de base a las políticas?

- Dado que muchas aplicaciones de IoT utilizan redes privadas y, por lo tanto, podrían no aparecer en los datos relativos a la oferta (es decir, los datos de los proveedores de servicios de comunicación), ¿qué otras fuentes de recopilación de datos del IoT existen?

En el Anexo A figura una lista más extensa de las preguntas que pueden conducir a futuros debates. 


\section{Anexo A. Principales preguntas/cuestiones pendientes relativas} a la medición del IoT

La siguiente lista resume las cuestiones que se han examinado en el presente informe y tiene por objeto fomentar las futuras discusiones entre los delegados.

\section{Preguntas generales}

- Aunque el uso de datos de IoT ha sido relativamente modesto hasta la fecha, ¿cómo se espera que las aplicaciones de próxima generación, como los vehículos autónomos, los dispositivos industriales de IoT, etc., cambien el perfil de uso de datos de estos dispositivos en el futuro? ¿El aumento exponencial de datos esperado de miles de millones de dispositivos conectados afectará los requisitos de infraestructura?

- Si algunas categorías de IoT merecen especial atención dadas sus implicaciones para la infraestructura (p. ej., los vehículos autónomos), ¿cuáles son las mejores formas de recopilar la información que en última instancia resulta necesaria para informar a los responsables de las políticas? Por ejemplo, ¿cuál es la mejor fuente para recopilar datos sobre los robots conectados (p. ej., los fabricantes de robots o los proveedores de la conectividad)? Del mismo modo, ¿cuál es el mejor canal para recopilar información sobre vehículos autónomos (p. ej., los registros de vehículos que existen en todos los países de la OCDE o los fabricantes de esos vehículos o los que proporcionan conectividad)?

- Dado que muchas aplicaciones de IoT utilizan redes privadas y, por lo tanto, pueden no aparecer en los datos relativos a la oferta (es decir, los datos de los proveedores de servicios de comunicación), ¿qué otras fuentes de recopilación de datos para el IoT existen?

- Teniendo en cuenta que muchos consumidores pueden desconocer si sus dispositivos están conectados, ¿son las encuestas de hogares una fuente fiable para la contabilidad de los dispositivos de IoT? Por ejemplo, ¿saben los consumidores que su vehículo está conectado y, en caso afirmativo, cuántas tarjetas SIM tiene? ¿Es consciente el consumidor que responde a una encuesta de que su dispositivo portátil tiene una eSIM en lugar de una tarjeta SIM normal?

En cuanto a la medición de los flujos de tráfico de datos de IoT/M2M:

- ¿Se medirán estos flujos de datos a través de redes públicas (fijas y móviles)?

- ¿Es el número de tarjetas SIM IoT/M2M un factor (pero solo uno entre otros) para calcular los flujos de datos, al menos para las redes celulares?

- ¿Cómo se tratarán las tarjetas SIM que permiten tanto aplicaciones IoT/M2M como aplicaciones no IoT/M2M a través de una única tarjeta SIM (p. ej., las SIM de consumo sobre las que se controlan las aplicaciones domésticas inteligentes)?

○ ¿Cómo debe evitarse el doble cómputo de las SIM (para IoT y no IoT)?

Preguntas especificas sobre las métricas M2M

- ¿Son sus categorías de dispositivos que utilizan tarjetas SIM las que merecen ser incluidas en los datos recogidos por las autoridades, dadas las diferentes exigencias que imponen a las infraestructuras? 
- Cuando un dispositivo, como un teléfono inteligente, tiene conectividad multihoming (p. ej., puede utilizar redes LTE-M y LoRa), ¿existe una doble contabilidad de los dispositivos M2M que utilizan tarjetas SIM y son dispositivos conectados a LPWA?

- A medida que empiezan a surgir nuevas tecnologías, como la eSIM (embedded SIM) en dispositivos portátiles, ¿cómo deberíamos tener en cuenta estas nuevas tarjetas SIM en la medición M2M?

- ¿Deberían considerarse los dispositivos que utilizan eSIM, como Apple Watch 3 , como una conexión única o múltiple?

- Si tales dispositivos embebidos se registran como conexiones múltiples, ¿se contabilizará este dispositivo portátil como un dispositivo móvil o como una conexión M2M?

Preguntas sobre vehiculos totalmente automatizados

Los vehículos totalmente automatizados, en ocasiones denominados vehículos de autoconducción, sin conductor o autónomos, generan enormes volúmenes de datos, lo que plantea cuestiones como las siguientes:

- ¿Cuántos datos generará un vehículo totalmente automatizado?

- ¿Cuántos de estos datos se transferirán a través de las redes de comunicación?

- ¿A través de qué tipo de red de comunicación (por ejemplo, ITS, red celular, etc.) se transferirán estos datos y en qué volumen?

- ¿Qué datos o aplicaciones son más sensibles a los problemas de latencia? Es decir, ¿cuánto de esta transmisión de datos tiene que ser en tiempo real? ¿Cuánta de esta información es on-net y off-net?

- ¿A qué distancia deberán transmitirse los datos para la comunicación de vehículo a vehículo o de otro tipo?

- ¿Qué cantidad de datos será necesario cargar y descargar cuando un vehículo está detenido, por ejemplo, en un garaje con una conexión de banda ancha fija?

- ¿Diferentes niveles de automatización requerirán diferentes niveles de conectividad?

Otras cuestiones se refieren a las consecuencias para la infraestructura de los datos generados por los vehículos totalmente automatizados:

- ¿En qué tipo de red de comunicación (ITS, red celular, etc.) se basarán los vehículos conectados?

- ¿Los vehículos totalmente automatizados dependerán de la conectividad 5G?

- ¿Cuánta más fibra debería desplegarse?

- Cuestiones de normalización y plataformas de IoT

- Servicios en la nube y centros de datos

Cuestiones relacionadas con los resultados económicos del IoT en distintos sectores:

- Indicadores de resultados del IoT, en contraposición a los indicadores de proceso, por ejemplo:

\section{- Indicadores de ciudades inteligentes:}

- Número o porcentaje de vehículos de transporte público; 
- Número/Porcentaje de semáforos inteligentes instalados;

- Número/Porcentaje de ciudades vigiladas por cámaras.

- Indicadores de salud:

- Pacientes con enfermedades crónicas que utilizan aplicaciones de IoT;

- Ahorro por las aplicaciones de IoT en las unidades de salud;

- Aplicaciones sanitarias de IoT desarrolladas por país.

- Indicadores rurales:

- Porcentaje de zonas rurales que utilizan aplicaciones de IoT para la vigilancia climática;

- Número de equipos o herramientas rurales (p. ej., tractores) conectados;

- Control de enfermedades y saneamiento en explotaciones ganaderas;

- Innovación nacional en el sector agrícola.

$\circ$ Indicadores de la industria:

- Incremento de la productividad mediante aplicaciones de IoT sobre gestión de operaciones y mantenimiento preventivo. 


\section{Anexo B. Algunos ejemplos de otras definiciones de IoT}

La Unión Internacional de Telecomunicaciones (UIT) definió el IoT como:

- "La definición de IoT se refiere a "una infraestructura global para la sociedad de la información que habilita servicios avanzados mediante la interconexión (física $y$ virtual) de cosas basadas en tecnologías de la información y las comunicaciones interoperables ya existentes y en evolución", y en donde la "cosa" es "un objeto del mundo fisico (cosas físicas) o del mundo de la información (cosas virtuales) que puede identificarse e integrarse en redes de comunicación" (UIT, 2012 [71]).

En 2014, la Comisión Europea, en el contexto del estudio "Definition of a Research and Innovation Policy Leveraging Cloud Computing and IoT Combination" (Comisión Europea, $\left.2014_{[72]}\right)$ menciona lo siguiente:

- "El Internet de las Cosas permite que los objetos compartan información con otros objetos/miembros de la red, reconociendo eventos y cambios para reaccionar de forma autónoma y adecuada. Por lo tanto, el IoT se basa en la comunicación entre cosas (máquinas, edificios, coches, animales, etc.) que conduce a la acción y a la creación de valor."

La Oficina de Análisis Económico del Departamento de Comercio de los Estados Unidos (Bureau of Economic Analysis of the United States Department of Commerce), en una publicación de 2018 sobre la medición de la Economía Digital, definió IoT como:

- "Dispositivos habilitados para Internet como electrodomésticos, maquinaria y automóviles con hardware integrado que les permite comunicarse entre sí y conectarse a Internet" (Barefoot et al., 2018[3]).

La Comisión de Comercio Internacional de los Estados Unidos se refiere al IoT de la siguiente manera (Comisión de Comercio Internacional de los Estados Unidos, $2017_{[73]}$ ):

- Página 14: "El Internet de las Cosas se refiere a tecnologías digitales que incluyen dispositivos físicos y sensores conectados a Internet."

- Página 24: "El IoT se refiere a la creciente red de cosas conectadas que son capaces de recopilar e intercambiar datos a través de sensores y otros dispositivos."

El Departamento de Defensa de los Estados Unidos utiliza en sus documentos la definición de IoT del Institute of Electrical and Electronics Engineers (IEEE) (Departamento de Defensa de los Estados Unidos, 2016 $\left.{ }_{[74]}\right]$. La definición del IEE, que distingue el IoT en función de la complejidad del entorno en el que operan los dispositivos, es la siguiente (IEEE, 2015 $[75]$ ):

- Escenario de entorno pequeño: "Un Iot es una red que conecta "Cosas" identificables de forma única a Internet. Las "Cosas" tienen capacidades de detección/actuación y programabilidad potencial. A través de la explotación de la identificación y la detección únicas, es posible recopilar información sobre la "Cosa" y su estado se puede cambiar desde cualquier lugar, en cualquier momento y por cualquier cosa".

- Escenario de entorno grande: "Internet de las Cosas prevé una red compleja, adaptable y autoconfigurable que interconecta "Cosas" a Internet mediante protocolos de comunicación estándar. Las cosas interconectadas tienen representación fisica o virtual en el mundo digital, capacidad de detección/ 
actuación, característica de programabilidad y son identificables de forma única. La representación contiene información que incluye la identidad de la cosa, su estado, ubicación o cualquier otra información comercial, social o privada relevante. Las cosas ofrecen servicios, con o sin intervención humana, a través de la explotación de la identificación única, la captura y comunicación de datos y la capacidad de actuación. El servicio se explota mediante el uso de interfaces inteligentes y está disponible en cualquier lugar, en cualquier momento y para cualquier cosa que tenga en cuenta la seguridad".

En 2017, la Oficina de Rendición de Cuentas del Gobierno de los Estados Unidos (US GAO) definió el IoT como:

- "tecnologías y dispositivos que detectan información y la comunican a Internet $u$ otras redes y, en algunos casos, actúan con base en esa información. Estos dispositivos "inteligentes" se utilizan cada vez con mayor frecuencia para comunicar y procesar cantidades y tipos de información que nunca antes se habian capturado y responden automáticamente para mejorar los procesos industriales, los servicios públicos y el bienestar de los consumidores individuales" (United States Government Accountability Office, 2017 [76]).

Además, la GAO de los Estados Unidos ha separado el IoT en diez ámbitos (o mercados/ segmentos):

- portátiles (wearables)

- casas y edificios inteligentes

- vehículos

- manufactura

- cadena de suministro

- agricultura

- servicios de salud

- energía

- medio ambiente

- y comunidades inteligentes.

AIG y Consumer Electronics Association (Estados Unidos):

- El "Internet de las Cosas" no depende principalmente de las computadoras para existir. Más bien, cada cosa, incluso el cuerpo humano, puede pasar a formar parte del IoT si está equipada con ciertas partes electrónicas. Esas partes ciertamente varian dependiendo de la función que la cosa debe realizar, pero se dividen en dos grandes categorías: 1) la cosa debe ser capaz de capturar datos, generalmente a través de sensores; y 2) la cosa debe ser capaz de transmitir esos datos a cualquier otro lugar a través de Internet. Un sensor y una conexión, por lo tanto, son las dos "partes" electrónicas principales de una cosa IoT" (AIG y Consumer Electronics Association, 2016 [77] $)$.

McKinsey en un informe (2017) definió el IoT como:

- "la red de dispositivos "inteligentes" conectados que se comunican sin problemas a través de Internet" (McKinsey, $\left.2017_{[25]}\right)$. 
En 2015, el Foro Económico Mundial definió IoT como:

- "Una red de objetos físicos que contienen tecnología incorporada para comunicarse y sentir o interactuar con sus estados internos o con el entorno externo" (WEF, $\left.2015_{[78]}\right)$. 


\section{Anexo C. Preguntas detalladas relacionadas con el IoT en las encuestas de uso de las TIC (hogares y particulares, empresas)}

Tabla A C.1. Preguntas relacionadas con el IoT en los cuestionarios de la encuesta sobre el uso de las TIC

Ejemplos recientes seleccionados de encuestas de hogares y particulares

\begin{tabular}{|c|c|c|c|c|c|c|c|}
\hline Artículos & Australia $^{1}$ & Canadá2 & Eurostat $^{3}$ & Japón ${ }^{4}$ & Corea $^{5}$ & México ${ }^{6}$ & $\begin{array}{l}\text { Estados } \\
\text { Unidos }^{7}\end{array}$ \\
\hline \multicolumn{8}{|l|}{ Electrodomésticos } \\
\hline $\begin{array}{l}\text { Interacción a través de Internet con equipos o aparatos domésticos } \\
\text { (como termostato, iluminación, aspiradora o sistema de seguridad) }\end{array}$ & & & 2019 & & & & \\
\hline $\begin{array}{l}\text { ¿Qué pasa con la interacción con los equipos o electrodomésticos } \\
\text { conectados a Internet, como un termostato, un foco o un sistema } \\
\text { de seguridad conectados? (Si es necesario) ¿Utiliza Internet para } \\
\text { interactuar con equipos o electrodomésticos? }\end{array}$ & & & & & & & 2017 \\
\hline $\begin{array}{l}\text { ¿Actualmente utiliza alguno de los siguientes electrodomésticos } \\
\text { inteligentes conectados a Internet en su residencia principal? }\end{array}$ & & 2018 & & & & & \\
\hline Electrodomésticos que pueden conectarse a Internet & & & & 2016 & & & \\
\hline $\begin{array}{l}\text { Calentador de cocina, refrigerador, etc. Aparatos inteligentes que } \\
\text { pueden conectarse a Internet }\end{array}$ & & & & 2015 & & & \\
\hline Televisor inteligente en casa (artículo separado) & & & $\begin{array}{l}2014, \\
2016\end{array}$ & & 2017 & 2016 & \\
\hline $\begin{array}{l}\text { ¿Cuántos televisores con conexión a Internet utiliza usted o su hogar } \\
\text { para acceder a Internet en casa? }\end{array}$ & $\begin{array}{l}2014-2015 \\
2016-2017\end{array}$ & & & & & & \\
\hline $\begin{array}{l}\text { TV Box: ¿Utiliza [usted/alguien en este hogar] un televisor inteligente, } \\
\text { un juego o sistema de video u otro dispositivo que se conecte a } \\
\text { Internet y juegue a través de un televisor? Los ejemplos incluyen una } \\
\text { Xbox, Apple TV, PlayStation, Roku o un reproductor de Blu-Ray que } \\
\text { pueda acceder a Internet. }\end{array}$ & & & & & & & 2017 \\
\hline
\end{tabular}

\section{Dispositivos portátiles}

¿Utiliza [usted/alguien en este hogar] un dispositivo portátil que esté conectado a Internet, como un reloj Inteligente o una banda de

fitness? Algunos ejemplos incluyen un reloj Apple Watch, un Fitbit 0 una banda de Microsoft. (Si la respuesta es sí y es un hogar de varias personas) ¿Quién?

¿Qué tipo de dispositivos portátiles tiene ahora? De tipo banda (Fitbit); tipo reloj; tipo de protección/monitoreo para bebés y ancianos; tipo ropa; tipo accesorios; tipo gafas;

Por favor elija todas las funciones de un dispositivo portátil que esté utilizando: hacer/recibir llamadas telefónicas o enviar/recibir mensajes conectándose con un teléfono inteligente; buscar información a través de Internet; atender la salud midiendo parámetros como la frecuencia cardíaca y la quema de calorías; registrar la distancia y el trayecto del viaje; guiar la dirección; experimentar la realidad virtual y la realidad aumentada; realizar seguimiento de la ubicación y proteger a los niños pequeños y a los ancianos. 
En un dispositivo portátil, ¿qué función es la que más se espera? 2016 Por favor, elija uno. Vea las funciones anteriores + control de electrodomésticos como un televisor inteligente, etc.; control de aire acondicionado y calefacción.

\begin{tabular}{|c|c|c|c|c|c|}
\hline Terminales portátiles (como gafas) & \multicolumn{5}{|c|}{2016} \\
\hline \multicolumn{6}{|l|}{ Salud } \\
\hline $\begin{array}{l}\text { ¿Utiliza algún servicio electrónico de monitoreo de la salud que } \\
\text { recopile y envíe datos a su médico o proveedor de atención médica } \\
\text { a través de Internet? Los ejemplos incluyen dispositivos conectados } \\
\text { que monitorean las estadísticas vitales, los niveles de glucosa en la } \\
\text { sangre o la presión arterial. }\end{array}$ & & & & & 2017 \\
\hline $\begin{array}{l}\text { Durante los últimos } 12 \text { meses, ¿cuál de las siguientes actividades la } \\
\text { ha realizado con su teléfono inteligente? } \\
{[\ldots]} \\
\text { Seguimiento de fitness o salud } \\
{[\ldots]}\end{array}$ & 2018 & & & & \\
\hline \multicolumn{6}{|l|}{ Nube } \\
\hline $\begin{array}{l}\text { Usar Internet como espacio de almacenamiento para guardar } \\
\text { archivos con fines privados }\end{array}$ & $\begin{array}{l}2014- \\
2017\end{array}$ & $\begin{array}{l}2015- \\
2016\end{array}$ & $\begin{array}{l}2015- \\
2016\end{array}$ & 2016 & \\
\hline
\end{tabular}

Nota: (1) Oficina Australiana de Estadística, Encuesta de Hogares de Propósitos Múltiples, MPHS 2016/17; (2) Encuesta Canadiense sobre el Uso de Internet 2018, borrador; (3) Eurostat, Encuesta Comunitaria sobre el uso de las TIC en los hogares y por parte de los particulares; (4) Encuesta sobre Tendencias del Uso de las Comunicaciones, Ministerio de Asuntos Internos y Comunicaciones, Japón; (5) Encuesta sobre el uso de Internet, KISA; (6) INEGI, Encuesta Nacional sobre Disponibilidad y Uso de TIC en Hogares, ENDUTIH 2016; (7) Noviembre 2017 Suplemento de uso de computadoras e Internet de CPS, Oficina del Censo de EE. UU.; (8). Refiérase a la propiedad de la siguiente lista detallada: Asistentes virtuales (p. ej., Google Home, Amazon Echo); cámaras de video (p. ej., cámaras de seguridad, Nest Cam, monitores de bebés); cerraduras de puertas o ventanas; termostatos (p. ej., Ecobee, Nest, Sensi); enchufes o luces; electrodomésticos grandes (p. ej., refrigerador, estufa, lavavajillas); televisores inteligentes; otros dispositivos inteligentes para el hogar (p. ej., puerta automática de garaje, aspiradora).

Fuente: Elaboración propia, recopilada a partir de Eurostat y de fuentes nacionales.

Tabla A C.2. Preguntas relativas al IoT en los cuestionarios de las encuestas sobre uso de las TIC

Algunos ejemplos recientes de encuestas a empresas

\begin{tabular}{|c|c|c|c|c|c|}
\hline Artículos & Australia $^{1}$ & Canadá2 & Eurostat $^{3}$ & Japón 4 & Corea $^{5}$ \\
\hline \multicolumn{6}{|l|}{ RFID } \\
\hline $\begin{array}{l}\text { El uso de tecnologías de identificación por radio frecuencia (RFID): } \\
\text { se refiere a un método de identificación automatizada para almacenar y } \\
\text { obtener datos de forma remota mediante etiquetas o transpondedores } \\
\text { RFID } \\
\text { incluye el uso del estándar de conectividad de Comunicación de Campo } \\
\text { Cercano (NFC, por sus siglas en inglés) }\end{array}$ & & & $\begin{array}{l}2017 \\
2014 \\
2011\end{array}$ & & \\
\hline \multicolumn{6}{|l|}{$\begin{array}{l}\text { Una etiqueta RFID es un dispositivo que se puede aplicar o incorporar a un } \\
\text { producto u objeto y que transmite datos a través de ondas de radio. NFC permite } \\
\text { la comunicación entre dispositivos a corta distancia (aprox.10 cm o menos). } \\
\text { [por favor, incluya ejemplos nacionales]. }\end{array}$} \\
\hline \multicolumn{6}{|l|}{$\begin{array}{l}\text { ¿Su empresa utiliza instrumentos de identificación por radiofrecuencia para los } \\
\text { siguientes fines? (Si /No) }\end{array}$} \\
\hline \multicolumn{6}{|l|}{ - identificación de personas o control de acceso } \\
\hline \multicolumn{6}{|l|}{$\begin{array}{l}\text { Como parte del proceso de producción y prestación de servicios (p. ej., supervisión } \\
\text { y control de la producción industrial, seguimiento de la cadena de suministro y de } \\
\text { inventarios; gestión de servicios, mantenimiento o activos, etc.). }\end{array}$} \\
\hline $\begin{array}{l}\text { Para la identificación de productos posterior al proceso de producción } \\
\text { (p. ej., control de robos, falsificación, información sobre alérgenos, etc.). }\end{array}$ & & & & & \\
\hline
\end{tabular}




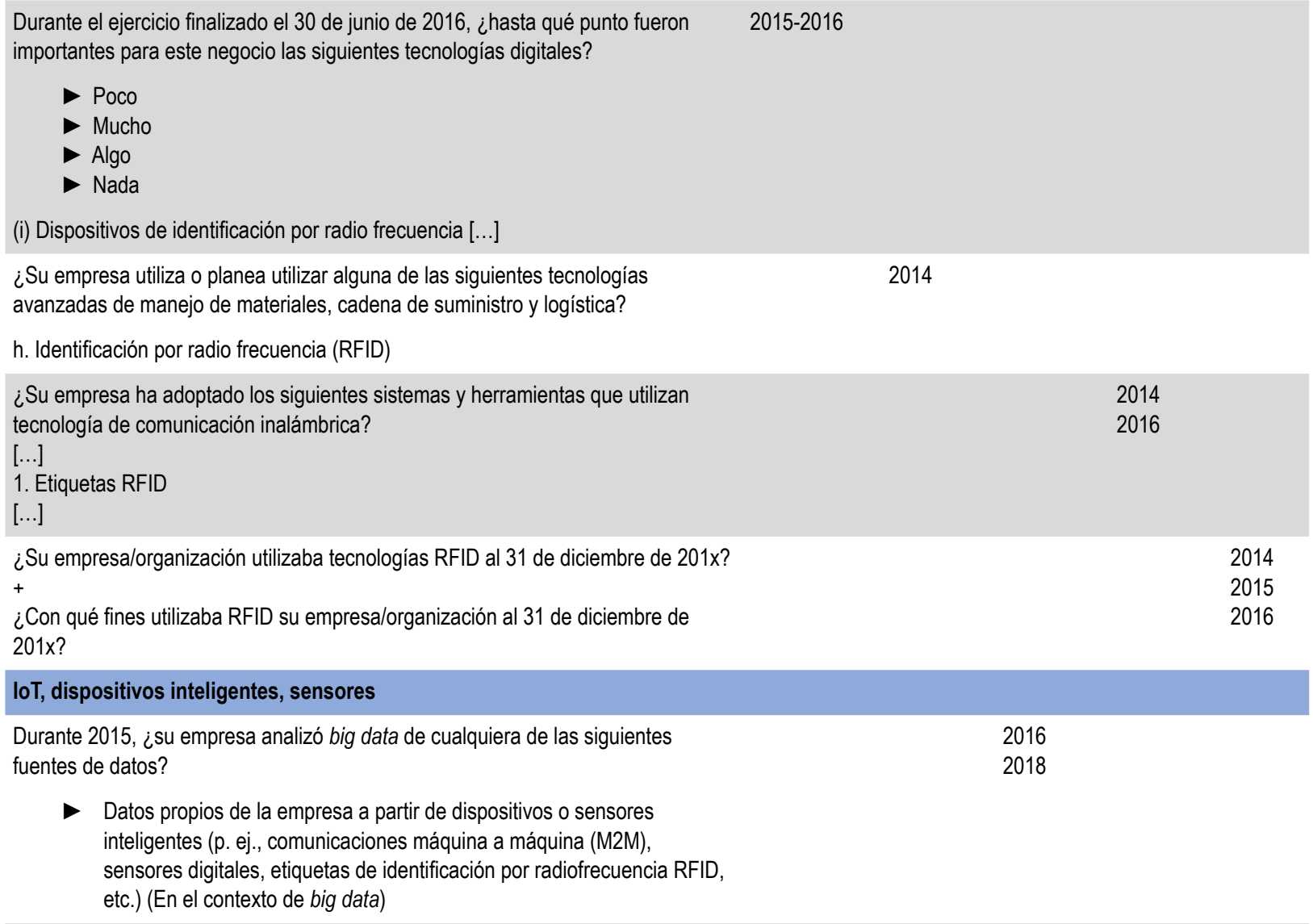

Durante el ejercicio finalizado el 30 de junio de 2016, ¿hasta qué punto fueron 2015-2016 importantes para esta empresa las siguientes tecnologías digitales?
Poco
- Mucho
- Algo
- Nada

(h) Internet de las cosas (p. ej., medidores inteligentes, dispositivos o recursos fisicos conectados digitalmente en red [...]

¿Su empresa utiliza o planea utilizar alguna de las siguientes Tecnologías de 2014

Diseño Avanzado y Control de la Información? [...]

h. Comunicaciones inalámbricas para la producción

i. Red e integración de sensores

j. Fabricación integrada por computadora (CIM, por sus siglas en inglés)

k. Sistemas automatizados de inspección ( $p$. ej., basados en visión, láser, rayos $X$ cámara de alta definición (HD) o basados en sensores) [...]

¿Su empresa utiliza o planea utilizar alguna de las siguientes tecnologías geomáticas o geoespaciales?

a. Sistemas de información geográfica (SIG, por sus siglas en inglés)

b. Sistema de posicionamiento global (GPS, por sus siglas en inglés) (excluido el

uso personal)

c. Teledetección (RS, por sus siglas en inglés)

d. Dispositivo móvil con capacidad de geolocalización

e. Sensores web o inalámbricos

f. Infraestructura de datos espaciales [...] 
Indique si su empresa utiliza estas aplicaciones de Nanotecnología.

Indique si su empresa desarrolla o produce alguna de estas aplicaciones de

Nanotecnología. [...]

[]: Nanomateriales (incluye nanocompuestos orgánicos e inorgánicos, nanopolvos, nanopartículas, nanocapas, nanotubos de carbono).

[...]: Nanodispositivos, incluidos los sensores, los sistemas nanoelectromecánicos (NEMS) y los sistemas microelectromecánicos habilitados para nanomateriales (MEMS).

[...]: Nanoelectrónica, incluyendo fotónica, dispositivos nanoópticos, sensores nanoópticos o emisores de luz nanoópticos [...]

¿Su empresa ha adoptado los siguientes sistemas y herramientas que utilizan tecnología de comunicación inalámbrica? [...]

¿Su empresa/organización utilizaba dispositivos y servicios de loT al 31 de

¿Con qué fines utilizaba su empresa/organización dispositivos y servicios de loT al

31 de diciembre de 2014 ?

1) Mejorar la productividad de los empleados

2) Disminución de los costos y de la mano de obra y el mantenimiento

3) Reducir el coste de funcionamiento de la marca de la empresa/organización

4) Fortalecer el ambiente de trabajo y la seguridad de la seguridad de los datos

5) Expansión de nuevos productos y nuevos servicios

6) Expansión del apoyo a nivel nacional

7) Otro (por favor especifique):

¿Con qué fines utilizaba su empresa/organización dispositivos y servicios de loT al

31 de diciembre de 2015 ?

¿Qué piensa de la eficacia mediante el uso (o el uso en el futuro) de equipos y

servicios de loT en su empresa (escala de eficacia del uso que va desde "ningún efecto" hasta "muy eficaz" para los puntos siguientes)?

1) Reducción de costos

2) Aumento de la eficiencia

3) Aumento de la productividad e intercambio de información

4) Refuerzo de la seguridad de la información

5) Mejora del ambiente de trabajo

6) Expansión de nuevas fuentes de beneficios y creación de productos (servicios)

7) Otro (especifique):

¿Por cuál de los siguientes motivos su empresa/organización no utilizaba los servicios de loT al 31 de diciembre de 2014? Marque todas las que correspondan.

1) Preocupaciones de la seguridad

2) Incertidumbre sobre el modelo de resultados

3) Falta de maquinaria básica para el uso de los dispositivos y servicios de loT.

(Dispositivos conectados. sellSOfS embebidos, etc.)

4) Falta de capacidad de mano de obra para el uso de dispositivos y servicios de loT.

5) Falta de compatibilidad de los productos y servicios existentes

6) Poca relevancia con su negocio/organización

7) Otro (Por favor especifique): 
¿Por cuál de los siguientes motivos su empresa/organización no utilizaba los

servicios de loT al 31 de diciembre de 2015? Marque todas las que correspondan.

1) Carga de los gastos económicos

2) Consideración con la seguridad

3) Complejidad del servicio (tecnología)

4) Falta de capacidad del personal de operación

5) Insuficiente compatibilidad

6) Insuficiente equipamiento básico

7) Mercado inmaduro del loT

8) Varios (sírvase especificar):

¿Su empresa/organización tiene previsto utilizar dispositivos y servicios de loT?

\section{Servicios en la nube}

Nota: (1). ABS, Business Characteristics Survey 2015-16; (2) Statistics Canada, Advanced Technology Survey 2014, http://www23.statcan.gc.ca/imdb/p3Instr.pl?Function=assembleInstr\&a=1\&lang=en\&Item Id=184557; (3) Eurostat, Encuesta Comunitaria sobre el uso de las TIC y el comercio electrónico en empresas; (4) Encuesta sobre Tendencias de Uso en la Comunicación, Ministerio de Asuntos Internos y Comunicaciones de Japón; (5) Encuesta sobre la Sociedad de la Información, Ministerio de Ciencias, Agencia de la Sociedad de la Información, TIC y Planeación de Corea.

Fuente: Elaboración propia, recopilada a partir de Eurostat y de fuentes nacionales. 


\section{Referencias}

3GLTEinfo (2015), 5G the Real Answer for Internet Of Things (IoT) Complexity - Why is LTE not Enough? | 3GLTEInfo, 10 March 2015, http://www.3glteinfo.com/5g-for-internet-ofthings/ (consultado el 05 de octubre de 2017).

5G Americas (2017), LTE to 5G: Cellular and Broadband Innovation, http://www.5gamericas.org/ files/6415/0282/1551/2017 5G Americas Rysavy LTE 5G Innovation Final for Upload.pdf (consultado el 05 de octubre de 2017).

AIG and Consumer Electronics Association (2016), "The Internet of Things: Evolution or Revolution? Part 1 in a Series", Chief Economist, https:/www.aig.com/content/dam/aig/ america-canada/us/documents/insights/aig-whitepaper-iot-english-digital-brochure.pdf (consultado el 09 de abril de 2018).

Alex Wright (2017), Mapping the Internet of Things, http://dx.doi.org/10.1145/3014392.

ARCEP (2016), Livre blanc - Préparer la révolution de l'Internet des objets - ARCEP |IoT, Autorité de Régulation des Communications Électroniques et des Postes, París, https://iot. arcep.fr/2016/11/07/livre-blanc-revolution-iot-nov2016/ (consultado el 10 de abril de 2018).

AT\&T (2017), AT\&amp;T INC. 2017 Annual Report, https://investors.att.com/ /media/Files/A/ ATT-IR/financial-reports/annualreports/2017/complete-2017-annual-report.pdf (consultado el 22 de agosto de 2018).

Automobile Mag (2017), The Big Data Boom | Automobile Magazine, 10 de octubre de 2017, http://www.automobilemag.com/news/the-big-data-boom/ (consultado el 11 de octubre de 2017).

Automotive News (2017), Fiat Chrysler joins autonomous driving platform from BMW / Intel / Mobileye | EETE Automotive, http://www.eenewsautomotive.com/news/fiat-chrysler-joinsautonomous-driving-platformbmw-intel-mobileye (consultado el 03 de octubre de 2017).

Barboutov, K. et al. (2017), Ericsson Mobility Report 2017, Ericsson, https://www.ericsson.com/assets/local/mobility-report/documents/2017/ericsson-mobilityreportjune-2017.pdf (consultado el 21 de septiembre de 2017).

Barefoot, K. et al. (2018), "Working Paper: Defining and Measuring the Digital Economy", https:/www.bea.gov/digital-economy/ pdf/defining-and-measuring-the-digital-economy.pdf (consultado el 10 de abril de 2018).

BEREC (2016), BEREC Report on Enabling the Internet of Things, http://berec.europa.eu/eng/document_register/subject matter/berec/reports/5755-berec-reporton-enabling-the-internet-of-things) (consultado el 09 de abril de 2018).

BMW Blog (2017), Level 5 Autonomous Technology Not Possible Yet, Claims BMW, 5 de octubre de 2017, http://www.bmwblog.com/2017/10/05/level-5-autonomous-technology-not-possible-yet-claimsbmw/ (consultado el 06 de octubre de 2017).

BNetzA (2017), "Numbering plan for mobile numbers", Official Gazette No, Vol. 14/16, https://www.bundesnetzagentur.de/SharedDocs/Downloads/EN/Areas/Telecommunications/ Companies/NumberManagement/MobileServices/Mobileservicees Numbering\%20Plan 2017. pdf? blob=publicationFile \&v=2 (consultado el 10 de abril de 2018). 
BNetzA (2016), "Extra-territorial use of foreign International Mobile Subscriber Identities (IMSIs) in the Federal Republic of Germany for machine-to-machine (M2M) communications" 11, https://www.bundesnetzagentur.de/SharedDocs/Downloads/EN/Areas/Telecommunications/ Companies/NumberManagement/TechnicalNumbers/IMSI Extraterritorial.pdf? $\underline{\text { blob }=\text { publicationFile \&v }=2}$ (consultado el 10 de abril de 2018).

BNetzA (2016), "Numbering plan for International Mobile Subscriber Identities" 11, https://www.bundesnetzagentur.de/SharedDocs/Downloads/EN/Areas/Telecommunications/ Companies/NumberManagement/TechnicalNumbers/IMSI_NP.pdf? blob=publicationFile \&v=2 (consultado el 10 de abril de 2018).

BNetzA (2011), Bundesnetzagentur Annual Report 2011, https://www.bundesnetzagentur.de/SharedDocs/Downloads/EN/BNetzA/PressSection/ ReportsPublications/2012/AnnualReport2011pdf.pdf? blob=publicationFile (consultado el 10 de abril de 2018).

BnetzA (2017), "Bundesnetzagentur Annual Report 2016 Markets in the digital revolution", https://www.bundesnetzagentur.de/SharedDocs/Downloads/EN/

BNetzA/PressSection/ReportsPublications/2017/AnnualReport2016. pdf;jsessionid=71B763A1F8F7D99BBBCD9D876BA823FE? blob=publicationFile \&v=2 (consultado el 10 de abril de 2018).

CarAdvice Australia (2017), BMW: Fully-autonomous driving technology not yet available, http:// www.caradvice.com.au/583583/bmw-fully-autonomous-driving-technology-not-yetavailable/ (consultado el 06 de octubre de 2017).

CCFA (2017), L'industrie automobile française, https://ccfa.fr/wpcontent/uploads/2018/01/Analyse_Statistiques_2017_FR.pdf (consultado el 10 de abril de 2018).

CEPT (2010), ECC REPORT 153 NUMBERING AND ADDRESSING IN MACHINETO-MACHINE (M2M) COMMUNICATIONS, European Conference of Postal and Telecommunications Administrations (CEPT), Luxemburgo, http://www.erodocdb.dk/Docs/doc98/official/pdf/ECCREP153.PDF (consultado el 09 de abril de 2018).

Chevrolet (2016), Chevrolet Lowers 4 G LTE Data Pricing Up to 50 Percent, http://media.chevrolet.com/media/us/en/chevrolet/home.detail.html/content/Pages/news/us/ en/2016/jun/0629-onstarData.html..html (consultado el 12 de octubre de 2017).

Chevrolet Media (2017), Chevrolet Offers More Options to Add Unlimited Data, http://media.chevrolet.com/media/us/en/chevrolet/news.detail.html/content/Pages/news/us/ en/2017/may/0511-data.html (consultado el 21 de septiembre de 2017).

Chevrolet Media (2017), Chevrolet Owners Consumed 4.22 Petabytes of Data in 2016, http://media.gm.com/media/us/en/chevrolet/news.detail.html/content/Pages/news/us/en/2017/ feb/0203-onstar.html (consultado el 21 de septiembre de 2017).

China Mobile (2017), China Mobile Corp. Limited Annual Report 2017, https://www.chinamobileltd.com/en/ir/reports/ar2017/2017_20f.pdf (consultado el 22 de agosto de 2018).

China Telecom (2017), China Telecom Corp. Limited Annual Report 2017, https://www.chinatelecom-h.com/en/ir/report/annual2017.pdf (consultado el 22 de agosto de 2018). 
CISCO (2017), Cisco Visual Networking Index: Global Mobile Data Traffic Forecast Update 2016-2021,

https://www.cisco.com/c/en/us/solutions/collateral/service-provider/visualnetworking-indexvni/mobile-white-paper-c11-520862.pdf (consultado el 22 de septiembre de 2017).

CISCO (2017), Cisco Visual Networking Index: Global Mobile Data Traffic Forecast Update, 2016-2021 White Paper-Cisco, https://www.cisco.com/c/en/us/solutions/collateral/serviceprovider/visual-networking-indexvni/mobile-white-paper-c11-520862.html (consultado el 22 de septiembre de 2017).

CISCO VNI (2017), VNI Mobile Forecast Highlights for Sweden, 2016-2021, https://www.cisco.com/assets/sol/sp/vni/forecast_highlights_mobile/\# Country (consultado el 10 de octubre de 2017).

CNBC Autos (2017), An 'ocean of auto big data' is coming, says Barclays, CNBC Autos, https://www.cnbc.com/2017/04/26/an-ocean-of-auto-big-data-is-coming-says-barclays.html (consultado el 11 de octubre de 2017).

DataCenter Knowledge (2017), Ford Plans \$200M Data Center in Anticipation of Connected Car Data Explosion | Data Center Knowledge, 29 de marzo de 2017, http://www.datacenterknowledge.com/archives/2017/03/29/ford-plans-200m-data-centerinanticipation-of-connected-car-data-explosion (consultado el 06 de octubre de 2017).

Deloitte US (2017), Deep fiber: The next internet battleground, https://www2.deloitte.com/us/en/pages/consulting/articles/communications-infrastructureupgradedeep-fiber-imperative.html\# (consultado el 05 de octubre de 2017).

Ericsson (2017), Ericsson White Paper: 5 G Systems - enabling digital transformation, https:// www.ericsson.com/assets/local/publications/white-papers/wp-5g-systems.pdf (consultado el 06 de octubre de 2017).

European Commission (2017), Connectivity Reports: Digital Scoreboard | Digital Single Market, https://ec.europa.eu/digital-single-market/en/connectivity (consultado el 14 de noviembre de 2017).

European Commission (2014), Definition of a Research and Innovation Policy Leveraging Cloud Computing and IoT Combination | Digital Single Market, https://ec.europa.eu/digital-singlemarket/news/definition-research-and-innovation-policyleveraging-cloud-computing-and-iotcombination (consultado el 09 de abril de 2018).

Fierce Wireless and TelecomAsia (2016), Will $5 G$ be the Answer to the Internet of Things?, 2016, https://pages.questexweb.com/CES FierceWireless_Breakfast 2016.html?ref=el (consultado el 05 de octubre de 2017).

Fondation MAIF (2018), Labellisation de confiance des objets connectés, https://www.fondation-maif.fr/pageArticle.php?rub=1\&id=407 (consultado el 10 de abril de 2018).

Google Cloud (2017), Cloud IoT Core | Google Cloud Platform, https://cloud.google.com/iotcore/ (consultado el 04 de octubre de 2017).

Google Cloud Platform (2017), Designing a Connected Vehicle Platform on Cloud IoT Core | Solutions | Google Cloud Platform, https://cloud.google.com/solutions/designingconnected-vehicle-platform (consultado el 22 de septiembre de 2017). 
GSMA (2017), Mobile IoT - Internet of Things,

https://www.gsma.com/iot/mobile-iot-executivesummary/ (consultado el 05 de octubre de 2017).

IBM (2017), Connected Cars with IBM Watson IoT, https://www.ibm.com/internet-of-things/iotsolutions/iot-automotive/connected-cars/ (consultado el 03 de octubre de 2017).

IEEE (2015), Toward a Definition of Internet of Things (IoT), https://iot.ieee.org/images/files/pdf/IEEE IoT Towards_Definition_Internet_of Things Revision1_27MAY15.pdf (consultado el 09 de abril de 2018).

Intel (2016), Data is the New Oil in the Future of Automated Driving | Intel Newsroom, 15 de noviembre de 2016, https://newsroom.intel.com/editorials/krzanich-the-future-of-automateddriving/ (consultado el 05 de octubre de 2017).

IoTUK Nation (2017), IoTUK Nation Database: IoT Sector Mapping, https://odileeds.org/projects/iot/ (consultado el 22 de septiembre de 2017).

IPO (2014), Eight Great Technologies - A summary of the series of patent landscape reports, http://www.ipo.gov.uk/informatics (consultado el 21 de septiembre de 2017).

IPO (2014), Eight Great Technologies: The Internet of Things, http://www.ipo.gov.uk/informatics (consultado el 21 de septiembre de 2017).

IPUMS CPS (2018), Current Population Survey, https://cps.ipums.org/cps/compint sample_notes.shtml (consultado el 10 de abril de 2018).

ISO (2018), ISO/IEC JTC 1/SC 41 - Internet of Things and related technologies, https://www.iso.org/committee/6483279/x/catalogue/p/0/u/1/w/0/d/0 (consultado el 09 de abril de 2018).

ITU (2015), Recommendation ITU-R M.2083-0 (09/2015), 'IMT Vision - Framework and overall objectives of the future development of IMT for 2020 and beyond', https://www.itu.int/dms_pubrec/itu-r/rec/m/R-REC-M.2083-0-201509-I!!PDF-E.pdf.

ITU (2012), Overview of the Internet of things, https://www.itu.int/rec/T-REC-Y.2060-201206-I (consultado el 09 de abril de 2018).

Le Monde (2018), “Auto, maison, santé: les assureurs font entrer les objets connectés dans les foyers", http://www.lemonde.fr/entreprises/article/2018/02/12/auto-maison-sante-lesassureurs-fontentrer-les-objets-connectes-dans-lesfoyers 5255295 1656994.html\#0wsY9duUA2qw7G74.99 (consultado el 10 de abril de 2018).

McKinsey (2017), The future of connectivity: Enabling the Internet of Things $\mid$ McKinsey \&amp; Company, https://www.mckinsey.com/global-themes/internet-of-things/our-insights/thefutureof-connectivity-enabling-the-internet-of-things (consultado el 09 de abril de 2018).

McKinsey Global Institute (2015), Unlocking the potential of the Internet of Things $\mid$ McKinsey \&amp; Company, http://www.mckinsey.com/business-functions/digital-mckinsey/ourinsights/ the-internet-of-things-the-value-of-digitizing-the-physical-world (consultado el 21 de septiembre de 2017).

MediaTek Blog (2017), MediaTek|Why NB-IoT is the best answer to the 5 G LPWA future |..., https://www.mediatek.com/blog/why-nb-iot-is-the-best-answer-to-the-5g-lpwa-future (consultado el 05 de octubre de 2017). 
MIC (2017), Information and Communications in Japan 2017,

http://www.soumu.go.jp/johotsusintokei/whitepaper/eng/WP2017/2017-index.html (consultado el 10 de abril de 2018).

Mobile World Live (2018), EU countries strike cross-border $5 G$ agreements - Mobile World Live, https://www.mobileworldlive.com/featured-content/home-banner/eu-countries-strikecross-border -5gagreements/?ID=003w000001z7mMOAAY\&utm_source=sfmc\&utm_medium=email\&utm campaign=MWL 20180410 (consultado el 11 de abril de 2018).

Nordic Business Insider (2017), Volvo just launched the world's most ambitious autonomous driving trial in Gothenburg - Business Insider Nordic,

http://nordic.businessinsider.com/volvo-just-launched-the-worlds-most-ambitiousautonomousdriving-trial-in-gothenburg-2017-1 (consultado el 04 December 2017).

NPR (2018), National Public Media The Smart Audio Report from NPR and Edison Research, https://www.nationalpublicmedia.com/smart-audio-report/ (consultado el 10 de abril de 2018).

NTIA (2017), Noviembre de 2017 CPS Computer and Internet Use Supplement, the National Telecommunications and Information Administration (NTIA)., https://www.ntia.doc.gov/files/ntia/publications/november_2017_cps_supplement_draft_for public comment.pdf (consultado el 10 de abril de 2018).

NYT (2017), BMW and Volkswagen Try to Beat Apple and Google at Their Own Game - The New York Times, 22 de junio de 2017, https:/www.nytimes.com/2017/06/22/automobiles/wheels/driverless-cars-big-datavolkswagenbmw.html (consultado el 03 de octubre de 2017).

NYT (2017), The Race for Self-Driving Cars - The New York Times, 6 de junio de 2017, https:// www.nytimes.com/interactive/2016/12/14/technology/how-self-driving-carswork.html (consultado el 03 de octubre de 2017).

OECD (2017), Industrial Robotics and the global organisation of production, OCDE, París, http://dx.doi.org/DSTI/CIIE(2017)14.

OECD (2017), The Next Production Revolution, OECD Publishing, París, http://dx.doi.org/10.1787/9789264271036-en.

OECD (2017), The Next Production Revolution: Implications for Governments and Business, OECD Publishing, París, http://dx.doi.org/10.1787/9789264271036-en.

OECD (2016), Unclassified DSTI/ICCP/CISP(2015)3/FINAL Working Party on Communication Infrastructures and Services Policy THE INTERNET OF THINGS: SEIZING THE BENEFITS AND ADDRESSING THE CHALLENGES Background report for Ministerial Panel 2.2, http:// www.oecd.org/officialdocuments/publicdisplaydocumentpdf/?cote=DSTI/ICCP/CISP(2015)3/ FINAL\&docLanguage $=$ En (consultado el 13 de octubre de 2017).

OECD (2015), OECD Digital Economy Outlook 2015, OECD Publishing, París, http://dx.doi.org/10.1787/9789264232440-en.

OECD (2015), OECD Digital Economy Outlook 2015, OECD Publishing, París, http://dx.doi.org/10.1787/9789264232440-en.

OECD (2015), OECD Science, Technology and Industry Scoreboard 2015: Innovation for growth and society, OECD Publishing, París, http://dx.doi.org/10.1787/sti scoreboard-2015-en.

OECD (2012), Machine-To-Machine Communications: Connecting Billions of Devices, http:// www.oecd.org/officialdocuments/publicdisplaydocumentpdf/?cote=DSTI/ICCP/CISP(2011)4/ $\underline{\text { FINAL\&docLanguage }=E n}$ (consultado el 19 de septiembre de 2017). 
OECD/ITF (2015), Automated and Autonomous Driving: Regulation Under Uncertainty, https://www.itf-oecd.org/sites/default/files/docs/15cpb autonomousdriving.pdf (consultado el 21 de septiembre de 2017).

Ofcom (2017), The Communications Market Report 2017: UK, https://www.ofcom.org.uk/_data/assets/pdf file/0017/105074/cmr-2017-uk.pdf (consultado el 19 de septiembre de 2017).

Popular Science (2017), IBM could have a solution to one of self-driving cars'biggest problems | Popular Science, 31 de marzo de 2017, https://www.popsci.com/ibm-self-driving-car-patentprevent-crashes (consultado el 03 de octubre de 2017).

Rivers, N. (2018), "Leveraging the Smart Grid: The Effect of Real-Time Information on Consumer Decisions", OECD Environment Working Papers, No. 127, OECD Publishing, París, http://dx.doi.org/10.1787/6ad4d5e3-en.

SAE (2014), SAE International J3016 Standard, https://www.sae.org/misc/pdfs/automated_driving.pdf (consultado el 21 de septiembre de 2017).

Sandvine (2016), Global Internet Phenomena 2016 - Latin America \& North America, https:// www.sandvine.com/downloads/general/global-internet-phenomena/2016/globalinternetphenomena-report-latin-america-and-north-america.pdf (consultado el 03 de octubre de 2017).

Sebastian Soriano (2017), The Internet of Things calls regulators to invent a pro-innovation approach-Medium, Medium, https://medium.com/@sorianotech/the-internet-of-things-callsregulators-to-invent-a-proinnovation-approach-55a74147a7cb (consultado el 10 de abril de 2018).

Seeking Alpha (2017), Verizon's (VZ) Management Presents at Goldman Sachs 26th Communacopia Conference (Transcript) | Seeking Alpha, https://seekingalpha.com/article/4107060-verizons-vZ-management-presents-goldman-sachs26th-communacopia-conference-transcript?part=single (consultado el 10 de octubre de 2017).

Semiconductor Engineering (2017), Semiconductor Engineering: Prioritizing Vehicle Data Traffic, 5 de enero de 2017, http://semiengineering.com/prioritizing-vehicle-data-traffic/ (consultado el 03 de octubre de 2017).

Semiconductor Engineering (2017), Semiconductor Engineering: Data Storage Issues Grow For Cars, https://semiengineering.com/data-issues-grow-for-cars/ (consultado el 21 de septiembre de 2017).

Tech Crunch (2017), Intel buys Mobileye in $\$ 15.3 B$ deal, moves its automotive unit to Israel $\mid$ TechCrunch, 13 de marzo de 2017, https:/techcrunch.com/2017/03/13/reports-intel-buyingmobileye-for-up-to-16b-to-expand-inself-driving-tech/ (consultado el 03 de octubre de 2017).

TechIn France (2018), Règlement européen E-privacy Un coup d'arrêt à la transformation numérique?, http://www.techinfrance.fr/static/2018/02/12/eprivacy.pdf?AsnIo Gg5tiX2OuyHtoSoA:jxSUTLVJsUe0iTkmebJeeA:LHczCbPxcBFBIbkN35dmDw (consultado el 10 de abril de 2018). 
Telecom Italia (2017), TIM: the Republic of San Marino is the first 5G State in Europe | Telecom Italia Group, 17 de julio de 2017, http://www.telecomitalia.com/tit/en/archivio/media/notestampa/corporate/2017/TIMRepubblica-San-Marino-MoU-5G-ENG.html (consultado el 06 de octubre de 2017).

Telecom Lead (2017), SK Telecom tests self-driving vehicle, plans to connect $5 G$ later TelecomLead, 21 de septiembre de 2017, http://www.telecomlead.com/5g/sk-telecom-tests-selfdriving-vehicle-plans-connect-5glater-79467 (consultado el 05 de octubre de 2017).

TEVAC (2017), Projet de Territoire d'Expérimentation Véhicule Autonome et Connecté, https://pole-moveo.org/wp-content/uploads/2017/07/TEVAC-WP1-Executive-Summary experimentations vehicule-autonome-et-connecte Vallee-de-la-Seine \% $\% 2 \% \mathrm{~A} 9 \mathrm{Moveo}$ Imagine-Mobility.pdf (consultado el 10 de abril de 2018).

TNS and Bearing Point (2016), Car manufacturers in the race for a connected futureBearingPoint, https://www.bearingpoint.com/en/about-us/news-and-media/press-releases/ carmanufacturers-in-the-race-for-a-connected-future/ (consultado el 22 de septiembre de 2017).

United States Department of Defense (2016), DoD Policy Recommendations for The Internet of Things (IoT), https://www.hsdl.org/?abstract\&did=799676 (consultado el 09 de abril de 2018).

United States Government Accountability Office (2017), Internet of Things Status and implications of an increasingly connected world, https://www.gao.gov/assets/690/684590.pdf (consultado el 09 de abril de 2018).

United States International Trade Commission (2017), "Global Digital Trade I: Market Opportunities and Key Foreign Trade Restrictions", https://www.usitc.gov/publications/332/pub4716 0.pdf (consultado el 09 de abril de 2018).

VB (2017), Why Intel believes $5 G$ wireless will make autonomous cars smarter | VentureBeat, 20 de mayo de 2017 , https://venturebeat.com/2017/05/20/why-intel-believes-5g-wireless-will-makeautonomouscars-smarter/ (consultado el 05 de octubre de 2017).

WEF (2015), Industrial Internet of Things: Unleashing the Potential of Connected Products and Services, http://www3.weforum.org/docs/WEFUSA_IndustrialInternet Report2015.pdf (consultado el 09 de abril de 2018). 


\section{Notas finales}

${ }^{1}$ La Oficina de Análisis Económico del Departamento de Comercio de los Estados Unidos (Bureau of Economic Analysis of the United States Department of Commerce) en su publicación de 2018 sobre la medición de la Economía Digital definió el IoT como: "Dispositivos habilitados para Internet como electrodomésticos, maquinaria y automóviles con hardware integrado que les permite comunicarse entre sí y conectarse a Internet" (Barefoot et al., 2018 $\left.{ }_{[1]}\right)$.

${ }^{2}$ Concretamente, el informe de la BEA (2018) menciona lo siguiente en la página 9: "BEA no incluyó estructuras e infraestructura de IoT en las estimaciones iniciales debido a la dificultad de determinar la asignación adecuada de estas categorías a componentes digitales y no digitales. Tanto para las estructuras como para la infraestructura del IoT, BEA no dispone de datos para separar la actividad de la economía digital de todas las demás actividades. El caso de la infraestructura del IoT plantea desafios adicionales. Por ejemplo, la conectividad de un refrigerador con acceso a Internet puede permitirle al propietario buscar y comprar alimentos cuando se estén agotando o registrar el uso. Sin embargo, la función principal del refrigerador es mantener los alimentos fríos, producción que BEA no clasificaría como parte de la economía digital" (Barefoot et al., 2018[1]).

${ }^{3}$ En la Tabla 1 del informe de Ericsson "5G Systems: enabling digital transformation" (Ericsson, $\left.2017_{[2]}\right)$ se pueden encontrar más ejemplos de los diferentes usos y los requisitos de red más importantes.

${ }^{4}$ Para nombrar algunos, la UIT había propuesto una definición en 2012, la Comisión Europea mencionó una definición en un informe de 2014, y el Departamento de Defensa de los Estados Unidos utiliza en sus documentos la definición del IoT del Instituto de Ingenieros Eléctricos y Electrónicos (IEEE) (Departamento de Defensa de los Estados Unidos, 2016 ${ }_{[7]}$ ).

${ }^{5}$ Concretamente, el ORECE menciona lo siguiente en su trabajo anterior: "Los servicios de IoT se encuentran en diversas fases de desarrollo y adoptan diversas formas, por lo que todavia no existe una comprensión o definición común de lo que son realmente los servicios y dispositivos de IoT. Para efectos del presente informe, no es necesario determinar en detalle qué definición es la más adecuada." (ORECE, 2016[59])

${ }^{6}$ En abril de 2018, el ORECE llevará a cabo una encuesta entre las ARN sobre la medición del IoT, que incluirá preguntas para responder a lo siguiente: ¿Qué tipos de datos de medición del IoT son necesarios y de mayor interés para las ARN? ¿Qué definición o definiciones de los dispositivos de IoT deben utilizarse? ¿Cuál es la mejor manera de medir el tráfico de la red de IoT?

${ }^{7}$ Por ejemplo, si Volvo, un cliente de Telenor Connexion, vende un automóvil con una tarjeta SIM, y este vehículo se vende fuera de Suecia en cualquier parte del mundo, aparece en las cifras M2M de Suecia proporcionadas por PTS. En este caso, el vehículo Volvo aparece en la red local fuera de Suecia como un vehículo extranjero.

${ }^{8}$ En este sentido, excluir ciertas cosas que en otras definiciones se consideran parte de M2M influirá en el indicador. A este respecto, el ORECE en su informe sobre "Habilitar el Internet de las Cosas" (2016) menciona lo siguiente: "Del mismo modo, algunas partes interesadas solo consideran este tipo de intercambio automatizado entre máquinas como la comunicación M2M, en la que no interviene el humano. Sin embargo, según otras definiciones, la intervención humana limitada puede formar parte de la comunicación M2M. En este caso, los servicios que pueden controlarse a distancia, como los teléfonos inteligentes o las tabletas, pueden ser también ejemplos de servicios de IoT, por ejemplo, el control a distancia de los sistemas de aire acondicionado y calefacción o el (des)bloqueo a distancia de automóviles. Sin embargo, esto no implica una declaración general 
sobre la calificación de un servicio como servicio de IoT con respecto a todos los casos en que se trate de una aplicación en un teléfono inteligente o tableta" (ORECE, 2016 [59]).

9 También utilizan esta definición en los análisis que intentan medir el tamaño total del mercado del IoT. McKinsey en 2016 estimó que el mercado del IoT en 2015 representaba hasta 900 millones de dólares y que crecería hasta 3700 millones de dólares en 2020, es decir, el 32.6\% de la CAGR. Ver presentación de McKinsey de 2016 El Internet de los objetos: La oportunidad del IoT-¿Está listo para capturar un fondo de valores único en la vida? [The Internet of Things: The IoT opportunityAre you ready to capture a once-in-a lifetime value pool?] http://hkiot-conference.gs $1 \mathrm{hk} .0 \mathrm{gg} / 2016 /$ pdf/ 04 Mc\%20Kinsey\%20-\%20(Chris\%20Ip\%20)\%20ppt \%20part\%20\%201\%20 IoT\%20- $\% 20$ Capturing\%20the\%20Opportunity\%20vF\%20-\%2021\%20June\%202016.1pptx.pdf

${ }^{10}$ De acuerdo con el Informe de Movilidad de Ericsson 2017, el IoT de corto alcance se refiere al "Segmento que consiste principalmente en dispositivos conectados por tecnologías de radio sin licencia, con un alcance típico de hasta 100 metros, como Wi-Fi, Bluetooth y Zigbee. Esta categoría también incluye los dispositivos conectados a través de redes de área local de línea fija y tecnologías de línea eléctrica".

${ }^{11}$ Consulte el Informe de Movilidad de Ericsson 2017 en la sección “The Internet of Things Outlook" (pág. 16), para más detalles: https://www.ericsson.com/assets/local/mobilityreport/documents/2017/ ericsson-mobility-report-june-2017.pdf

12 En el Informe de Movilidad de 2016, Ericsson se referiría a estos dos segmentos del IoT como IoT Celular y No Celular. El cambio metodológico es que en el segmento del IoT de amplio alcance en 2017, ahora incluyen tanto el IoT celular como las tecnologías de baja potencia. Véase https:// www.ericsson.com/res/docs/2016/ericsson-mobility-report-2016.pdf. Además, en el Informe de Movilidad de 2016, Ericsson estimó que los dispositivos de IoT crecerán de 15000 millones de dispositivos en 2015 a 28000 millones en 2021. En 2015, el IoT estaba conformado por 400 millones de IoT celulares, 4200 millones de IoT no celulares, 1700 millones de PC/laptop/tableta, 7100 millones de teléfonos móviles y 1300 millones de teléfonos fijos. En 2021, la mayoría de las conexiones de IoT serán de IoT no celular (14200 millones).

13 Consulte el Libro Blanco del Ministerio del Interior y de Comunicaciones de Japón, capítulo 3, sección 3 (MIC, 2017 [24]).

${ }^{14}$ La variedad de electrodomésticos inteligentes crece casi todos los días. En los Estados Unidos, las bocinas inteligentes no se mencionan actualmente en la encuesta de hogares y particulares (NTIA, $2017_{[25]}$, a pesar de su creciente difusión: según una encuesta privada reciente, el $16 \%$ de los estadounidenses mayores de 18 años tenían una bocina inteligente a finales de 2017, y dos tercios de ellos dicen que no querrían volver a la vida sin su bocina inteligente (NPR, 2018 [71]).

${ }^{15}$ Las compañías de seguros empiezan a ofrecer a los particulares una gama cada vez más amplia de dispositivos de IoT "relacionados con la salud" (Le Monde, 2018[ [73]).

${ }^{16}$ La pregunta utilizada en el "Suplemento de Uso de Computadoras e Internet de CPS", que es un bloque de encuesta patrocinado por NTIA e incluye la encuesta de población actual (IPUMS CPS, $2018_{[70]}$ ), es: “¿Qué pasa con la interacción con los equipos o electrodomésticos conectados a Internet, como un termostato, un foco o un sistema de seguridad conectados? ¿Utiliza Internet para interactuar con electrodomésticos?" (NTIA, 2017 [25]).

${ }^{17}$ La definición de robots industriales utilizada por IFR procede de la Organización Internacional de Normalización (ISO) 8373:2012, que establece que un robot es una máquina con las siguientes características: puede reprogramarse, tiene múltiples funciones, permite la alteración física y está montado sobre un eje.

${ }^{18}$ La definición de "comunicaciones M2M masivas" es análoga a la definición establecida por la UIT en su visión de la quinta generación de redes inalámbricas, o la norma IMT 2020, que aún 
no se ha finalizado en 2019 en la Conferencia Mundial de Radiocomunicaciones de la UIT (UIT, $2015_{[82]}$ ). Esta norma está siendo concebida con el IoT en mente y teniendo en cuenta tres escenarios principales de uso (es decir, banda ancha móvil mejorada, comunicaciones masivas de tipo máquina y comunicaciones/aplicaciones críticas)

19 En Ontario, Canadá, el despliegue de los medidores inteligentes a los clientes residenciales se completó en 2010 (Rivers, 2018 [30]).

${ }^{20}$ Radar son las siglas de Radio Detection and Ranging Technology (tecnología de detección y alcance por radio).

21 LiDAR, Light Detection and Ranging (Detección y localización por luz), es un método de teledetección que utiliza luz en forma de láser pulsado para medir intervalos.

22 Otro ejemplo de proyectos de investigación en Europa que involucran vehículos automatizados es el caso de los fabricantes de automóviles franceses que actualmente están trabajando con el Instituto VEDECOM (investigación avanzada) y el IRT System X (arquitectura electrónica y ciberseguridad) para realizar pruebas. Mientras que en Estados Unidos se han desarrollado experimentos en carreteras durante muchos años, en Francia no se iniciaron sino hasta 2015 (CCFA, 2017 [87]).

${ }^{23}$ Véase el informe del ORECE sobre "Habilitar la Internet de las Cosas", p. 4 (ORECE, 2016 [46] $)$.

${ }^{24}$ En la Tabla 1 del informe de Ericsson "5G Systems: enabling digital transformation" (Ericsson, $2017_{[2]}$ ) es posible encontrar más ejemplos de los distintos usos y los requisitos de red más importantes.

25 “En los últimos acuerdos, España y Portugal firmaron una carta de intención para establecer dos corredores conjuntos entre Vigo y Oporto, y Mérida y Évora, que permitirán probar la conducción automatizada conectada a través de las fronteras. Además, Italia y los tres presidentes de la Eurozona Tirol - Sudtirol- Trentino también confirmaron su intención de trabajar con otros estados miembros interesados en el desarrollo del corredor 5G en la autopista del Brennero" (Mobile World Live, 2018 [61] $)$.

${ }^{26}$ Actualmente se está llevando a cabo un proyecto de investigación, en colaboración con una compañía de seguros francesa, sobre una plataforma destinada a analizar el flujo de datos procedente de los objetos conectados, centrándose en los protocolos, la densidad, el tipo y las modalidades, así como en las medidas de seguridad relacionadas con los flujos de datos. Las pruebas incluirán varios mercados específicos (dispositivos inteligentes para el hogar, vehículos conectados, bienestar). Varios productores de objetos (cosas) están involucrados, con la intención de diferenciarse a través de un mayor nivel de transparencia en el trabajo de sus productos y el respeto de la privacidad del usuario (Fondation MAIF, 2018 $8_{[81]}$ ).

${ }^{27}$ Un ejemplo de clasificación de los datos en función de su uso previsto lo constituye un estudio de caso sobre agricultura, en el que los datos se organizan en función del dominio al que se refieren: agronomía — rendimiento de los cultivos y cantidad de insumos utilizados —; máquinas — máquinas y equipos utilizados-; y meteorología (TechIn France, $2018_{[80]}$ ). 